\title{
Bariatric surgery and its effect on the metabolic and inflammatory aspects of morbid obesity
}

Citation for published version (APA):

Nijhuis, J. (2008). Bariatric surgery and its effect on the metabolic and inflammatory aspects of morbid obesity. [Doctoral Thesis, Maastricht University]. Maastricht University.

https://doi.org/10.26481/dis.20080625jn

Document status and date:

Published: 01/01/2008

DOI:

10.26481/dis.20080625jn

Document Version:

Publisher's PDF, also known as Version of record

\section{Please check the document version of this publication:}

- A submitted manuscript is the version of the article upon submission and before peer-review. There can be important differences between the submitted version and the official published version of record.

People interested in the research are advised to contact the author for the final version of the publication, or visit the DOI to the publisher's website.

- The final author version and the galley proof are versions of the publication after peer review.

- The final published version features the final layout of the paper including the volume, issue and page numbers.

Link to publication

\footnotetext{
General rights rights.

- You may freely distribute the URL identifying the publication in the public portal. please follow below link for the End User Agreement:

www.umlib.nl/taverne-license

Take down policy

If you believe that this document breaches copyright please contact us at:

repository@maastrichtuniversity.nl

providing details and we will investigate your claim.
}

Copyright and moral rights for the publications made accessible in the public portal are retained by the authors and/or other copyright owners and it is a condition of accessing publications that users recognise and abide by the legal requirements associated with these

- Users may download and print one copy of any publication from the public portal for the purpose of private study or research.

- You may not further distribute the material or use it for any profit-making activity or commercial gain

If the publication is distributed under the terms of Article $25 \mathrm{fa}$ of the Dutch Copyright Act, indicated by the "Taverne" license above, 


\section{Bariatric surgery and its effect on the metabolic and inflammatory aspects of morbid obesity}


( J. Nijhuis, Maastricht 2008

ISBN: 978-90-5278-731-2

Layout: Tiny Wouters

Production: Datawyse | Universitaire Pers Maastricht

The publication of this thesis was financially supported by.

Allergan, AstraZeneca, Boehringer Ingelheim, Bristol-Meyers Squibb, Covidien, Ethicon, Fortis, Eli Lilly, Merck Sharp \& Dohme, Nederlandse Associatie voor de Studie van Obesitas, Novartis Pharma, Novo Nordisk, Daiichi Sankyo, Schering-Plough and Will Pharma. 


\section{Bariatric surgery and its effect on the metabolic and inflammatory aspects of morbid obesity}

\section{PROEFSCHRIFT}

ter verkrijging van de graad van doctor aan de Universiteit Maastricht, op gezag van de Rector Magnificus, Prof. dr. G.P.M.F. Mols volgens het besluit van het College van Decanen, in het openbaar te verdedigen op woensdag 25 juni 2008 om 12:00 uur

door

Jeroen Nijhuis

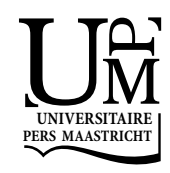




\section{Promotores:}

Prof. Dr. W.A. Buurman

Prof. Dr. J.W.M. Greve

Copromotor:

Dr. S.S.M. Rensen

Beoordelingscommissie:

Prof. dr. E.E. Blaak (voorzitter)

Prof. dr. M.H. Hofker

Prof. dr. P.B. Soeters

Prof. dr. C.D.A. Stehouwer

Dr. C.W. le Roux 
Voor Kirsten, Julian en Aimée 



\section{Contents}

$\begin{array}{lll}\text { Chapter } 1 & \text { Outline of the thesis } & 9\end{array}$

Chapter $2 \quad$ The surgical treatment of diabetic obesity 21

Chapter $3 \quad$ Ghrelin, leptin and insulin levels after restrictive 47 surgery, a 2 year follow-up study

Chapter $4 \quad$ Leptin in morbid obese patients, no role for treatment of morbid obesity but important in the post operative immune response

Chapter $5 \quad$ Endothelial activation markers and their key regulators after restrictive bariatric surgery, a 2 year follow-up study

Chapter $6 \quad$ Neutrophil activation in morbid obesity, chronic activation of acute inflammation

Chapter $7 \quad$ Insulin sensitivity during the first months after restrictive bariatric surgery, inconsistency between HOMA-IR and steady state plasma glucose (SSPG) levels

Chapter $8 \quad$ Short term overfeeding induces insulin resistance in weight stable patients after bariatric surgery

9

\section{1}

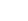





\section{Chapter 1}

Outline of the thesis 
$10 \mid$ Chapter 1 


\section{Outline of the thesis}

In 2000 obesity was declared a chronic disease by the World Health Organization emphasizing the importance of the obesity epidemic in the $21^{\text {st }}$ century. According to figures from 2005 of the adult population in the Netherlands provided by the Central Bureau of Statistics $44.9 \%$ was overweight (Body Mass Index (BMI) $>25 \mathrm{~kg} / \mathrm{m}^{2}$ ), while obesity has a prevalence of $10.8 \%$ (BMI between $30-40 \mathrm{~kg} / \mathrm{m}^{2}$ ). Because clear data of the prevalence of morbid obesity (BMl above $40 \mathrm{~kg} / \mathrm{m}^{2}$ ) in the Netherlands are lacking, these results were extrapolated using the outcome of similar North American studies. The prevalence of morbid obesity in the Netherlands was estimated to be $1.5 \%$ of the adult population. In Figure 1.1 the data of 2005 for the Netherlands are summarized.

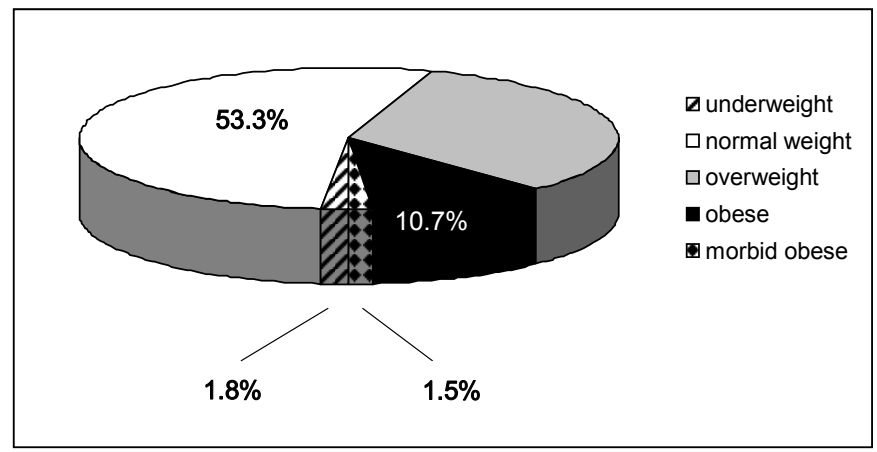

Figure 1.1 Weight class prevalence in the Netherlands in 2005; in total $44.9 \%$ of the adult population is considered overweight. Adapted from Centraal Bureau voor de Statistiek, Voorburg/Heerlen.

Several diseases with high prevalence in the population are associated with obesity. Cardiovascular diseases and type II diabetes mellitus comprise the majority of co-morbidities related to obesity. It is reported that obese patients are at a 5-20 times greater risk for developing type II diabetes mellitus. Cardiovascular diseases are directly correlated to type II diabetes mellitus and it is therefore not surprising that obesity results in a 4-6 fold increased risk for cardiovascular diseases. In addition, a 40 fold increased risk of dying from sudden cardiac arrest is reported. Besides type II diabetes mellitus and cardiovascular diseases cancer is also a serious condition associated with obesity. A 4-6 fold increased risk for breast and colon cancer is reported in obesity. These figures illustrate that the morbidities of obesity have a major impact on Dutch healthcare, reflected by an estimated $€ 505$ million direct costs and $€ 2$ billion indirect costs annually ${ }^{1,2}$. 
Losing weight is the most effective treatment of, or prophylaxis for the comorbidities accompanying obesity. In general two approaches are available: non-invasive (diet, physical training, psychotherapy and pharmacotherapy) and invasive (bariatric surgery $=$ surgical treatment of morbid obesity) interventions. Non-invasive therapy leads to reduced body weight with a maximum of approximately $10 \%$ and is therefore not suitable for the morbidly obese population. On the other hand, invasive therapy (bariatric surgery) can result in weight loss in the order of $50-70 \%$ of excess weight ${ }^{3-5}$. In addition, bariatric surgery is able to dramatically reduce the risk for co-morbidities, like type II diabetes and cardiovascular diseases ${ }^{6-8}$. Therefore bariatric surgery is considered the most effective treatment of morbid obesity.

The types of surgery which are covered by this thesis will shortly be discussed. Bariatric surgery is based on two main principles: malabsorption and restriction. The ingested food is either not properly absorbed by the gut or intake is limited. In malabsorptive surgery, a short bowel is created, while in restrictive surgery the stomach size is reduced ${ }^{9,10}$. The result is substantial weight loss, which averages $40 \mathrm{~kg}$ (14.2 BMl points) reported by Buchwald et. al. in a metaanalysis of all types of surgical procedures ${ }^{11}$.

Recently laparoscopic surgery has gained popularity because of its less invasive nature ${ }^{12}$. Morbidly obese patients are at risk of developing serious postoperative complications ${ }^{13}$. Laparoscopic surgery is thought to decrease the postoperative complication rate dramatically. Laparoscopic gastric banding compared to an 'open' restrictive procedure, like vertical gastric banding showed reduced direct postoperative complications ${ }^{14}$.

\section{Vertical banded gastroplasty}

This procedure was initially described by Mason and has probably been the technique that has popularized bariatric surgery due to its simplicity and relative safety ${ }^{15}$. In short a small pouch of the stomach (approximately $15-20 \mathrm{ml}$ ) is created with a linear stapler precisely to the angle of His and a Dacron band placed through the window formed by a circular stapler leaving a very small opening for food to pass from the small pouch to the remaining stomach. Because of the small capacity of the gastric pouch the amount of ingested food is considerably limited leading to extensive weight loss ${ }^{16}$. Due to the relatively large numbers of long term failure this procedure is not performed routinely anymore.

\section{Adjustable laparoscopic gastric banding}

The adjustable gastric band is made of soft silicone and equipped with an elastic balloon that can be inflated to the desired volume by means of injection postoperatively. After inflation the outlet diameter will be reduced leading to 
diminished food intake and consequently to weight loss. Belachew developed in the early nineties a laparoscopic technique ${ }^{17}$. In short, the adjustable gastric band is placed laparoscopically around the stomach. On indications, for definitive positioning of the band, a $15-\mathrm{ml}$ calibration balloon advanced by the anesthetist and pulled up to the gastroesophageal junction is placed right below the cardia. Under this balloon the band is closed and with three or four sutures the ventral aspect of the greater curvature of the stomach is fixed to the pouch to ensure a stable anterior position of the band. Finally the band is placed in the perigastric fascia. Nowadays all surgeons use the pars flaccida technique in which the mesentery of the proximal stomach is included in the band. Six weeks postoperatively the band is insufflated when weight loss is insufficient (less than $6 \mathrm{~kg}$ ). The band is insufflated as often as needed to induce sufficient weight loss (approximately $0.5-1 \mathrm{~kg}$ weight loss per week).

\section{Gastric bypass}

This technique was introduced by Mason ${ }^{18}$ and has been adjusted to the technique currently carried out ${ }^{19}$. Although gastric bypass surgery is a combination of malabsorptive and restrictive surgery, its effects on weight loss are thought to arise from the restrictive component of the surgical intervention. In short a vertical gastric pouch is created. To create the Roux limb the jejunum is transected at approximately $30 \mathrm{~cm}$ from the ligament of Treitz where a comfortable length of mesentery exists. The Roux limb is measured $75-150 \mathrm{~cm}$ distally and an end-to-side anastomosis is created with the proximal jejunal limb. The gastrojejunostomy is created using either a circular stapled end-to-end anastomosis, a linear stapler technique or a hand sewn technique.

\section{Biliopancreatic diversion}

This malabsorptive surgical technique was introduced by Scopinaro ${ }^{20}$. It consists of a distal gastrectomy with a long Roux-en-Y reconstruction. The enteroenterostomy is placed $200 \mathrm{~cm}$ distal to the gastroenterostomy and $50 \mathrm{~cm}$ proximal to the ileocaecal valve. This results in three intestinal limbs, the alimentary loop from the gastroenterostomy to enteroenterostomy, the common loop from the enteroenterostomy to the ileocaecal valve and the pancreaticobiliary loop from the duodenum to the enteroenterostomy. The role of the gastrectomy is to allow a rapid emptying of gastric content into the ileum. The effect of the operation is the creation of a "controlled" short bowel.

The effect of bariatric surgery on body weight, type II diabetes and insulin resistance is further discussed in Chapter 2. Bariatric surgery leads to decreased nutrient intake. Consequently adipose tissue mass decreases which 
results in weight loss. Moreover, it is reported that weight loss is associated with decreased accumulation of fat metabolites in organs crucial in glucose metabolism (liver and muscle) $)^{21,22}$. In this review hypotheses regarding the effect of these changes on insulin sensitivity after bariatric surgery are discussed. Furthermore, theories on the effect of changes in gut anatomy due to bariatric surgery on gut hormones and their impact on insulin sensitivity are evaluated in this chapter.

The experimental part of this thesis addresses two topics in bariatric surgery. The first topic relates to plasma levels of satiety hormones after bariatric surgery and the second topic regards the low-grade inflammatory condition associated with morbid obesity and the effect of bariatric surgery on this condition.

In Chapter 3 plasma levels of satiety hormones after bariatric surgery are studied. As mentioned before, operative techniques in bariatric surgery can be divided in malabsorptive (biliopancreatic diversion) and restrictive (gastric bypass, vertical gastric banding and gastric banding) procedures. The mechanism behind weight loss in procedures which are solely based on restriction is well defined. Due to a smaller stomach size already small amounts of food results in distention of the gastric pouch inducing rapid satiety and prohibiting further food intake. Interestingly, compared to solely restrictive procedures, despite an equal size of the gastric pouch, gastric bypass surgery was reported to result in improved weight loss ${ }^{11,23}$. The influence of gastric bypass on postoperative plasma levels of satiety hormones could partly account for this finding. In contrast to vertical banded gastroplasty (VBG) and gastric banding gastric bypass surgery results in bypassing of the fundus of the stomach. Cells of the fundus play a role in regulating food intake: in absence of food in the fundus the cells produce the orexigenic hormone ghrelin ${ }^{24}$. Paradoxically literature data show that gastric bypass surgery results in decreased or unaltered plasma levels of ghrelin which consequently reduced appetite leading to decreased food intake and weight loss ${ }^{25-27}$. In this context the effect of VBG and gastric banding on plasma ghrelin levels and other satiety hormones leptin and insulin were studied. The data are presented in the background of reported data on gastric bypass surgery.

Circulating levels of the satiety hormone leptin were also studied in an immunological perspective. Bariatric surgery results in a rapid decrease in food intake which starts with a short period of fasting followed by a continuous reduced food intake. During fasting plasma leptin levels are reported to decrease rapidly ${ }^{28}$. Recently immunoregulatory properties of leptin are reported which are reviewed in more detail in Chapter 4 . The immunoregulatory function of leptin was largely deduced from literature data showing immunological 
abnormalities in leptin deficient animals ${ }^{29,30}$. In line the general view is that low plasma leptin levels are unfavorable for an individual. In this context we have investigated circulating leptin levels during the first days after bariatric surgery when the patient is in a fasting condition.

The second topic addressed in this thesis concerns the low-grade inflammatory condition associated with morbid obesity and the effects of bariatric surgery on this condition. The aim of bariatric surgery is to reduce weight as well as the prevalence of co-morbidities associated with morbid obesity. Considerable evidence from human studies indicates a role of inflammation as a causal factor in obesity induced morbidities ${ }^{31,32}$. It is well known that in man obesity is associated with increased levels of inflammatory cytokines like Tumor Necrosis Factor alpha (TNF- $\alpha$ ), Interleukin-6 (IL-6) and Interleukin-8 (IL-8) ${ }^{33-35}$. In addition obesity is associated with increased circulating levels of acute phase proteins ${ }^{36-40}$. Supplementary evidence for the involvement of inflammation in co-morbidities associated with morbid obesity has been obtained by studying the effect of aspirin treatment of obese patients. The aspirin treatment induced a decrease in inflammatory markers, which was accompanied by an increase in insulin sensitivity an important co-morbidity of obesity ${ }^{41}$. Bariatric surgery not only leads to weight loss, but also results in reduction of the low-grade inflammatory condition ${ }^{39,42,43}$.

The low-grade inflammatory condition is further characterized in Chapter 5 by studying endothelial cell activation. Earlier studies show that morbid obesity is associated with increased plasma levels of cytokines and acute phase proteins $^{39}$. Moreover, circulating monocytes of obese individuals express more Nuclear Factor-kappa B (NF-KB) than monocytes derived from normal weight healthy controls ${ }^{44}$. Furthermore, morbid obesity is also associated with activation of the complement system ${ }^{42}$. These observations show that different aspects of the innate immune response are activated in morbidly obese individuals. Endothelial cell activation is one of the initial steps in inflammatory processes. It is associated with several diseases which are also related to morbid obesity ${ }^{45}$. In this perspective it was hypothesized that morbid obesity is associated with increased endothelial cell activation. Bariatric surgery results in decreased incidence of co-morbidities of morbid obesity ${ }^{11}$. Consequently endothelial cell activation could decrease after bariatric surgery. Therefore plasma levels of endothelial cell activation markers were studied preoperatively as well as during the first two years after bariatric surgery. Moreover, pre- and postoperative plasma levels of resistin and adiponectin, which are reported to be mediators of endothelial cell activation, were measured. 
In Chapter 6, neutrophil activation in morbidly obese individuals was evaluated. Neutrophils represent one of the most prominent components of the innate immune system displaying strong phagocytic and anti-microbial activity. Moreover, neutrophils play an important role in the pathophysiology of non alcoholic steatohepatitis (NASH), a condition frequently associated with morbid obesity ${ }^{46}$. Therefore it was hypothesized that neutrophils are activated in morbidly obese patients. Circulating levels of neutrophil activation makers as well as membrane bound expression of neutrophil activation markers are studied in morbidly obese patients. Moreover, the long term effect of bariatric surgery on plasma levels of neutrophil activation markers is studied.

In the context of Chapter 5 it was shown that, despite substantial weight loss, several parameters of the low-grade inflammatory condition associated with morbid obesity did not decrease during the first months after bariatric surgery ${ }^{39}$. Interestingly, the low-grade inflammatory condition is thought to play a major role in the pathophysiology of insulin resistance ${ }^{47}$. Therefore, insulin resistance as well as circulating inflammatory mediators were measured in subjects that had lost $26 \%$ excess weight approximately three months after restrictive bariatric surgery (Chapter 7). Several authors have stated that insulin resistance depicted as HOMA-IR levels is improving directly after restrictive bariatric surgery ${ }^{48-50}$. A second goal of this study was to compare both HOMAIR and Steady State Plasma Glucose (SSPG) levels as measurements of insulin resistance in the early postoperative period.

Insulin sensitivity increases in the long term after bariatric surgery ${ }^{51}$. In Chapter 2 it is suggested that a decrease in macronutrient intake could partly be responsible for this effect of bariatric surgery on insulin resistance. In Chapter 8 the opposite, the effect of overfeeding on insulin sensitivity, is studied. The starting point was the reported data on overfeeding of rats resulting in decreased insulin sensitivity ${ }^{52}$. Interestingly, this has not been shown in a human study ${ }^{53}$. This could be explained by the selection of healthy normal weight individuals for these experiments. Therefore, the effect of overfeeding was studied in individuals with a history of morbid obesity, insulin resistance and low-grade inflammation. These individuals might be genetically predisposed to develop insulin resistance and a low-grade inflammatory condition in response to morbid obesity. The study was designed to investigate in weight stable individuals approximately three years after bariatric surgery the effect of overfeeding for seven days on insulin sensitivity and inflammatory markers. 


\section{References}

1. Anonymous. Advies gezondheid en gedrag. Zoetermeer: Raad voor de Volksgezondheid en Zorg (publicatieno 02/14) 2002.

2. Takken J PJ, Meerding WJ. Kosten van ziekten in Nederland. Bilthoven: Rijksinstituut voor Volksgezondheid en Milieu (RIVM rapportnummer 270751004, www.kostenvanziekten.nl) 2002.

3. NIH conference. Gastrointestinal surgery for severe obesity. Consensus Development Conference Panel. Ann Intern Med 1991;115:956-61.

4. Clinical Guidelines on the Identification, Evaluation, and Treatment of Overweight and Obesity in Adults--The Evidence Report. National Institutes of Health. Obes Res 1998;6 Suppl 2:51S-209S.

5. Obesity: preventing and managing the global epidemic. Report of a WHO consultation. World Health Organ Tech Rep Ser 2000;894:i-xii, 1-253.

6. Pories WJ, Swanson MS, MacDonald KG, Long SB, Morris PG, Brown BM, Barakat HA, deRamon RA, Israel G, Dolezal JM, et al. Who would have thought it? An operation proves to be the most effective therapy for adult-onset diabetes mellitus. Ann Surg 1995;222:339-50; discussion 350-2.

7. Kopp HP, Krzyzanowska K, Mohlig M, Spranger J, Pfeiffer AF, Schernthaner G. Effects of marked weight loss on plasma levels of adiponectin, markers of chronic subclinical inflammation and insulin resistance in morbidly obese women. Int $\mathrm{J}$ Obes (Lond) 2005; 29:766-71.

8. Gokce N, Vita JA, McDonnell M, Forse AR, Istfan N, Stoeckl M, Lipinska I, Keaney JF, Jr., Apovian CM. Effect of medical and surgical weight loss on endothelial vasomotor function in obese patients. Am J Cardiol 2005;95:266-8.

9. Pender JR, Pories WJ. Surgical treatment of obesity. Psychiatr Clin North Am 2005;28: 219-34.

10. Demaria EJ, Jamal MK. Surgical options for obesity. Gastroenterol Clin North Am 2005; 34:127-42.

11. Buchwald H, Avidor $\mathrm{Y}$, Braunwald $\mathrm{E}$, Jensen MD, Pories $\mathrm{W}$, Fahrbach $\mathrm{K}$, Schoelles $\mathrm{K}$. Bariatric surgery: a systematic review and meta-analysis. JAMA 2004;292:1724-37.

12. Cottam DR, Nguyen NT, Eid GM, Schauer PR. The impact of laparoscopy on bariatric surgery. Surg Endosc 2005;19:621-7.

13. Byrne TK. Complications of surgery for obesity. Surg Clin North Am 2001;81:1181-93, vii-viii.

14. van Dielen FM, Soeters PB, de Brauw LM, Greve JW. Laparoscopic adjustable gastric banding versus open vertical banded gastroplasty: a prospective randomized trial. Obes Surg 2005;15:1292-8.

15. Mason EE. Vertical banded gastroplasty for obesity. Arch Surg 1982;117:701-6.

16. Sagar PM. Surgical treatment of morbid obesity. Br J Surg 1995;82:732-9.

17. Belachew M, Legrand MJ, Defechereux TH, Burtheret MP, Jacquet N. Laparoscopic adjustable silicone gastric banding in the treatment of morbid obesity. A preliminary report. Surg Endosc 1994;8:1354-6.

18. Mason EE, Ito C. Gastric bypass in obesity. Surg Clin North Am 1967;47:1345-51.

19. Scruggs DM, Cowan GS, Jr., Klesges L, Defibaugh N, Walker R, Kuyper B, Hiler ML. Weight Loss and Caloric Intake after Regular and Extended Gastric Bypass. Obes Surg 1993;3: 233-8.

20. Scopinaro N, Gianetta E, Civalleri D, Bonalumi U, Bachi V. Bilio-pancreatic bypass for obesity: II. Initial experience in man. Br J Surg 1979;66:618-20.

21. Dixon JB, Bhathal PS, Hughes NR, O'Brien PE. Nonalcoholic fatty liver disease: Improvement in liver histological analysis with weight loss. Hepatology 2004;39:1647-54.

22. Mingrone G, Rosa G, Greco AV, Manco M, Vega N, Nanni G, Castagneto M, Vidal H. Intramyocitic lipid accumulation and SREBP-1c expression are related to insulin resistance and cardiovascular risk in morbid obesity. Atherosclerosis 2003;170:155-61. 
23. Colquitt J, Clegg A, Loveman E, Royle P, Sidhu MK. Surgery for morbid obesity. The Cochrane Database of Systematic Reviews 2005(4).

24. Wynne K, Stanley S, Bloom S. The gut and regulation of body weight. J Clin Endocrinol Metab 2004;89:2576-82.

25. Stoeckli R, Chanda R, Langer I, Keller U. Changes of body weight and plasma ghrelin levels after gastric banding and gastric bypass. Obes Res 2004;12:346-50.

26. Fruhbeck G, Diez-Caballero A, Gil MJ, Montero I, Gomez-Ambrosi J, Salvador J, Cienfuegos $\mathrm{JA}$. The decrease in plasma ghrelin concentrations following bariatric surgery depends on the functional integrity of the fundus. Obes Surg 2004;14:606-12.

27. Cummings DE, Weigle DS, Frayo RS, Breen PA, Ma MK, Dellinger EP, Purnell JQ. Plasma ghrelin levels after diet-induced weight loss or gastric bypass surgery. N Engl J Med 2002; 346:1623-30.

28. Boden G, Chen X, Mozzoli M, Ryan I. Effect of fasting on serum leptin in normal human subjects. J Clin Endocrinol Metab 1996;81:3419-23.

29. Faggioni R, Moser A, Feingold KR, Grunfeld C. Reduced leptin levels in starvation increase susceptibility to endotoxic shock. Am J Pathol 2000;156:1781-7.

30. Fantuzzi G, Faggioni R. Leptin in the regulation of immunity, inflammation, and hematopoiesis. J Leukoc Biol 2000;68:437-46.

31. Hotamisligil GS. Inflammatory pathways and insulin action. Int J Obes Relat Metab Disord 2003;27 Suppl 3:S53-5.

32. Hotamisligil GS, Spiegelman BM. Tumor necrosis factor alpha: a key component of the obesity-diabetes link. Diabetes 1994;43:1271-8.

33. Katsuki A, Sumida Y, Murashima S, Murata K, Takarada Y, Ito K, Fuji M, Tsuchihashi K, Goto H, Nakatani K, Yano Y. Serum levels of tumor necrosis factor-alpha are increased in obese patients with noninsulin-dependent diabetes mellitus. J Clin Endocrinol Metab 1998; 83:859-62.

34. Straczkowski M, Dzienis-Straczkowska S, Stepien A, Kowalska I, Szelachowska M, Kinalska I. Plasma interleukin-8 concentrations are increased in obese subjects and related to fat mass and tumor necrosis factor-alpha system. J Clin Endocrinol Metab 2002;87:4602-6.

35. Yudkin JS, Kumari M, Humphries SE, Mohamed-Ali V. Inflammation, obesity, stress and coronary heart disease: is interleukin-6 the link? Atherosclerosis 2000;148:209-14.

36. Bastard JP, Jardel C, Delattre J, Hainque B, Bruckert E, Oberlin F. Evidence for a link between adipose tissue interleukin- 6 content and serum C-reactive protein concentrations in obese subjects. Circulation 1999;99:2221-2.

37. Gomez-Ambrosi J, Catalan V, Diez-Caballero A, Martinez-Cruz LA, Gil MJ, Garcia-Foncillas J, Cienfuegos JA, Salvador J, Mato JM, Fruhbeck G. Gene expression profile of omental adipose tissue in human obesity. Faseb J 2004;18:215-7.

38. Visser M, Bouter LM, McQuillan GM, Wener MH, Harris TB. Elevated C-reactive protein levels in overweight and obese adults. JAMA 1999;282:2131-5.

39. van Dielen FM, Buurman WA, Hadfoune M, Nijhuis J, Greve JW. Macrophage inhibitory factor, plasminogen activator inhibitor-1, other acute phase proteins, and inflammatory mediators normalize as a result of weight loss in morbidly obese subjects treated with gastric restrictive surgery. J Clin Endocrinol Metab 2004;89:4062-8.

40. van Dielen FM, van't Veer C, Schols AM, Soeters PB, Buurman WA, Greve JW. Increased leptin concentrations correlate with increased concentrations of inflammatory markers in morbidly obese individuals. Int J Obes Relat Metab Disord 2001;25:1759-66.

41. Hundal RS, Petersen KF, Mayerson AB, Randhawa PS, Inzucchi S, Shoelson SE, Shulman $\mathrm{GI}$. Mechanism by which high-dose aspirin improves glucose metabolism in type 2 diabetes. $J$ Clin Invest 2002;109:1321-6.

42. Hanusch-Enserer U, Cauza E, Spak M, Dunky A, Rosen HR, Wolf H, Prager R, Eibl MM. Acute-phase response and immunological markers in morbid obese patients and patients following adjustable gastric banding. Int J Obes Relat Metab Disord 2003;27:355-61. 
43. Vazquez LA, Pazos F, Berrazueta JR, Fernandez-Escalante C, Garcia-Unzueta MT, Freijanes J, Amado JA. Effects of changes in body weight and insulin resistance on inflammation and endothelial function in morbid obesity after bariatric surgery. J Clin Endocrinol Metab 2005;90:316-22.

44. Ghanim H, Aljada A, Hofmeyer D, Syed T, Mohanty P, Dandona P. Circulating mononuclear cells in the obese are in a proinflammatory state. Circulation 2004;110:1564-71.

45. Caballero AE. Endothelial dysfunction in obesity and insulin resistance: a road to diabetes and heart disease. Obes Res 2003;11:1278-89.

46. Reid AE. Nonalcoholic steatohepatitis. Gastroenterology 2001;121:710-23.

47. Shoelson SE, Lee J, Goldfine AB. Inflammation and insulin resistance. J Clin Invest 2006; 116:1793-801.

48. Ballantyne GH, Farkas D, Laker S, Wasielewski A. Short-term Changes in Insulin Resistance following Weight Loss Surgery for Morbid Obesity: Laparoscopic Adjustable Gastric Banding versus Laparoscopic Roux-en-Y Gastric Bypass. Obes Surg 2006;16:1189-97.

49. Garrapa GG, Canibus P, Gatti C, Santangelo M, Frezza F, Feliciotti F, Boscaro M, Faloia E. Changes in body composition and insulin sensitivity in severely obese subjects after laparoscopic adjustable silicone gastric banding (LASGB). Med Sci Monit 2005; 11:CR522-8.

50. Shargorodsky M, Fleed A, Boaz M, Gavish D, Zimlichman R. The effect of a rapid weight loss induced by laparoscopic adjustable gastric banding on arterial stiffness, metabolic and inflammatory parameters in patients with morbid obesity. Int J Obes (Lond) 2006.

51. Mattar SG, Velcu LM, Rabinovitz M, Demetris AJ, Krasinskas AM, Barinas-Mitchell E, Eid GM, Ramanathan R, Taylor DS, Schauer PR. Surgically-induced weight loss significantly improves nonalcoholic fatty liver disease and the metabolic syndrome. Ann Surg 2005; 242:610-7; discussion 618-20.

52. Wang J, Obici S, Morgan K, Barzilai N, Feng Z, Rossetti L. Overfeeding rapidly induces leptin and insulin resistance. Diabetes 2001;50:2786-91.

53. Ohannesian JP, Marco CC, Najm PS, Goldstein BJ, Caro JF, Kolaczynski JW. Small weight gain is not associated with development of insulin resistance in healthy, physically active individuals. Horm Metab Res 1999;31:323-5. 
20 


\section{Chapter}

\section{The surgical treatment of diabetic obesity}

Jeroen Nijhuis, Wim A. Buurman, Jan Willem M. Greve Immunology, Endocrine and Metabolic Agents in Medicinal Chemistry, 2007;7:19-29 


\section{Abstract}

Morbid obesity is associated with serious co-morbidities like cardiovascular disease, insulin resistance and type 2 diabetes (T2DM). Conventional therapy for T2DM consists of weight loss and pharmacotherapy. Recently, surgery was suggested to be the best treatment for T2DM in morbid obese patients. This review will focus on the effects of bariatric surgery on T2DM. The outcomes of different bariatric techniques will be discussed. Moreover, the question why weight loss is advantageous in treating T2DM will be addressed. In this view the effect of decreased nutrient intake, decreased intracellular fatty acid accumulation as well as decreased body fat mass on T2DM are discussed. 


\section{Introduction}

"Who would have thought it? An operation proves to be the most effective therapy for adult-onset diabetes mellitus". It was this paper from Walter Pories, which was the first to demonstrate the effectiveness of bariatric surgery on type 2 diabetes mellitus (T2DM) ${ }^{1}$.

T2DM is a growing problem in modern society. In 2002 the prevalence of T2DM in the United States was 6.3\%. 1.3 million inhabitants developed T2DM annually, an epidemic that was assessed to cost 132 billion dollars per year ${ }^{2}$. Treatment of T2DM is aimed at normalizing blood glucose levels by improving insulin sensitivity and/or increasing insulin secretion. Besides pharmacological interventions weight loss is very effective in T2DM patients ${ }^{3,4}$. Although diet induced weight loss can be favorable in obese individuals, not al obese patients can benefit from this treatment. In a subcategory of obesity, the morbidly obese patient (Body Mass Index (BMI) $>40 \mathrm{~kg} / \mathrm{m}^{2}$ ), this intervention is considered inefficient ${ }^{5-7}$. Within the morbidly obese population approximately $15 \%$ suffer from T2DM ${ }^{8}$. Conventional therapy is able to reduce weight with a maximum of $10 \%$. This only is achieved when psychotherapy, physiotherapy and dieting are combined ${ }^{9}$. Most of the patients are not capable of sustaining weight loss for more than five years. Moreover, $10 \%$ weight loss in morbid obese individuals is negligible compared to their substantial overweight. Currently, the most effective way to lose weight is bariatric surgery. As was reported by Buchwald surgically treated patients lose weight with a mean of $40 \mathrm{~kg}$ (14.2 BMI points) with excellent long term results ${ }^{8}$. Moreover, bariatric surgery appears cost effective within three years after surgery. In an observational two cohort study, 1035 subjects receiving bariatric surgery were compared with 5746 control subjects. Over a five year period the total costs per 1000 patients were 19.5 and 25.2 million Canadian dollars for the bariatric and control group respectively ${ }^{10}$.

This review focuses on the effect of bariatric surgery on T2DM. Both clinical and biochemical evidence will be discussed. Firstly we describe evidence in literature that bariatric surgery is an effective treatment of T2DM in morbid obese subjects. Next we focus on the types of surgery frequently used and the difference in effect of these surgical techniques on resolution of T2DM. The last part of this review addresses the question why weight loss is effective in treating T2DM.

\section{Bariatric surgery as a possible treatment of T2DM in morbidly obese patients}

Bariatric surgery is a subspecialty of surgery dealing with the surgical treatment of obesity. Numerous studies have been performed showing effectiveness of 
this intervention in morbidly obese individuals ${ }^{11-13}$. Since the original article of Pories was published another 30 studies have demonstrated similar effects of bariatric surgery on T2DM. Pories included 608 patients with a follow-up of 14 years after gastric bypass surgery. Impaired glucose intolerance recovered in 150 of 152 patients. Of the 146 patients with T2DM 83\% (121 patients) were cured. In another study $64 \%$ resolution of T2DM one year after gastric banding was reported in a group of 50 patients; $26 \%$ showed improved glucose control and $10 \%$ did not improve ${ }^{14}$. Most of these studies are summarized in the metaanalysis by Buchwald ${ }^{8}$. In this meta-analysis evidence of the effect of bariatric surgery on the different co-morbidities accompanying morbid obesity is described. In total 136 primary studies (19,388 patients) were included (5 randomized controlled trials, 28 nonrandomized controlled trials and 101 uncontrolled case series). Resolution of diabetes was defined as discontinuance of all diabetes-related medications as well as the ability to maintain blood glucose levels within the normal range. Studies reporting on diabetes showed $76.8 \%$ resolution (1417 out of 1846 patients). If studies reported both resolution and improvement, or only improvement of diabetes, $85.4 \%$ (414 out of 485 patients) experienced resolution or improvement of diabetes. Overall, plasma glucose levels in diabetic patients decreased with an average of $3.97 \mathrm{mmol} / \mathrm{l}$ (296 patients). Matching data were found in studies published after the inclusion date of the meta-analysis. Recently, between $83 \%$ and $88 \%$ resolution of T2DM was reported ${ }^{15-19}$. However, other studies report lower resolution rates ${ }^{20,21}$. The Swedish Obese Subjects (SOS) study reports $72 \%$ resolution within the first two years following surgery ${ }^{22}$. After ten years $36 \%$ of the patients with preoperative diabetes were cured. The SOS study is a non-randomized trial comparing 2010 patients who received bariatric surgery with 2037 conventional treated individuals. After ten years $13 \%$ of the patients with overt T2DM at the start of the study were cured in the conventional treated group. Moreover, the incidence of T2DM in the surgical group was $1 \%$ and $7 \%$ after two and ten years respectively. In contrast, in the conventional treated group the incidence of T2DM was $8 \%$ and $24 \%$ after two and ten years. These data indicate that, even in the long term follow-up, bariatric surgery is superior to conventional therapy in morbid obese patients.

A possible explanation for the differences observed in resolution of diabetes after bariatric surgery can be the history of T2DM before surgery. It was reported that the duration of T2DM before bariatric surgery is inversely correlated with the restoration of $\beta$-cell function postoperatively. With increasing duration of T2DM before surgery ( $>3$ years), the probability of $\beta$-cell recovery decreased $^{14,19,23,24}$. Moreover, older subjects with T2DM are also reported to benefit less from bariatric surgery ${ }^{25}$.

In literature evidence exists concerning cost effectiveness of bariatric surgery regarding T2DM. In the article of Sampalis on impact of bariatric surgery on 
health care costs the cumulative endocrinological costs per 1000 patients were 764,104 and 986,381 Canadian dollars for the bariatric and control group respectively ${ }^{10}$. Moreover, another study comparing the pharmaceutical costs between a bariatric and obese control group reported that surgery significantly reduced the costs of $\mathrm{T}_{2} \mathrm{DM}^{26}$. Furthermore, a $77.3 \%$ reduction of costs related to T2DM was reported in gastric bypass patients ${ }^{27}$. These studies show that bariatric surgery is a cost- effective treatment for T2DM.

Although the effect of bariatric surgery on resolution of T2DM is promising some reservations have to be made. Many studies were not randomized and follow-up was low. The Swedish Obesity Subjects (SOS) study was a well matched non-randomized trial comparing surgery with conventional therapy. In conclusion, more randomized studies are needed comparing conventional therapy with bariatric surgery with respect to resolution of $\mathrm{T}_{2} \mathrm{DM}^{28}$.

Different types of bariatric surgery techniques are available to reduce weight. According to the above mentioned meta-analysis, these surgical approaches have different outcomes on $\mathrm{T}^{2} \mathrm{DM}^{8}$ (Table 2.1.).

Table 2.1 Weight loss and T2DM resolution after bariatric surgery.

\begin{tabular}{lccc}
\hline & Gastric bypass & Biliopancreatic diversion & Gastric banding \\
\hline$\%$ EWL & $62.56 \%(56.68-66.45)^{\mathrm{a}}$ & $70.12 \%(66.34-73.91)^{\mathrm{a}}$ & $47.4 \%(40.68-54.23)^{\mathrm{a}}$ \\
$\%$ T2DM resolution & $83.7 \%(77.3-90.1)^{\mathrm{a}}$ & $98.9 \%(96.8-100)^{\mathrm{a}}$ & $47.9 \%(29.1-66.7)^{\mathrm{a}}$ \\
\hline
\end{tabular}

${ }^{a}$ Mean (95\% confidence interval), EWL: excess weight loss, T2DM: type II diabetes mellitus.

\section{Types of surgery}

Bariatric surgery is based on two main principles: malabsorption and restriction. The ingested food is either not properly absorbed by the gut or intake is limited. In malabsorptive surgery a short bowel is created while in restrictive surgery the stomach is reduced ${ }^{12,13}$. The result is substantial weight loss which averages $40 \mathrm{~kg}$ (14.2 BMI points $)^{8}$. We will discuss three major types of surgery: gastric bypass (Figure 2.1A), biliopancreatic diversion (Figure 2.1B) and adjustable laparoscopic gastric banding (Figure 2.1C).

Recently laparoscopic surgery has gained popularity because of its less invasive nature ${ }^{29}$. Morbid obese patients are at risk of developing serious postoperative complications ${ }^{30}$. Laparoscopic surgery is thought to decrease the postoperative complication rate dramatically. Laparoscopic gastric banding compared to an 'open' restrictive procedure like vertical gastric banding showed reduced direct postoperative complications ${ }^{31}$.

In our hospital laparoscopic gastric banding is preferred. In our opinion laparoscopic gastric banding is a safe procedure which results in substantial weight loss. If weight loss is insufficient a conversion to a gastric bypass is performed. Currently morbidly obese individuals with a BMI over $60 \mathrm{~kg} / \mathrm{m}^{2}$ are 
treated with biliopancreatic diversion. The rationale for this approach is not entirely evidence based since randomized controlled trials comparing different surgical techniques are limited.
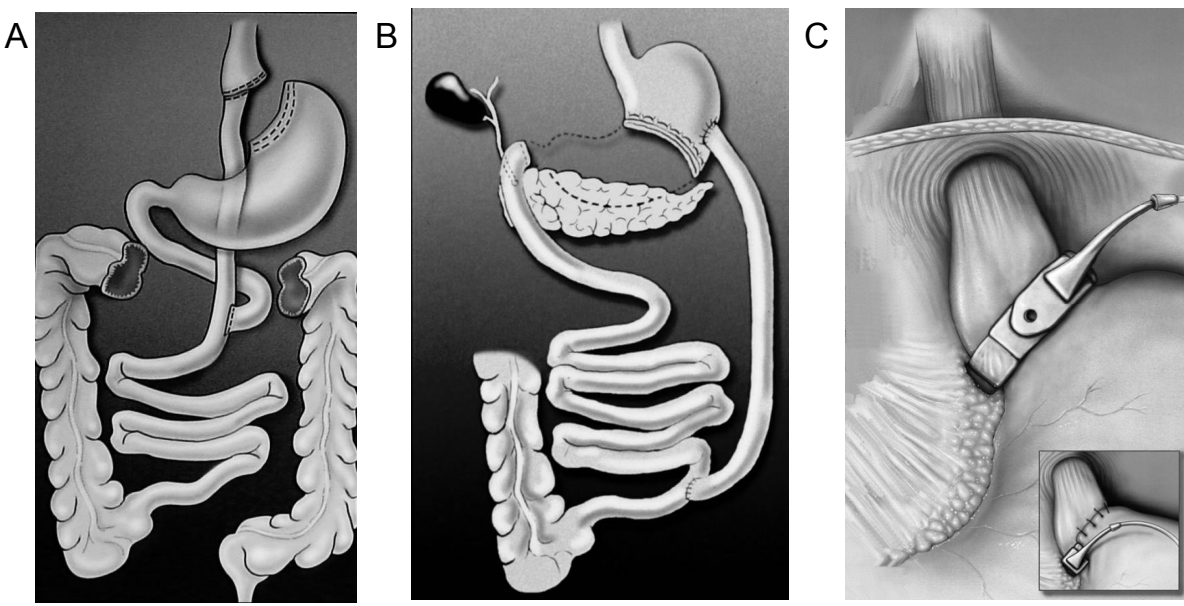

Figure 2.1 A. Gastric bypass (source: American Society of Bariatric Surgery)

B. Biliopancreatic diversion (source: American Society of Bariatric Surgery)

C. Gastric banding (source: American Society of Bariatric Surgery)

\section{Gastric bypass}

Gastric bypass surgery is a combination of malabsorptive and restrictive surgery (Figure 2.1A). This technique was introduced by Mason ${ }^{32}$ and has been adjusted to the technique currently carried out ${ }^{33}$. In short a vertical gastric pouch is created. To create the Roux limb, the jejunum is transected at approximately $30 \mathrm{~cm}$ from the ligament of Treitz where a comfortable length of mesentery exists. The Roux limb is measured $75-150 \mathrm{~cm}$ distally and an endto-side anastomosis is created with the proximal jejunal limb. The gastrojejunostomy is created using either a circular stapled end-to-end anastomosis, a linear stapler technique or a hand sewn technique.

\section{Biliopancreatic diversion}

This malabsorptive surgical technique was introduced by Scopinaro ${ }^{34}$. It consists of a distal gastrectomy with a long Roux-en-Y reconstruction (Figure 2.1B). The enteroenterostomy is placed $200 \mathrm{~cm}$ distal to the gastroenterostomy and $50 \mathrm{~cm}$ proximal to the ileocaecal valve. This results in three intestinal limbs, the alimentary loop from the gastroenterostomy to enteroenterostomy, the common loop from the enteroenterostomy to the ileocaecal valve and the 
pancreaticobiliary loop from the duodenum to the enteroenterostomy. The role of the gastrectomy is to allow a rapid emptying of gastric content into the ileum. The effect of the operation is the creation of a "controlled" short bowel.

\section{Adjustable laparoscopic gastric banding}

The adjustable gastric band is made of soft silicone and equipped with an elastic balloon that can be inflated to the desired volume by means of injection postoperatively. After inflation the outlet diameter will be reduced, leading to diminished food intake and consequently to weight loss. Belachew developed in the early nineties a laparoscopic technique ${ }^{34}$. In short the adjustable gastric banding is placed laparoscopically around the stomach. For definitive positioning of the band a $15-\mathrm{ml}$ calibration balloon advanced by the anesthetist and pulled up to the gastroesophageal junction is placed right below the cardia. Under this balloon the band is closed and with three or four sutures the ventral aspect of the greater curvature of the stomach is fixed to the pouch to ensure a stable anterior position of the band. Six weeks postoperatively the band is insufflated when weight loss is insufficient (less than $6 \mathrm{~kg}$ ). The band is insufflated as often as needed, to induce sufficient weight loss (approximately $0.5-1 \mathrm{~kg}$ weight loss per week).

\section{Comparing different surgical techniques}

A resolution of T2DM of $98.9 \%$ of the type 2 diabetic patients is seen after biliopancreatic diversion. This number was $83.7 \%$ for gastric bypass and $47.9 \%$ for laparoscopic gastric banding ${ }^{8}$. The difference was thought to be caused by the lack of malabsorption in laparoscopic gastric banding. However, in the same meta-analysis, vertical gastric banding, which is a purely restrictive procedure, shows a $71.6 \%$ resolution of T2DM. Differences in outcome can also be explained from inexperience with laparoscopic gastric banding. This can result in insufficient weight loss and poor resolution of diabetes. Laparoscopic gastric banding has lately been optimized, resulting in less complications and better weight loss ${ }^{35}$.

Recently, our group found contrasting data on insulin resistance (IR) after bariatric surgery. According to literature, bariatric surgery leads to increased insulin sensitivity directly after surgery. We found however no change in insulin sensitivity during the first months after restrictive bariatric surgery. In another group, which was weight stable (approximately two years after surgery), insulin sensitivity was improved ${ }^{36}$. We hypothesize that during the first months after surgery the weight losing individuals endures metabolic stress. This is illustrated by the observation that inflammatory parameters like C-Reactive Protein (CRP) and the endothelial activation markers soluble Intercellular Adhesion Molecule-1 (sICAM-1) and soluble Vascular Cell Adhesion 
Molecule-1 (sVCAM-1) are still increased during the first months after surgery $^{37,38}$.

Biliopancreatic diversion and gastric bypass have shown remarkable outcomes on diabetes. Within a few days after surgery, glucose levels decreased substantially. Also insulin sensitivity, measured using clamp studies increased rapidly ${ }^{39,40}$. During this period the amount of excess weight still was $80 \%$. It is hypothesized that the effect of this type of surgery on diabetes can not be explained from weight loss ${ }^{41}$. Hormones derived from the gut are thought to play an important role in resolution of T2DM directly after surgery ${ }^{41}$. This aspect will be elaborated in the next paragraph.

\section{Gut hormones explain it all?}

Administration of oral glucose leads to increased plasma insulin levels, much more than compared to intravenous administration of glucose. This effect is thought to arise from incretins secreted by the foregut and is called the incretin effect ${ }^{42,43}$. It was calculated that the incretin effect is responsible for $50-70 \%$ of the insulin response to oral glucose ${ }^{44}$. The two most important incretins are Glucose-dependent Insulinotropic Polypeptide (GIP) and Glucagon-Like Peptide 1 (GLP-1). GIP is almost exclusively secreted in the duodenum by $\mathrm{K}$-cells upon stimulation with lipids and absorbable carbohydrates ${ }^{45}$. Meal ingestion results in a 10 to 20 -fold increase in the plasma concentration ${ }^{46}$. GLP-1 is secreted by L-cells of the intestinal mucosa upon presence of nutrients. GIP is more expressed in the proximal intestine, while GLP-1 is predominately expressed in the terminal ileum ${ }^{47,48}$. Experiments neutralizing these incretins rendered animals and humans glucose intolerant ${ }^{49,50}$. Different hypotheses have been postulated on the origin of T2DM resolution taken into account the activity of incretins. These hypotheses are based on the finding that almost directly after malabsorptive surgery plasma glucose concentrations normalized and the need for insulin decreased without substantial weight loss. The only difference is that ingested food is bypassed and that the duodenum and proximal jejunum do not encounter food any more. Also of importance is that the terminal ileum now encounters undigested food more rapidly after ingestion. Pories and Rubino have based their hypothesis on the absence of food in the proximal gut ${ }^{41,51}$. Morbid obese patients have increased GIP plasma levels before bariatric surgery. It is speculated that GIP plasma levels are increased because of GIP resistance induced by an anti-incretin produced by the fore-gut. After gastric bypass, exclusion of these cells from the enteroinsulinemic axis can result in decreased anti-incretin levels. Consequently plasma levels of GIP decrease ${ }^{52}$. Until now the anti-incretin has not been found. Moreover, this hypothesis does not take into account the effect of unprocessed food in the terminal ileum. This, according to another hypothesis 
leads to increased postprandial GLP-1 production and increased insulin production and sensitivity ${ }^{53}$.

Purely restrictive surgery does not result in exclusion of the gut from ingested food. In contrast to our findings, other studies report increased insulin sensitivity directly after restrictive surgery ${ }^{38}$. These observations point out that alterations in plasma gut hormones levels are not solely responsible for the curative effect of bariatric surgery on T2DM. Weight loss is also responsible for improved insulin sensitivity after bariatric surgery. In the following paragraphs we will elaborate on this subject.

\section{Why weight loss is advantageous}

The low-grade inflammatory condition observed in obese individuals is thought to play a key role in the pathophysiology of obesity induced Insulin Resistance (IR) and T2DM ${ }^{54,55}$. Inflammatory mediators like Tumor Necrosis Factor alpha (TNF- $\alpha$ ) are reported to induce $\mathrm{IR}^{55}$. Moreover, high dose salicylate treatment for 14 days of patients with T2DM was reported to improve insulin sensitivity ${ }^{56-58}$. Substantial weight loss reduced the low-grade inflammatory condition $^{37}$. It is tempting to speculate that weight loss, by reducing inflammation, is an effective treatment for IR and T2DM. We will focus on the different mechanisms described in literature by which weight loss can facilitate improved insulin secretion and sensitivity. The following conditions associated with weight loss are discussed together with their contribution to increased insulin sensitivity and secretion: decreased intake of nutrients, decreased intracellular accumulation of fatty acids, and decreased fat mass.

\section{Decreased intake of nutrients}

Obesity is amongst others caused by a misbalance the metabolic need for and the intake of nutrients. Several observations link the excessive intake of nutrients directly to decreased insulin sensitivity. Overfeeding rats for one week resulted in reduced insulin sensitivity ${ }^{59}$. Moreover, liposuction in individuals with impaired glucose tolerance did not result in increased insulin sensitivity ${ }^{60}$. Recently we performed an overfeeding study in humans, which confirmed the data obtained in rat studies ${ }^{36}$. Studies in which overfeeding induced IR no change in BMI was observed, whereas insulin sensitivity decreased. The common denominator in the liposuction and overfeeding studies is increased nutrient intake. This leads to the hypothesis that increased nutrient intake itself can induce IR. Further support for this hypothesis is the observation that morbid obese individuals with a stable weight after bariatric surgery, are healthier than matched obese with similar BMI who did not loose weight ${ }^{61}$. Patients treated with bariatric surgery have less nutrient intake compared to the matched obese individuals. 
A possible mechanism behind these observations could imply the formation of reactive oxygen species (ROS) and their ability to activate the pro-inflammatory Nuclear Factor (NF)-kB pathway. In man a single oral dose of 75 gram glucose resulted in increased formation of ROS by polymorphonuclear and mononuclear cells. Moreover, concurrently the circulating concentration of the antioxidant $a$-tocopherol decreased ${ }^{62}$. Furthermore, a single dose of lipids (33 gram per $100 \mathrm{ml}, 300 \mathrm{kCal}$ ), resulted in increased ROS production by leucocytes and increased thiobarbituric acid-reactive substances (TBARS) while a-tocopherol plasma levels were not decreased. An isocaloric dose of protein only resulted in increased ROS production by leucocytes. It did not result in elevated TBARS or decreased $\alpha$-tocopherol plasma levels ${ }^{63}$. These results led to the hypothesis that nutrient intake can result in increased oxidative stress. Fasting decreased ROS formation by leucocytes and decreased systemic oxidative stress further supporting the hypothesis that increased nutrient intake leads via ROS formation to $\mathrm{IR}^{64,65}$.

ROS are reported to activate the NF-KB pathway resulting in increased proinflammatory cytokine production ${ }^{66}$. NF-KB is a heterodimer, generally consisting of RelA (p65) and p50 molecules. It resides in the cytosol where it is bound to IkB, which inhibits its activity. Upon activation of the cell, for example by lipopolysaccharides or TNF- $\alpha$, IKB becomes phosphorylated by the IKB kinase (IKK) complex and detaches from NF- KB. The IKK complex consists of IKK- $\alpha$, IKK- $\beta$ and a regulatory unit IKK- $\gamma^{67}$. The active form of NF-KB diffuses through the nuclear membrane to act as a transcription factor in the nucleus ${ }^{68}$. Theoretically the intake of nutrients can therefore lead, via the production of ROS, to increased inflammatory cytokine production. Mononuclear cells from human individuals subjected to a single dose of 75 gram glucose showed increased NF-KB binding ${ }^{69}$. This could result in increased production of proinflammatory cytokines in leucocytes or adhesion molecules in endothelial cells. Obesity, which is associated with chronic excessive nutrient intake, could therefore via ROS production result in low-grade inflammatory state. Cells can become insensitive to insulin in a low-grade inflammatory environment. Decreased energy intake accompanying weight loss (with or without the aid of surgical interventions) could therefore be one of the underlying mechanisms by which weight loss improves insulin sensitivity. Further research studying inflammatory cytokines after nutrient intake are needed to clarify this subject.

ER-stress is another mechanism by which increased nutrient intake can lead to IR. The Endoplasmatic Reticulum (ER) provides an environment in which newly formed proteins are processed. The function of this organelle can be regulated via a negative feedback loop called the unfolded protein response. If the ER is stressed, e.g. by increased input of proteins that have to be processed, more proteins are misfolded or unfolded. Such proteins trigger the unfolded protein response, which inhibits protein synthesis and promote protein breakdown ${ }^{70}$. 
Recently ER-stress and the unfolded protein response have been linked to IR and obesity. Markers of ER-stress are increased in obese mice. Obesity is thought to increase the metabolic workload for the cell, resulting in accumulation of reactive oxygen species, fatty acids and other intermediary metabolites which activates the unfolded protein response. The serine kinase c-Jun amino terminal kinase (JNK1) is a key molecule in the association between ER-stress and insulin resistance. This protein facilitates the serine phosphorylation of the insulin receptor substrate-1 suppressing insulin signaling and is also activated in ER-stress ${ }^{71}$. In this study no evidence of ER-stress was found in muscle and $\beta$-cells, only hepatic and adipose tissue displayed ER-stress in obesity.

Increased nutrient intake could therefore both via activation of the NF-KB pathway and ER-stress lead to IR. In this context weight loss induced by decreased intake of nutrients could result in decreased activation of the NF-KB pathway and reduced ER-stress.

\section{Intracellular lipid accumulation}

Apart from supplying the "building blocks" of phospholipids, glycolipids and hormones, fatty acids serve as fuel molecules used by cells in the body. Obesity and T2DM are associated with increased concentration of plasma fatty acids $^{72,73}$. The main storage organ for fatty acids is adipose tissue where large quantities are stored as triglycerides. Other cells also are capable of storing triglycerides, but their capacity is very limited. T2DM is associated with conditions where the storage capacity of cells for fatty acids is exceeded e.g. obesity or lipodystrophy. Thus T2DM developed in individuals in which the storage capacity of adipose tissue for triglycerides is exceeded.

Based on the observation that increased intracellular triglyceride content disrupts $\beta$-cell function of the pancreas the lipotoxicity hypothesis was postulated ${ }^{74,75}$. Besides the pancreas, muscle and liver tissue also play a major role in the pathogenesis of IR. Weight loss results in decreased accumulation of fatty acids in these organs ${ }^{76,77}$. In the following paragraph the effects of lipid accumulation in pancreas, liver and muscle are discussed to clarify the role of decreased intracellular accumulation of lipids in the increased sensitivity to insulin. An overview is given in Figure 2.2.

\section{Pancreas}

Lipotoxicity is thought to play a central role in decreased insulin secretion of $\beta$-cells. Fatty acids are reported to inhibit glucose stimulated insulin release in isolated rat $\beta$-cells ${ }^{75}$. Furthermore, lipid infusion in normal rats inhibited glucose-induced insulin release ${ }^{78}$. 
Accumulation of fatty acids by $\beta$-cells causes apoptosis. Fatty acids lead in vitro to apoptosis of isolated human $\beta$-cells, possible via ceramides ${ }^{79,80}$. Moreover, a synergistic action of glucose and fatty acids is reported on apoptosis in $\beta$-cells. The extent of fatty acid induced cell death and the magnitude of caspase activation increases with increasing glucose concentrations ${ }^{81}$. Another mechanism by which fatty acids can alter $\beta$-cell function is the loss of pancreas duodenum homebox-1 gene regulation, decreasing insulin promoter activity and therefore decreasing insulin secretion ${ }^{82,83}$.

Besides lipids hyperglycemia also has dysregulating effects on $\beta$-cells. Hyperglycemia leads to decreased insulin secretion by the pancreas. Proposed mechanisms are increased oxidative stress caused by increased oxidation of glucose combined with naturally low levels of antioxidants $(\mathrm{GSH}$, superoxide dismutase $)^{84}$. Moreover, it is hypothesized that hyperglycemia is a requirement for lipotoxicity to occur ${ }^{85}$.

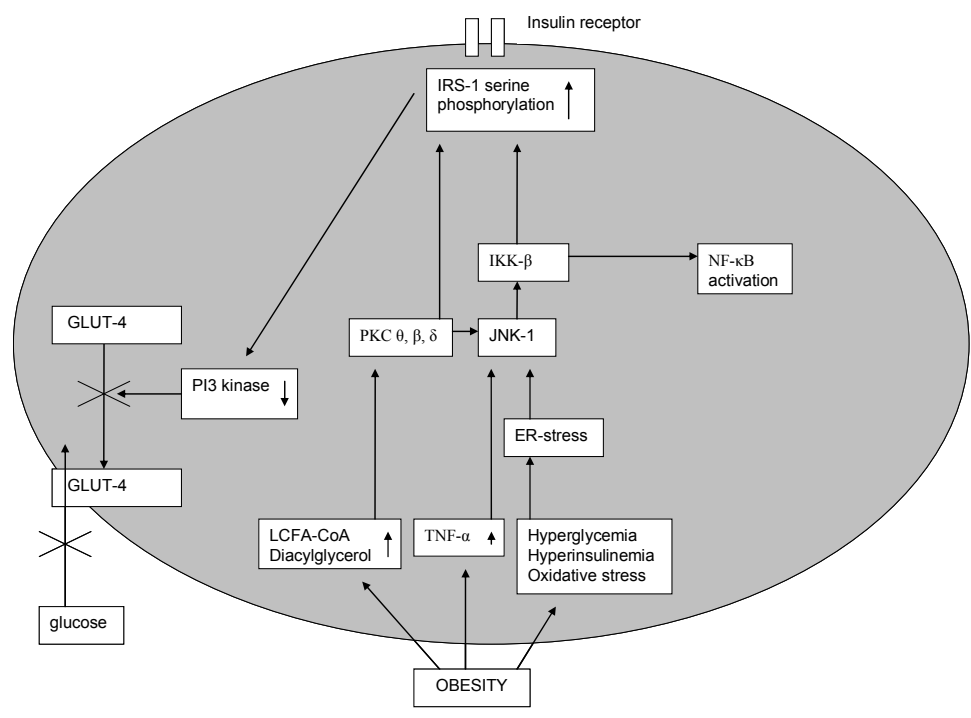

Figure 2.2 Pathways involved in obesity induced diabetes.

Obesity leads to increased accumulation of metabolites of fatty acids in cells. Moreover, obesity is associated with increased inflammatory parameters like TNF- $\alpha$. Furthermore, postprandial hyperglycemia, hyperinsulinemia and oxidative stress are reported in obesity. LCFA-CoA and diacylglycerol increase expression of PKC $\theta, \beta$ and $\delta$, which can directly via serine kinases or indirectly through JNK-1 and IKK- $\beta$ activation increase serine phosphorylation of the IRS-1. TNF- $\alpha$ and ER-stress lead through JNK-1 to IRS-1 serine phosphorylation.

IRS-1 which is serine phosphorylated can not activate PI3 kinase. Therefore GLUT-4 controlled glucose transport is impaired.

PKC: PhosphoKinase C, JNK-1: c-Jun NH-terminal Kinase-1, IKK- $\beta$ : Inhibitor of KappaB Kinase- $\beta$, IRS-1: Insulin Receptor Substrate-1, LCFA-CoA: Long Chain Fatty Acyl-CoA, ER: Endoplasmatic Reticulum, PI3: Phosphlnositol-3, GLUT-4: Glucose Transporter-4. 
Obesity is associated with increased accumulation of lipids in hepatocytes. Fatty liver is defined when deposition of fat in the liver accounts for more than $5 \%$ of liver weight or when more than $3 \%$ of hepatocytes are affected ${ }^{86}$. IR has been proposed to be a cause and a consequence of non alcoholic fatty liver disease (NAFLD). The causative hypothesis is founded on the observation that many patients with NAFLD are hyperinsulinemic. Moreover, NAFLD is found in IR and metabolic syndrome even if patients are not suffering from T2DM and are not obese ${ }^{87,88}$. NAFLD has also been reported in patients with lipodystrophy ${ }^{89}$. NAFLD is thought to evolve in non alcoholic steatohepatitis (NASH) via a two-hit model. Firstly IR of hepatocytes causes triglycerides to accumulate in hepatocytes. Increased oxidative stress and increased influx of pro-inflammatory cytokines are considered the second hit $^{90}$. IR and increased mass of the visceral fat depot are thought to play an important role. Increased flux of fatty acids and cytokines arising from the visceral fat depots reach the liver directly via the portal vein.

On the other hand other groups have shown that hepatic IR is a consequence of hepatic steatosis ${ }^{91-93}$. Rats fed a high fat diet for three days develop hepatic steatosis. Moreover, they develop hepatic IR in the absence of peripheral $\mathrm{IR}^{92}$. When hepatic fat accumulation was pharmacologically prevented the high fat diet did not result in hepatic $\mathbb{I R}^{91}$. Fatty acids are thought to decrease insulin sensitivity through serine phosphorylation of the insulin receptor substrate-1. In hepatocytes IKK- $\beta$ plays an important role in the pathway leading to serine phosphorylation ${ }^{94}$. Salicylates are IKK- $\beta$ inhibitors and this mechanism is thought to explain the beneficial effects of salicylate treatment on $\mathrm{T}_{2} \mathrm{DM}^{56-58}$. Weight loss is reported to decrease NAFLD ${ }^{76}$. Hypothetically, decreased accumulation of lipids in hepatocytes increases insulin sensitivity which could lead to decreased gluconeogenesis and increased insulin clearance.

\section{Muscle}

Obesity is associated with increased amounts of triglycerides in muscle tissue $^{95}$. These intramyocellular triglycerides (IMTG) are located near the mitochondria. It has been proposed that impaired capacity to oxidize fatty acids causes an increase in intracellular triglycerides content. The amount of IMTG was positively correlated with $\mathrm{IR}^{96,97}$. Besides increased oxidative stress as described in $\beta$-cells, other pathways leading to insulin sensitivity are described. In the 1960's Randle proposed a theory called the Randle cycle, which was the first to link intracellular fatty acids to $\mathrm{IR}^{98-100}$. This theory was based on the observation that glucose and fatty acids compete for substrate oxidation in rat heart muscle. The mechanism they proposed starts with increased oxidation of fatty acids resulting in increase acetyl CoA/CoA and NADH/NAD+ ratios. This 
on its turn inactivates the enzyme pyruvate dehydrogenase, resulting in accumulation of citrate. High intracellular levels of citrate could hypothetically inhibit the enzymatic activity of phosphofructokinase leading to increased intracellular glucose-6-phosphate levels. Increased levels of glucose-6phosphate inhibit hexokinase II. Consequently intracellular glucose concentrations increase inhibiting glucose uptake. Randle and coworkers proposed that this mechanism links obesity to IR.

Recently this hypothesis was questioned. It was postulated that metabolites of fatty acids which accumulate in the cell inhibit insulin signaling. This can result in failure of GLUT-4 to facilitate glucose transport. Long chain fatty acids-CoAs and diacylglycerol more than ceramides and triglycerides activate protein kinase $\mathrm{C} \theta, \mathrm{C} \delta$ or $\beta \mathrm{II}$. These kinases in turn potentiate serine/threonine phosphorylation of the insulin receptor and insulin receptor substrate-1. Moreover, tyrosine phosphorylation of the insulin receptor is inhibited. The increased serine/threonine and decreased tyrosine phosphorylation leads to dysfunctional insulin signaling preventing phosphoinositol-3-kinase activation leading to failure of GLUT-4 to facilitate glucose transport $^{101-104}$.

Weight loss results in decreased IMTG. Also the intracellular long chain fatty acid-acyl-CoA concentration, which is related to IR, decreases. Moreover, weight loss improves insulin sensitivity increasing tyrosine phosphorylation of insulin receptor substrate- $1^{105,106}$. Both the induction of IR by intracellular lipids and the decreased intracellular lipid amount caused by weight loss support the hypothesis that an important mechanism in IR in muscle includes lipid accumulation inside myocytes.

\section{Decreased fat mass}

\section{Adipokines}

Adipose tissue is no longer solely considered to be a fat-storing organ. The observation that adipose tissue could secrete TNF- $\alpha$ was the first to directly link adipose tissue to IR. In the years to follow different adipokines were discovered and many of them play a role in the etiology of IR.

In 1993 TNF- $\alpha$ was found to be expressed in adipose tissue of rodents ${ }^{107}$. Later this finding was confirmed in human adipose tissue ${ }^{108,109}$. These observations linked obesity to IR. TNF- $\alpha$ is thought to play a causative role in the development of IR, rendering target tissues like adipose tissue insensitive for insulin $^{110-112}$. Additionally, circulating TNF- $\alpha$ plasma levels are increased in obese individuals $^{37,113}$. The possible mechanisms by which TNF- $\alpha$ decreases insulin sensitivity include increased serine phosphorylation of the insulin receptor and down regulation of GLUT-4 expression ${ }^{110-112}$. Moreover, TNF- $\alpha$ is thought to act as an adipostat reducing triglyceride content in adipocytes which 
reach their storage threshold ${ }^{114}$. TNF- $\alpha$ inhibits lipoprotein lipase activity, preventing fatty acids uptake into the adipocyte. Furthermore, the hormone sensitive lipase activity in adipocytes is increased under the influence of TNF- $\alpha{ }^{115,116}$. These findings stress the importance of TNF- $\alpha$ in the pathogenesis of IR. However, treatment of diabetic patients with antibodies directed against TNF- $\alpha$ does not lead to increased insulin sensitivity in diabetic patients $^{117}$.

Plasma Interleukin (IL-6) originates for $30 \%$ from adipocytes ${ }^{118}$. It is thought that IL-6 production by visceral fat induces CRP production by the liver. This is seen as the main cause for increased CRP levels in obese individuals ${ }^{119}$. IL-6 was reported to decrease activation of insulin substrate-1 and phosphoinositol 3 phosphate kinase ${ }^{120,121}$. Administration of recombinant IL-6 in animal models as well as humans induced hepatic gluconeogenesis ${ }^{122}$. These results indicate that IL-6 can cause IR.

Adiponectin is produced by adipocytes, but in contrast to e.g. leptin does not increase in obesity. Obesity and T2DM are associated with decreased adiponectin levels ${ }^{123,124}$. The role of adiponectin in IR is multifactorial. Adiponectin decreases hepatic glucose output in animal studies and is associated with hepatic glucose output in humans ${ }^{125-127}$. Moreover, administration of adiponectin in mice treated with LPS resulted in decreased TNF- $\alpha$ plasma levels ${ }^{128}$. In addition, human macrophages treated with adiponectin show decreased TNF- $\alpha$ and IL-6 production ${ }^{129}$. On the other hand, TNF- $\alpha$ was reported to decrease adiponectin secretion of isolated human adipocytes $^{130}$.

Resistin was formerly seen as the molecule linking obesity to IR. In animal studies resistin concentrations are associated with $I R$ and infusion of recombinant resistin causes hepatic IR. Furthermore, glucose tolerance is impaired in wild type mice given recombinant resistin ${ }^{131}$. The former enthusiasm towards resistin has somewhat been tapered off. In humans the close association between IR and resistin levels does not exist ${ }^{132}$. However, plasma resistin levels are reported to be associated with waist-hip ratio and body fat mass ${ }^{133}$. The major production site of resistin in man are monocytes ${ }^{134}$. Resistin production is induced by inflammatory mediators like TNF- $\alpha$ and LPS and can on its turn induce TNF- $\alpha$ and IL-12 production from macrophages ${ }^{135-137}$. This leads to the hypothesis that resistin plays a central role in IR associated with sepsis and other inflammatory conditions.

Weight loss results in decreased plasma levels of TNF- $\alpha$ or its receptors and IL-6 $6^{37,113,138}$. In addition, TNF- $\alpha$ mRNA expression in adipose tissue decreased after weight loss ${ }^{139}$. Plasma adiponectin levels as well as adiponectin mRNA derived from adipose tissue increased after weight loss ${ }^{140,141}$. 


\section{Macrophage accumulation}

With increasing BMI macrophages accumulate in adipose tissue ${ }^{142,143}$. These adipose tissue resident macrophages could potentially play a role in the status of low-grade inflammation of obesity induced IR. Specific macrophage IKK- $\beta$ knockout mice are protected against IR induced either by inflammation or a high fat diet ${ }^{144}$. Weight loss results in decreased numbers of macrophages ${ }^{145}$. Moreover, treatment of individuals with impaired glucose tolerance with the insulin sensitizing agent pioglitazone reduced CD68 mRNA expression in adipose tissue ${ }^{146}$. Further studies are needed to elucidate if the accumulation of macrophages has any pathophysiological consequences.

\section{Summary}

Bariatric surgery is the treatment of choice for individuals with a BMI over $35 \mathrm{~kg} / \mathrm{m}^{2}$ with co-morbidities or a BMI over $40 \mathrm{~kg} / \mathrm{m}^{2}$. Bariatric surgery is also effective in treating T2DM in morbid obese individuals. The immediate effect of biliopancreatic diversion and gastric bypass on insulin sensitivity led to hypotheses regarding gut hormones. Exclusion of part of the gut and consequently absence of food in the foregut could reduce the production of GIP via the decreased secretion of an anti-incretin by the foregut. More plausible is the hypothesis that due to the bypass of nutrients, the distal ileum receives increased amounts of unprocessed nutrients. This could result in increased GLP-1 plasma levels, increasing insulin sensitivity.

The effect of bariatric surgery on gut hormones can not solely explain the effect on T2DM. Bariatric surgery also results in decreased nutrient intake, decreased intracellular fatty acid load and decreased fat mass. These behavioral and metabolic changes could underlie the success of bariatric surgery in treating T2DM. Caloric restriction resulted in decreased formation of ROS and therefore could decrease the low-inflammatory state. Decreased accumulation of lipids in the pancreas improves $\beta$-cell functioning. Moreover, in myocytes and hepatocytes the intracellular pathway of insulin signaling is less impaired. In addition, decreased fat mass induced by weight loss results in alterations in plasma levels of adipokines. Furthermore, the number of macrophages in adipose tissue decreased after weight loss. Prodiabetogenic factors TNF- $\alpha$ and IL-6 levels decreased whereas the insulin sensitizing adipokine adiponectin increased after weight loss.

\section{Future directions}

The International Federation for the Surgery of Obesity (IFSO) guidelines regarding bariatric surgery state that bariatric surgery is reserved to obese 
individuals with a BMI over $35 \mathrm{~kg} / \mathrm{m}^{2}$ with serious co-morbidities and individuals with a BMI over $40 \mathrm{~kg} / \mathrm{m}^{2}$. Recently O'Brien proposed to lower this BMI border. In a randomized clinical trial they included patients with BMI ranging from 30-35 and found that patients were able to decrease their bodyweight more effectively than using conventional treatment. Moreover, quality of life and measures of the metabolic syndrome showed more improvement in the surgically treated group ${ }^{147}$. The observation that moderately obese patients with T2DM could also benefit from surgery initiates the discussion that these patients should be taken into consideration for bariatric surgery. 


\section{References}

1. Pories WJ, Swanson MS, MacDonald KG, Long SB, Morris PG, Brown BM, Barakat HA, deRamon RA, Israel G, Dolezal JM, et al. Who would have thought it? An operation proves to be the most effective therapy for adult-onset diabetes mellitus. Ann Surg 1995;222:339-50; discussion 350-2.

2. Hogan P, Dall T, Nikolov P. Economic costs of diabetes in the US in 2002. Diabetes Care 2003;26:917-32.

3. Hauner H. Managing type 2 diabetes mellitus in patients with obesity. Treat Endocrinol 2004; 3:223-32.

4. Reaven GM. The insulin resistance syndrome: definition and dietary approaches to treatment. Annu Rev Nutr 2005;25:391-406.

5. NIH conference. Gastrointestinal surgery for severe obesity. Consensus Development Conference Panel. Ann Intern Med 1991;115:956-61.

6. Clinical Guidelines on the Identification, Evaluation, and Treatment of Overweight and Obesity in Adults--The Evidence Report. National Institutes of Health. Obes Res 1998;6 Suppl 2:51S-209S.

7. Obesity: preventing and managing the global epidemic. Report of a WHO consultation. World Health Organ Tech Rep Ser 2000;894:i-xii, 1-253.

8. Buchwald H, Avidor Y, Braunwald E, Jensen MD, Pories W, Fahrbach K, Schoelles K. Bariatric surgery: a systematic review and meta-analysis. JAMA 2004;292:1724-37.

9. Kharroubi I, Rasschaert J, Eizirik DL, Cnop M. Expression of adiponectin receptors in pancreatic beta cells. Biochem Biophys Res Commun 2003;312:1118-22.

10. Sampalis JS, Liberman M, Auger S, Christou NV. The impact of weight reduction surgery on health-care costs in morbidly obese patients. Obes Surg 2004;14:939-47.

11. DeMaria EJ, Jamal MK. Laparoscopic adjustable gastric banding: evolving clinical experience. Surg Clin North Am 2005;85:773-87, vii.

12. Demaria EJ, Jamal MK. Surgical options for obesity. Gastroenterol Clin North Am 2005; 34:127-42.

13. Pender JR, Pories WJ. Surgical treatment of obesity. Psychiatr Clin North Am 2005;28:219$34, x$

14. Dixon JB, O'Brien PE. Health outcomes of severely obese type 2 diabetic subjects 1 year after laparoscopic adjustable gastric banding. Diabetes Care 2002;25:358-63.

15. Papasavas PK, Gagne DJ, Kelly J, Caushaj PF. Laparoscopic Roux-En-Y gastric bypass is a safe and effective operation for the treatment of morbid obesity in patients older than 55 years. Obes Surg 2004;14:1056-61.

16. Sugerman HJ, Wolfe LG, Sica DA, Clore JN. Diabetes and hypertension in severe obesity and effects of gastric bypass-induced weight loss. Ann Surg 2003;237:751-6; discussion 757-8.

17. Weber M, Muller MK, Bucher T, Wildi S, Dindo D, Horber F, Hauser R, Clavien PA. Laparoscopic gastric bypass is superior to laparoscopic gastric banding for treatment of morbid obesity. Ann Surg 2004;240:975-82; discussion 982-3.

18. Valera-Mora ME, Simeoni B, Gagliardi L, Scarfone A, Nanni G, Castagneto M, Manco M, Mingrone G, Ferrannini E. Predictors of weight loss and reversal of comorbidities in malabsorptive bariatric surgery. Am J Clin Nutr 2005;81:1292-7.

19. Schauer PR, Burguera B, Ikramuddin S, Cottam D, Gourash W, Hamad G, Eid GM, Mattar S, Ramanathan R, Barinas-Mitchel E, Rao RH, Kuller L, Kelley D. Effect of laparoscopic Rouxen $Y$ gastric bypass on type 2 diabetes mellitus. Ann Surg 2003;238:467-84; discussion 84-5.

20. Spivak H, Hewitt MF, Onn A, Half EE. Weight loss and improvement of obesity-related illness in 500 U.S. patients following laparoscopic adjustable gastric banding procedure. Am J Surg 2005;189:27-32.

21. Obeid F, Falvo A, Dabideen H, Stocks J, Moore M, Wright M. Open Roux-en-Y gastric bypass in 925 patients without mortality. Am J Surg 2005;189:352-6. 
22. Sjostrom L, Lindroos AK, Peltonen M, Torgerson J, Bouchard C, Carlsson B, Dahlgren S, Larsson B, Narbro K, Sjostrom CD, Sullivan M, Wedel H. Lifestyle, diabetes, and cardiovascular risk factors 10 years after bariatric surgery. N Engl J Med 2004;351:2683-93.

23. Guichard-Rode S, Charrie A, Penet D, Teboul F, Thivolet C. Massive weight loss does not restore normal insulin secretory pulses in obese patients with type 2 (non-insulin-dependent) diabetes mellitus. Diabetes Metab 1997;23:506-10.

24. Dixon JB, Dixon AF, O'Brien PE. Improvements in insulin sensitivity and beta-cell function (HOMA) with weight loss in the severely obese. Homeostatic model assessment. Diabet Med 2003;20:127-34.

25. Pories WJ, MacDonald KG, Jr., Morgan EJ, Sinha MK, Dohm GL, Swanson MS, Barakat HA, Khazanie PG, Leggett-Frazier N, Long SD. Surgical treatment of obesity and its effect on diabetes: 10-y follow-up. Am J Clin Nutr 1992;55(2 Suppl):582S-585S.

26. Narbro K, Agren G, Jonsson E, Naslund I, Sjostrom L, Peltonen M. Pharmaceutical costs in obese individuals: comparison with a randomly selected population sample and long-term changes after conventional and surgical treatment: the SOS intervention study. Arch Intern Med 2002;162:2061-9.

27. Potteiger CE, Paragi PR, Inverso NA, Still C, Reed MJ, Strodel W, 3rd, Rogers M, Petrick A. Bariatric surgery: shedding the monetary weight of prescription costs in the managed care arena. Obes Surg 2004;14:725-30.

28. Pinkney J, Kerrigan D. Current status of bariatric surgery in the treatment of type 2 diabetes. Obes Rev 2004;5:69-78.

29. Cottam DR, Nguyen NT, Eid GM, Schauer PR. The impact of laparoscopy on bariatric surgery. Surg Endosc 2005;19:621-7.

30. Byrne TK. Complications of surgery for obesity. Surg Clin North Am 2001;81:1181-93, vii-viii.

31. van Dielen FMH, Soeters P.B., de Brauw L.M., Greve J.W.M. Laparoscopic adjustable gastric banding versus open vertical banded gastroplasty: a prospective randomized trial. Obes Surg 2005;15:1292-8.

32. Mason EE, Ito C. Gastric bypass in obesity. Surg Clin North Am 1967;47:1345-51.

33. Scruggs DM, Cowan GS, Jr., Klesges L, Defibaugh N, Walker R, Kuyper B, Hiler ML. Weight Loss and Caloric Intake after Regular and Extended Gastric Bypass. Obes Surg 1993;3: 233-8.

34. Scopinaro N, Gianetta E, Civalleri D, Bonalumi U, Bachi V. Bilio-pancreatic bypass for obesity: II. Initial experience in man. Br J Surg 1979;66:618-20.

35. O'Brien PE, Dixon JB, Laurie C, Anderson M. A prospective randomized trial of placement of the laparoscopic adjustable gastric band: comparison of the perigastric and pars flaccida pathways. Obes Surg 2005;15:820-6.

36. Nijhuis J, van Dielen FM, Schaper NC, Wiebolt J, Koks A, Prakken FJ, Rensen SS, Buurman WA, Greve JW. Short-term Overfeeding Induces Insulin Resistance in Weight-stable Patients After Bariatric Surgery. Obes Surg 2008.

37. van Dielen FM, Buurman WA, Hadfoune M, Nijhuis J, Greve JW. Macrophage inhibitory factor, plasminogen activator inhibitor-1, other acute phase proteins, and inflammatory mediators normalize as a result of weight loss in morbidly obese subjects treated with gastric restrictive surgery. J Clin Endocrinol Metab 2004;89:4062-8.

38. Vazquez LA, Pazos F, Berrazueta JR, Fernandez-Escalante C, Garcia-Unzueta MT, Freijanes J, Amado JA. Effects of changes in body weight and insulin resistance on inflammation and endothelial function in morbid obesity after bariatric surgery. J Clin Endocrinol Metab 2005;90:316-22.

39. Scopinaro N, Adami GF, Marinari GM, Gianetta E, Traverso E, Friedman D, Camerini G, Baschieri G, Simonelli A. Biliopancreatic diversion. World J Surg 1998;22:936-46.

40. Pories WJ, Swanson MS, MacDonald KG, Long SB, Morris PG, Brown BM, Barakat HA, deRamon RA, Israel G, Dolezal JM. Who would have thought it? An operation proves to be the most effective therapy for adult-onset diabetes mellitus. Ann Surg 1995;222:339-50; discussion 350-2.

41. Pories WJ, Albrecht RJ. Etiology of type II diabetes mellitus: role of the foregut. World J Surg 2001;25:527-31. 
42. McIntyre N, Holdsworth CD, Turner DS. Intestinal factors in the control of insulin secretion. J Clin Endocrinol Metab 1965;25:1317-24.

43. Perley MJ, Kipnis DM. Plasma insulin responses to oral and intravenous glucose: studies in normal and diabetic sujbjects. J Clin Invest 1967;46:1954-62.

44. Nauck MA, Homberger E, Siegel EG, Allen RC, Eaton RP, Ebert R, Creutzfeldt W. Incretin effects of increasing glucose loads in man calculated from venous insulin and C-peptide responses. J Clin Endocrinol Metab 1986;63:492-8.

45. Mortensen K, Petersen LL, Orskov C. Colocalization of GLP-1 and GIP in human and porcine intestine. Ann N Y Acad Sci 2000;921:469-72.

46. Vilsboll T, Holst JJ. Incretins, insulin secretion and Type 2 diabetes mellitus. Diabetologia 2004;47:357-66.

47. Mojsov S, Heinrich G, Wilson IB, Ravazzola M, Orci L, Habener JF. Preproglucagon gene expression in pancreas and intestine diversifies at the level of post-translational processing. $\mathrm{J}$ Biol Chem 1986;261:11880-9.

48. Holst JJ. Glucagon-like Peptide 1 (GLP-1): An Intestinal Hormone, Signalling Nutritional Abundance, with an Unusual Therapeutic Potential. Trends Endocrinol Metab 1999; 10:229-235.

49. Wang Z, Wang RM, Owji AA, Smith DM, Ghatei MA, Bloom SR. Glucagon-like peptide-1 is a physiological incretin in rat. J Clin Invest 1995;95:417-21.

50. Edwards CM, Todd JF, Mahmoudi M, Wang Z, Wang RM, Ghatei MA, Bloom SR. Glucagonlike peptide 1 has a physiological role in the control of postprandial glucose in humans: studies with the antagonist exendin 9-39. Diabetes 1999;48:86-93.

51. Rubino F, Gagner M. Potential of surgery for curing type 2 diabetes mellitus. Ann Surg 2002; 236:554-9.

52. Rubino F, Gagner M, Gentileschi P, Kini S, Fukuyama S, Feng J, Diamond E. The early effect of the Roux-en-Y gastric bypass on hormones involved in body weight regulation and glucose metabolism. Ann Surg 2004;240:236-42.

53. Patriti A, Facchiano E, Sanna A, Gulla N, Donini A. The enteroinsular axis and the recovery from type 2 diabetes after bariatric surgery. Obes Surg 2004;14:840-8.

54. Wellen KE, Hotamisligil GS. Obesity-induced inflammatory changes in adipose tissue. J Clin Invest 2003;112:1785-8.

55. Hotamisligil GS. Inflammatory pathways and insulin action. Int J Obes Relat Metab Disord 2003;27 Suppl 3:S53-5.

56. Yuan M, Konstantopoulos N, Lee J, Hansen L, Li ZW, Karin M, Shoelson SE. Reversal of obesity- and diet-induced insulin resistance with salicylates or targeted disruption of Ikkbeta. Science 2001;293:1673-7.

57. Kim JK, Kim YJ, Fillmore JJ, Chen Y, Moore I, Lee J, Yuan M, Li ZW, Karin M, Perret P, Shoelson SE, Shulman GI. Prevention of fat-induced insulin resistance by salicylate. J Clin Invest 2001;108:437-46.

58. Hundal RS, Petersen KF, Mayerson AB, Randhawa PS, Inzucchi S, Shoelson SE, Shulman Gl. Mechanism by which high-dose aspirin improves glucose metabolism in type 2 diabetes. $J$ Clin Invest 2002;109:1321-6.

59. Wang J, Obici S, Morgan K, Barzilai N, Feng Z, Rossetti L. Overfeeding rapidly induces leptin and insulin resistance. Diabetes 2001;50:2786-91.

60. Klein S, Fontana L, Young VL, Coggan AR, Kilo C, Patterson BW, Mohammed BS. Absence of an effect of liposuction on insulin action and risk factors for coronary heart disease. $\mathrm{N}$ Engl J Med 2004;350:2549-57.

61. Dixon JB, Anderson M, Cameron-Smith D, O'Brien PE. Sustained weight loss in obese subjects has benefits that are independent of attained weight. Obes Res 2004;12:1895-902.

62. Mohanty P, Hamouda W, Garg R, Aljada A, Ghanim H, Dandona P. Glucose challenge stimulates reactive oxygen species (ROS) generation by leucocytes. J Clin Endocrinol Metab 2000;85:2970-3.

63. Mohanty P, Ghanim H, Hamouda W, Aljada A, Garg R, Dandona P. Both lipid and protein intakes stimulate increased generation of reactive oxygen species by polymorphonuclear leukocytes and mononuclear cells. Am J Clin Nutr 2002;75:767-72. 
64. Dandona P, Mohanty P, Hamouda W, Ghanim H, Aljada A, Garg R, Kumar V. Inhibitory effect of a two day fast on reactive oxygen species (ROS) generation by leucocytes and plasma ortho-tyrosine and meta-tyrosine concentrations. J Clin Endocrinol Metab 2001;86:2899-902.

65. Dandona P, Mohanty P, Ghanim H, Aljada A, Browne R, Hamouda W, Prabhala A, Afzal A, Garg R. The suppressive effect of dietary restriction and weight loss in the obese on the generation of reactive oxygen species by leukocytes, lipid peroxidation, and protein carbonylation. J Clin Endocrinol Metab 2001;86:355-62.

66. Herrlich $\mathrm{P}$, Bohmer FD. Redox regulation of signal transduction in mammalian cells. Biochem Pharmacol 2000;59:35-41.

67. Karin M, Ben-Neriah Y. Phosphorylation meets ubiquitination: the control of NF-[kappa]B activity. Annu Rev Immunol 2000;18:621-63.

68. Baeuerle PA, Baltimore D. NF-kappa B: ten years after. Cell 1996;87:13-20.

69. Dhindsa S, Tripathy D, Mohanty P, Ghanim H, Syed T, Aljada A, Dandona P. Differential effects of glucose and alcohol on reactive oxygen species generation and intranuclear nuclear factor-kappaB in mononuclear cells. Metabolism 2004;53:330-4.

70. Xu C, Bailly-Maitre B, Reed JC. Endoplasmic reticulum stress: cell life and death decisions. J Clin Invest 2005;115:2656-64.

71. Ozcan U, Cao Q, Yilmaz E, Lee AH, Iwakoshi NN, Ozdelen E, Tuncman G, Gorgun C, Glimcher LH, Hotamisligil GS. Endoplasmic reticulum stress links obesity, insulin action, and type 2 diabetes. Science 2004;306:457-61.

72. Campbell PJ, Carlson MG, Nurjhan N. Fat metabolism in human obesity. Am J Physiol 1994; 266:E600-5.

73. Fraze E, Donner CC, Swislocki AL, Chiou YA, Chen YD, Reaven GM. Ambient plasma free fatty acid concentrations in noninsulin-dependent diabetes mellitus: evidence for insulin resistance. J Clin Endocrinol Metab 1985;61:807-11.

74. Lee $\mathrm{Y}$, Hirose $\mathrm{H}$, Ohneda M, Johnson JH, McGarry JD, Unger RH. Beta-cell lipotoxicity in the pathogenesis of non-insulin-dependent diabetes mellitus of obese rats: impairment in adipocyte-beta-cell relationships. Proc Natl Acad Sci U S A 1994;91:10878-82.

75. Zhou YP, Grill VE. Long-term exposure of rat pancreatic islets to fatty acids inhibits glucoseinduced insulin secretion and biosynthesis through a glucose fatty acid cycle. J Clin Invest 1994;93:870-6.

76. Mattar SG, Velcu LM, Rabinovitz M, Demetris AJ, Krasinskas AM, Barinas-Mitchell E, Eid GM, Ramanathan R, Taylor DS, Schauer PR. Surgically-Induced Weight Loss Significantly Improves Nonalcoholic Fatty Liver Disease and the Metabolic Syndrome. Ann Surg 2005; 242:610-20.

77. Fabris R, Mingrone G, Milan G, Manco M, Granzotto M, Dalla Pozza A, Scarda A, Serra R, Greco AV, Federspil G, Vettor R. Further lowering of muscle lipid oxidative capacity in obese subjects after biliopancreatic diversion. J Clin Endocrinol Metab 2004;89:1753-9.

78. Sako Y, Grill VE. A 48-hour lipid infusion in the rat time-dependently inhibits glucose-induced insulin secretion and $B$ cell oxidation through a process likely coupled to fatty acid oxidation. Endocrinology 1990;127:1580-9.

79. Shimabukuro M, Zhou YT, Levi M, Unger RH. Fatty acid-induced beta cell apoptosis: a link between obesity and diabetes. Proc Natl Acad Sci U S A 1998;95:2498-502.

80. Lupi R, Dotta F, Marselli L, Del Guerra S, Masini M, Santangelo C, Patane G, Boggi U, Piro S, Anello M, Bergamini E, Mosca F, Di Mario U, Del Prato S, Marchetti P. Prolonged exposure to free fatty acids has cytostatic and pro-apoptotic effects on human pancreatic islets: evidence that beta-cell death is caspase mediated, partially dependent on ceramide pathway, and Bcl-2 regulated. Diabetes 2002;51:1437-42.

81. El-Assaad W, Buteau J, Peyot ML, Nolan C, Roduit R, Hardy S, Joly E, Dbaibo G, Rosenberg L, Prentki M. Saturated fatty acids synergize with elevated glucose to cause pancreatic betacell death. Endocrinology 2003;144:4154-63.

82. Gremlich S, Bonny C, Waeber G, Thorens B. Fatty acids decrease IDX-1 expression in rat pancreatic islets and reduce GLUT2, glucokinase, insulin, and somatostatin levels. J Biol Chem 1997;272:30261-9. 
83. Yoshikawa H, Tajiri Y, Sako Y, Hashimoto T, Umeda F, Nawata H. Effects of free fatty acids on beta-cell functions: a possible involvement of peroxisome proliferator-activated receptors alpha or pancreatic/duodenal homeobox. Metabolism 2001;50:613-8.

84. Robertson RP, Harmon J, Tran PO, Tanaka Y, Takahashi H. Glucose toxicity in beta-cells: type 2 diabetes, good radicals gone bad, and the glutathione connection. Diabetes 2003; 52:581-7.

85. Robertson RP, Harmon J, Tran PO, Poitout V. Beta-cell glucose toxicity, lipotoxicity, and chronic oxidative stress in type 2 diabetes. Diabetes 2004;53 Suppl 1:S119-24.

86. Cairns SR, Peters TJ. Biochemical analysis of hepatic lipid in alcoholic and diabetic and control subjects. Clin Sci (Lond) 1983;65:645-52.

87. Marchesini G, Brizi M, Bianchi G, Tomassetti S, Bugianesi E, Lenzi M, McCullough AJ, Natale $\mathrm{S}$, Forlani G, Melchionda N. Nonalcoholic fatty liver disease: a feature of the metabolic syndrome. Diabetes 2001;50:1844-50.

88. Sonsuz A, Basaranoglu M, Bilir M, Senturk H, Akin P. Hyperinsulinemia in nondiabetic, both obese and nonobese patients with nonalcoholic steatohepatitis. Am J Gastroenterol 2002; 97:495.

89. Powell EE, Searle J, Mortimer R. Steatohepatitis associated with limb lipodystrophy. Gastroenterology 1989;97:1022-4.

90. Day CP, James OF. Steatohepatitis: a tale of two "hits"? Gastroenterology 1998;114:842-5.

91. Samuel VT, Liu ZX, Qu X, Elder BD, Bilz S, Befroy D, Romanelli AJ, Shulman GI. Mechanism of hepatic insulin resistance in non-alcoholic fatty liver disease. J Biol Chem 2004; 279:32345-53.

92. Kraegen EW, Clark PW, Jenkins AB, Daley EA, Chisholm DJ, Storlien LH. Development of muscle insulin resistance after liver insulin resistance in high-fat-fed rats. Diabetes 1991; 40:1397-403.

93. Kim JK, Fillmore JJ, Chen Y, Yu C, Moore IK, Pypaert M, Lutz EP, Kako Y, Velez-Carrasco W, Goldberg IJ, Breslow JL, Shulman GI. Tissue-specific overexpression of lipoprotein lipase causes tissue-specific insulin resistance. Proc Natl Acad Sci U S A 2001;98:7522-7.

94. Cai D, Yuan M, Frantz DF, Melendez PA, Hansen L, Lee J, Shoelson SE. Local and systemic insulin resistance resulting from hepatic activation of IKK-beta and NF-kappaB. Nat Med 2005;11:183-90.

95. Szczepaniak LS, Babcock EE, Schick F, Dobbins RL, Garg A, Burns DK, McGarry JD, Stein DT. Measurement of intracellular triglyceride stores by $\mathrm{H}$ spectroscopy: validation in vivo. Am J Physiol 1999;276:E977-89.

96. Goodpaster BH, Thaete FL, Simoneau JA, Kelley DE. Subcutaneous abdominal fat and thigh muscle composition predict insulin sensitivity independently of visceral fat. Diabetes 1997; 46:1579-85.

97. Pan DA, Lillioja S, Kriketos AD, Milner MR, Baur LA, Bogardus C, Jenkins AB, Storlien LH. Skeletal muscle triglyceride levels are inversely related to insulin action. Diabetes 1997; 46:983-8.

98. Randle PJ, Garland PB, Hales CN, Newsholme EA. The glucose fatty-acid cycle. Its role in insulin sensitivity and the metabolic disturbances of diabetes mellitus. Lancet 1963;1:785-9.

99. Randle PJ, Garland PB, Newsholme EA, Hales CN. The glucose fatty acid cycle in obesity and maturity onset diabetes mellitus. Ann N Y Acad Sci 1965;131:324-33.

100. Randle PJ, Newsholme EA, Garland PB. Regulation of glucose uptake by muscle. 8. Effects of fatty acids, ketone bodies and pyruvate, and of alloxan-diabetes and starvation, on the uptake and metabolic fate of glucose in rat heart and diaphragm muscles. Biochem J 1964; 93:652-65.

101. Roden M, Price TB, Perseghin G, Petersen KF, Rothman DL, Cline GW, Shulman GI. Mechanism of free fatty acid-induced insulin resistance in humans. J Clin Invest 1996; 97:2859-65.

102. Dresner A, Laurent D, Marcucci M, Griffin ME, Dufour S, Cline GW, Slezak LA, Andersen DK, Hundal RS, Rothman DL, Petersen KF, Shulman GI. Effects of free fatty acids on glucose transport and IRS-1-associated phosphatidylinositol 3-kinase activity. J Clin Invest 1999; 103:253-9. 
103. Griffin ME, Marcucci MJ, Cline GW, Bell K, Barucci N, Lee D, Goodyear LJ, Kraegen EW, White MF, Shulman GI. Free fatty acid-induced insulin resistance is associated with activation of protein kinase C theta and alterations in the insulin signaling cascade. Diabetes 1999; 48:1270-4.

104. Kim YB, Kotani K, Ciaraldi TP, Henry RR, Kahn BB. Insulin-stimulated protein kinase C lambda/zeta activity is reduced in skeletal muscle of humans with obesity and type 2 diabetes: reversal with weight reduction. Diabetes 2003;52:1935-42.

105. Houmard JA, Tanner CJ, Yu C, Cunningham PG, Pories WJ, MacDonald KG, Shulman GI. Effect of weight loss on insulin sensitivity and intramuscular long-chain fatty acyl-CoAs in morbidly obese subjects. Diabetes 2002;51:2959-63.

106. Greco AV, Mingrone G, Giancaterini A, Manco M, Morroni M, Cinti S, Granzotto M, Vettor R, Camastra S, Ferrannini E. Insulin resistance in morbid obesity: reversal with intramyocellular fat depletion. Diabetes 2002;51:144-51.

107. Hotamisligil GS, Shargill NS, Spiegelman BM. Adipose expression of tumor necrosis factoralpha: direct role in obesity-linked insulin resistance. Science 1993;259:87-91.

108. Kern PA, Saghizadeh M, Ong JM, Bosch RJ, Deem R, Simsolo RB. The expression of tumor necrosis factor in human adipose tissue. Regulation by obesity, weight loss, and relationship to lipoprotein lipase. J Clin Invest 1995;95:2111-9.

109. Hotamisligil GS, Arner P, Caro JF, Atkinson RL, Spiegelman BM. Increased adipose tissue expression of tumor necrosis factor-alpha in human obesity and insulin resistance. J Clin Invest 1995;95:2409-15.

110. Stephens JM, Lee J, Pilch PF. Tumor necrosis factor-alpha-induced insulin resistance in 3T3L1 adipocytes is accompanied by a loss of insulin receptor substrate-1 and GLUT4 expression without a loss of insulin receptor-mediated signal transduction. J Biol Chem 1997; 272:971-6.

111. Xu H, Hirosumi J, Uysal KT, Guler AD, Hotamisligil GS. Exclusive action of transmembrane TNF alpha in adipose tissue leads to reduced adipose mass and local but not systemic insulin resistance. Endocrinology 2002;143:1502-11.

112. Xu H, Uysal KT, Becherer JD, Arner P, Hotamisligil GS. Altered tumor necrosis factor-alpha (TNF-alpha) processing in adipocytes and increased expression of transmembrane TNFalpha in obesity. Diabetes 2002;51:1876-83.

113. Dandona P, Weinstock R, Thusu K, Abdel-Rahman E, Aljada A, Wadden T. Tumor necrosis factor-alpha in sera of obese patients: fall with weight loss. J Clin Endocrinol Metab 1998; 83:2907-10.

114. Spiegelman BM, Hotamisligil GS. Through thick and thin: wasting, obesity, and TNF alpha. Cell 1993;73:625-7.

115. Semb H, Peterson J, Tavernier J, Olivecrona T. Multiple effects of tumor necrosis factor on lipoprotein lipase in vivo. J Biol Chem 1987;262:8390-4.

116. Grunfeld C, Gulli R, Moser AH, Gavin LA, Feingold KR. Effect of tumor necrosis factor administration in vivo on lipoprotein lipase activity in various tissues of the rat. J Lipid Res 1989;30:579-85.

117. Ofei F, Hurel S, Newkirk J, Sopwith M, Taylor R. Effects of an engineered human anti-TNFalpha antibody (CDP571) on insulin sensitivity and glycemic control in patients with NIDDM. Diabetes 1996;45:881-5.

118. Mohamed-Ali V, Goodrick S, Rawesh A, Katz DR, Miles JM, Yudkin JS, Klein S, Coppack SW. Subcutaneous adipose tissue releases interleukin-6, but not tumor necrosis factor-alpha, in vivo. J Clin Endocrinol Metab 1997;82:4196-200.

119. Khaodhiar L, Ling PR, Blackburn GL, Bistrian BR. Serum levels of interleukin-6 and Creactive protein correlate with body mass index across the broad range of obesity. JPEN J Parenter Enteral Nutr 2004;28:410-5.

120. Senn JJ, Klover PJ, Nowak IA, Mooney RA. Interleukin-6 induces cellular insulin resistance in hepatocytes. Diabetes 2002;51:3391-9.

121. Rotter V, Nagaev I, Smith U. Interleukin-6 (IL-6) induces insulin resistance in 3T3-L1 adipocytes and is, like IL-8 and tumor necrosis factor-alpha, overexpressed in human fat cells from insulin-resistant subjects. J Biol Chem 2003;278:45777-84. 
122. Tsigos C, Papanicolaou DA, Kyrou I, Defensor R, Mitsiadis CS, Chrousos GP. Dosedependent effects of recombinant human interleukin-6 on glucose regulation. J Clin Endocrinol Metab 1997;82:4167-70.

123. Hu E, Liang P, Spiegelman BM. AdipoQ is a novel adipose-specific gene dysregulated in obesity. J Biol Chem 1996;271:10697-703.

124. Hotta K, Funahashi T, Arita Y, Takahashi M, Matsuda M, Okamoto Y, Iwahashi H, Kuriyama H, Ouchi N, Maeda K, Nishida M, Kihara S, Sakai N, Nakajima T, Hasegawa K, Muraguchi M, Ohmoto Y, Nakamura T, Yamashita S, Hanafusa T, Matsuzawa Y. Plasma concentrations of a novel, adipose-specific protein, adiponectin, in type 2 diabetic patients. Arterioscler Thromb Vasc Biol 2000;20:1595-9.

125. Yamauchi T, Kamon J, Minokoshi Y, Ito Y, Waki H, Uchida S, Yamashita S, Noda M, Kita S, Ueki K, Eto K, Akanuma Y, Froguel P, Foufelle F, Ferre P, Carling D, Kimura S, Nagai R, Kahn BB, Kadowaki T. Adiponectin stimulates glucose utilization and fatty-acid oxidation by activating AMP-activated protein kinase. Nat Med 2002;8:1288-95.

126. Tomas E, Tsao TS, Saha AK, Murrey HE, Zhang Cc C, Itani SI, Lodish HF, Ruderman NB. Enhanced muscle fat oxidation and glucose transport by ACRP30 globular domain: acetylCoA carboxylase inhibition and AMP-activated protein kinase activation. Proc Natl Acad Sci U S A 2002;99:16309-13.

127. Wu X, Motoshima H, Mahadev K, Stalker TJ, Scalia R, Goldstein BJ. Involvement of AMPactivated protein kinase in glucose uptake stimulated by the globular domain of adiponectin in primary rat adipocytes. Diabetes 2003;52:1355-63.

128. Masaki T, Chiba S, Tatsukawa H, Yasuda T, Noguchi H, Seike M, Yoshimatsu H. Adiponectin protects LPS-induced liver injury through modulation of TNF-alpha in KK-Ay obese mice. Hepatology 2004;40:177-84.

129. Wulster-Radcliffe MC, Ajuwon KM, Wang J, Christian JA, Spurlock ME. Adiponectin differentially regulates cytokines in porcine macrophages. Biochem Biophys Res Commun 2004;316:924-9.

130. Wang B, Jenkins JR, Trayhurn P. Expression and secretion of inflammation-related adipokines by human adipocytes differentiated in culture: integrated response to TNF-alpha. Am J Physiol Endocrinol Metab 2005;288:E731-40.

131. Steppan CM, Bailey ST, Bhat S, Brown EJ, Banerjee RR, Wright CM, Patel HR, Ahima RS, Lazar MA. The hormone resistin links obesity to diabetes. Nature 2001;409:307-12.

132. Nagaev I, Smith U. Insulin resistance and type 2 diabetes are not related to resistin expression in human fat cells or skeletal muscle. Biochem Biophys Res Commun 2001; 285:561-4.

133. Yannakoulia M, Yiannakouris N, Bluher S, Matalas AL, Klimis-Zacas D, Mantzoros CS. Body fat mass and macronutrient intake in relation to circulating soluble leptin receptor, free leptin index, adiponectin, and resistin concentrations in healthy humans. J Clin Endocrinol Metab 2003;88:1730-6.

134. Savage DB, Sewter CP, Klenk ES, Segal DG, Vidal-Puig A, Considine RV, O'Rahilly S. Resistin / Fizz3 expression in relation to obesity and peroxisome proliferator-activated receptor-gamma action in humans. Diabetes 2001;50:2199-202.

135. Silswal N, Singh AK, Aruna B, Mukhopadhyay S, Ghosh S, Ehtesham NZ. Human resistin stimulates the pro-inflammatory cytokines TNF-alpha and IL-12 in macrophages by NFkappaB-dependent pathway. Biochem Biophys Res Commun 2005;334:1092-101.

136. Kaser S, Kaser A, Sandhofer A, Ebenbichler CF, Tilg H, Patsch JR. Resistin messenger-RNA expression is increased by proinflammatory cytokines in vitro. Biochem Biophys Res Commun 2003;309:286-90.

137. Lu SC, Shieh WY, Chen CY, Hsu SC, Chen HL. Lipopolysaccharide increases resistin gene expression in vivo and in vitro. FEBS Lett 2002;530:158-62.

138. Kopp HP, Kopp CW, Festa A, Krzyzanowska K, Kriwanek S, Minar E, Roka R, Schernthaner G. Impact of weight loss on inflammatory proteins and their association with the insulin resistance syndrome in morbidly obese patients. Arterioscler Thromb Vasc Biol 2003; 23:1042-7. 
139. Kern PA, Ranganathan S, Li C, Wood L, Ranganathan G. Adipose tissue tumor necrosis factor and interleukin-6 expression in human obesity and insulin resistance. Am J Physiol Endocrinol Metab 2001;280:E745-51.

140. Milan G, Granzotto M, Scarda A, Calcagno A, Pagano C, Federspil G, Vettor R. Resistin and adiponectin expression in visceral fat of obese rats: effect of weight loss. Obes Res 2002; 10:1095-103.

141. Faraj M, Havel PJ, Phelis S, Blank D, Sniderman AD, Cianflone K. Plasma acylationstimulating protein, adiponectin, leptin, and ghrelin before and after weight loss induced by gastric bypass surgery in morbidly obese subjects. J Clin Endocrinol Metab 2003;88: 1594-602.

142. Weisberg SP, McCann D, Desai M, Rosenbaum M, Leibel RL, Ferrante AW, Jr. Obesity is associated with macrophage accumulation in adipose tissue. J Clin Invest 2003;112: 1796-808.

143. Xu H, Barnes GT, Yang Q, Tan G, Yang D, Chou CJ, Sole J, Nichols A, Ross JS, Tartaglia $\mathrm{LA}$, Chen $\mathrm{H}$. Chronic inflammation in fat plays a crucial role in the development of obesityrelated insulin resistance. J Clin Invest 2003;112:1821-30.

144. Arkan MC, Hevener AL, Greten FR, Maeda S, Li ZW, Long JM, Wynshaw-Boris A, Poli G, Olefsky J, Karin M. IKK-beta links inflammation to obesity-induced insulin resistance. Nat Med 2005;11:191-8.

145. Cancello R, Henegar C, Viguerie N, Taleb S, Poitou C, Rouault C, Coupaye M, Pelloux V, Hugol D, Bouillot JL, Bouloumie A, Barbatelli G, Cinti S, Svensson PA, Barsh GS, Zucker JD, Basdevant $A$, Langin $D$, Clement $K$. Reduction of macrophage infiltration and chemoattractant gene expression changes in white adipose tissue of morbidly obese subjects after surgeryinduced weight loss. Diabetes 2005;54:2277-86.

146. Di Gregorio GB, Yao-Borengasser A, Rasouli N, Varma V, Lu T, Miles LM, Ranganathan G, Peterson CA, McGehee RE, Kern PA. Expression of CD68 and Macrophage Chemoattractant Protein-1 Genes in Human Adipose and Muscle Tissues: Association With Cytokine Expression, Insulin Resistance, and Reduction by Pioglitazone. Diabetes 2005;54:2305-13.

147. O'Brien PE, Dixon JB, Laurie C, Skinner S, Proietto J, McNeil J, Strauss B, Marks S, Schachter L, Chapman L, Anderson M. Treatment of mild to moderate obesity with laparoscopic adjustable gastric banding or an intensive medical program: a randomized trial. Ann Intern Med 2006;144:625-33. 
46 


\section{Chapter 3}

Ghrelin, leptin and insulin levels after restrictive surgery, a 2 year follow-up study

Jeroen Nijhuis, Francois M.H. van Dielen, Wim A. Buurman, Jan Willem M. Greve Obes Surg. 2004;14:783-7 


\section{Abstract}

\section{Background}

Ghrelin is a recently discovered orexigenic gastric hormone, which production is induced by the lack of food in the stomach. In morbidly obese individuals, ghrelin levels are low compared to lean persons. During dieting plasma ghrelin levels increase, leading to an orexigenic signal which could explain the lack of success of dieting in morbidly obese patients. Morbid obesity is best treated with bariatric surgery of which gastric bypass surgery is reported to be more effective than restrictive surgery. A possible explanation could be the difference in plasma ghrelin levels after both techniques of bariatric surgery. In this study plasma ghrelin levels are investigated during a two year follow-up.

\section{Methods}

Seventeen morbid obese patients received restrictive surgery. Plasma ghrelin, leptin and insulin levels were evaluated preoperatively, one year and two years postoperatively.

Results

BMI decreased from $47.5 \pm 6.2 \mathrm{~kg} / \mathrm{m}^{2}$ to $33.2 \pm 5.8 \mathrm{~kg} / \mathrm{m}^{2}$ ( $\left.p<0.001\right)$. Plasma ghrelin levels were significantly increased one year $(p<0.05)$ and two years $(p<0.02)$ postoperatively. Fasting plasma leptin and insulin levels were significantly lower at two years after surgery $(p<0.001)$.

\section{Conclusion}

After restrictive surgery ghrelin levels increased, this in contrast to the reported fall in ghrelin levels after gastric bypass surgery. This difference in ghrelin levels between these operative techniques can be the key to understanding the superiority of gastric bypass in sustaining weight loss compared to restrictive surgery. 


\section{Introduction}

Via receptors present in the arcuate nucleus of the hypothalamus satiety hormones influence a feedback mechanism that controls energy intake. These receptors are situated on the catabolic proopiomelanocortin (POMC) and anabolic neuropeptide-Y/Agouti related protein (NPY/AgRP) neurons. The catabolic neurons are activated by leptin as well as insulin and suppressed in states of genetically defective leptin signaling. In response to leptin POMC is cleaved into melanocortins of which receptors are present in brain areas that regulated food intake and autonomic activity. The anabolic neurons are stimulated by ghrelin and suppressed by leptin and insulin. This explains the orexigenic effect of ghrelin and the satiety inducing property of leptin and insulin ${ }^{1}$. These and other feedback mechanisms balance food intake and energy expenditure.

Ghrelin is a 28 amino acids peptide with strong Growth Hormone (GH) releasing activity and is mainly produced by the X/A like cells of the oxyntic glands in the fundus of the stomach which are nowadays referred to as ghrelin cells or $\mathrm{Gr}$ cells. Production of ghrelin is attenuated by the presence and stimulated by the absence of food in the stomach ${ }^{2,3}$. In rats ghrelin acts orexigenic: administration of ghrelin results in increased food intake ${ }^{4}$. Other actions are inhibition of insulin producing $\beta$ - and somatostatin producing D-cells in the pancreas ${ }^{5}$.

In the morbidly obese individual satiety regulating mechanisms are disturbed, leptin and insulin levels are high and ghrelin levels are low ${ }^{6,7}$. Non invasive methods used to treat morbid obesity as weight reduction achieved by exercise, medical therapy and dieting, usually does not result in long term weight loss ${ }^{8}$. This is thought to be caused by increasing ghrelin and decreasing leptin levels resulting in strong orexigenic signals after weight $\operatorname{loss}^{9}$. Bariatric surgery is far more effective in maintaining weight loss with loss of excess weight as high as $50-70 \%{ }^{10}$. Compared to restrictive surgery patients treated with gastric bypass surgery are less hungry, eat fewer meals and reduce the intake of high calorie food voluntarily ${ }^{11}$. It is suggested that this is not due to the gastric restriction alone but also to a decline in ghrelin levels postoperatively ${ }^{9,12}$. After gastric bypass surgery the main producer of ghrelin, the stomach, receives no food. Paradoxically, in contrast to the high plasma ghrelin levels expected in these patients, low ghrelin levels are found, maybe as a result of exhaustion of the $\mathrm{Gr}$ cells. In patients treated with restrictive bariatric surgery, the stomach still receives food, although to a lesser extent. We therefore hypothesized that in the long term restrictive bariatric surgery results in a rise in ghrelin levels, giving the patient an orexigenic signal. 


\section{Patients and methods}

In total 17 subjects who were admitted to the Surgical Department of the University Hospital Maastricht to undergo an operation for morbid obesity, were included in the study. The group contained 14 female and 3 male individuals aged $44 \pm 7$ years. These patients underwent a primary operation for morbid obesity (vertical banded gastroplasty (VBG, $n=7$ ) or LapBand ${ }^{\circledR}(n=10)$ ). All subjects were otherwise healthy according to history, clinical examination and routine laboratory findings. Blood samples were collected after at least eight hours fasting using evacuated blood collection tubes containing EDTA at the day of admission to the hospital, one day before surgery. The blood samples were immediately put on melting ice and plasma was prepared by centrifugation at $1,400 \mathrm{~g}$ for $10 \mathrm{~min}$ at $4^{\circ} \mathrm{C}$. The supernatants were centrifuged at $2,700 \mathrm{~g}$ for $10 \mathrm{~min}$ at $4^{\circ} \mathrm{C}$ and stored in aliquots at $-80^{\circ} \mathrm{C}$. All participants gave written informed consent. The study was approved by the local ethical committee of the Academic Hospital Maastricht.

\section{Vertical banded gastroplasty (VBG)}

The procedure was performed as described by Mason ${ }^{13}$. In short a small stomach pouch of approximately $15-20 \mathrm{ml}$ was created with a 4-row linear stapler (TA-90B) precisely to the angle of His and a Dacron band of $5.0 \mathrm{~cm}$ in circumference, placed through the window formed by a circular stapler (Premium Plus CEEA $31 \mathrm{~mm}$, United States Surgical Corp., Norwalk, CT) leaving a small opening for food to pass ${ }^{14}$.

\section{Laparoscopic gastric banding (LapBand ${ }^{\circledR}$ )}

The LapBand ${ }^{\circledR}$ (BioEnterics, Carpinteria, CA) is made of soft silicone and equipped with an elastic balloon. For definitive positioning of the band a $15 \mathrm{ml}$ calibration balloon was pulled up to the gastroesophageal junction. Under this balloon the band was closed and with three or four sutures the ventral aspect of the greater curvature of the stomach was fixed to the pouch to ensure a stable anterior position of the band. Six weeks postoperatively the LapBand ${ }^{\circledR}$ was insufflated when weight loss was insufficient (less than 6 kilogram). Thereafter the balloon was gradually inflated based on weight loss and food restriction (max. 4,5cc) $)^{15,16}$

\section{Measurements}

BSA was purchased from Sigma (St. Louis, MO). Bovine calf serum purchased from HyClone Laboratories, Inc. (Logan, UT) was heated at $56^{\circ} \mathrm{C}$ for 30 min before storage at $4^{\circ} \mathrm{C}$. 
Plasma concentrations of ghrelin and leptin were measured using sandwich ELISAs. For detection of plasma leptin levels, plates (Nunc maxisorb, Nunc, Roskilde, Denmark) were coated overnight at $4^{\circ} \mathrm{C}$ with the murine antihuman leptin mAb 4G1. After blocking with $1 \%$ BSA in PBS, diluted plasma samples and a dilution series of recombinant human leptin, the standard curve, were added to the plate. Recombinant human leptin was purchased from R\&D systems (Minneapolis, MN). Bound leptin was detected by incubation with antihuman leptin $\mathrm{mAb} 4 \mathrm{~F} 8$, followed by peroxidase-conjugated goat antimurine IgA (Caltag Laboratories, Burlingame, CA). 3,3',5,5'-tetramethylbenzidine (Kirkegaard \& Perry Laboratories, Gaithersburg, MD) was used as substrate for peroxidase, and color intensity was determined by measuring absorbency at $450 \mathrm{~nm}$. The detection limit of this leptin assay is $0.04 \mathrm{ng} / \mathrm{ml}$. Both $\mathrm{mAb}, 4 \mathrm{G} 1$ and 4F8, were kindly provided by Dr. R. Devos (Hoffmann La-Roche, Welwyn Garden City, UK).

Ghrelin concentrations were measured using a competitive ELISA kit from Phoenix peptides (Phoenix pharmaceuticals, Belmont, CA).

Plasma insulin levels were routinely assessed by the clinical chemistry laboratory of the academic hospital by means of the AutoDELPHIA automatic immunoassay system (Wallac, Turku, Finland). The plasma insulin assay had a detection limit of $3 \mathrm{pmol} / \mathrm{l}$.

All plasma samples were analyzed in the same run. When plasma concentrations exceeded the upper detection limit of the assay, samples were additionally diluted and analyzed in a separate run with an overlap to correct for inter-assay variation. The intra- and inter-assay coefficients of variance of both assays were $<10 \%$.

Plasma levels of ghrelin, leptin and insulin were expressed in mean \pm SEM. Pre and post operative results were compared using the paired student's t-test, a $p$ value less than 0.05 was considered as statistical significant.

\section{Results}

As expected restrictive bariatric surgery resulted in a significant loss of excess weight (EWL) of $61.7 \pm 24.6 \%$ at the end of the two year follow-up. This is illustrated by a decrease of BMl from $47.5 \pm 6.2 \mathrm{~kg} / \mathrm{m}^{2}$ to $33.2 \pm 5.8 \mathrm{~kg} / \mathrm{m}^{2}$ $(p<0.01)$. \%EWL was not influenced by the restrictive bariatric surgical techniques used. In accordance with our hypothesis mean ghrelin levels increased after bariatric surgery from $742 \pm 246 \mathrm{pg} / \mathrm{ml}$ preoperative to $904 \pm 127 \mathrm{pg} / \mathrm{ml}$ two years postoperative $(p<0.05)$ (Figure $3.1 \mathrm{~A})$. As in $\% E W L$ there was no correlation between the surgical technique used and difference in pre- and postoperative ghrelin levels. An increase of more than $40 \%$ in circulating plasma ghrelin levels was seen in nine out of seventeen patients, 
whereas four patients showed minimal increased postoperative ghrelin levels, ranging from 1 to $26 \%$. In four patients ghrelin levels decreased with $6,11,13$ and $38 \%$ respectively.

Ghrelin has an orexigenic effect. Hypothetically a rise in ghrelin levels would lead to an increase in food uptake. Therefore \%EWL was correlated with the difference in pre- and postoperative ghrelin levels. However, no correlation was found.

Other factors that influence satiety are leptin and insulin. In line with the observed fall in BMI fasting plasma leptin levels were reduced from $97 \pm 37 \mathrm{ng} / \mathrm{ml}$ to $48 \pm 44 \mathrm{ng} / \mathrm{ml}(p<0.001)$ during the two year follow-up period (Figure 3.1B). Another important hormone with similar effects as leptin on satiety is insulin. After two years, fasting plasma insulin levels decreased from $26 \pm 12 \mathrm{IU} / \mathrm{ml}$ to $6 \pm 6 \mathrm{IU} / \mathrm{ml}(p<0.001$ ) (Figure 3.1C). Although in literature fasting insulin levels are negatively correlated with fasting ghrelin levels ${ }^{17}$ in this study no correlation was found between preoperative insulin and ghrelin levels. Moreover after surgery differences in pre- and postoperative insulin and ghrelin levels did not correlate.

A

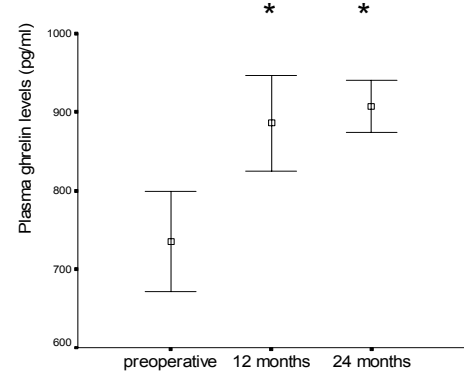

C
B

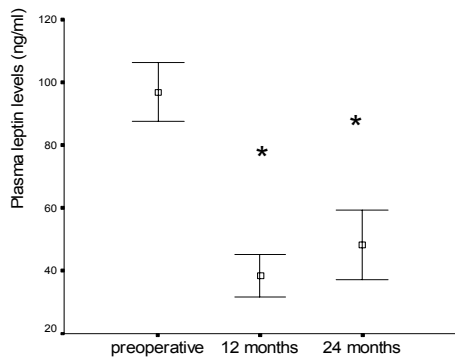

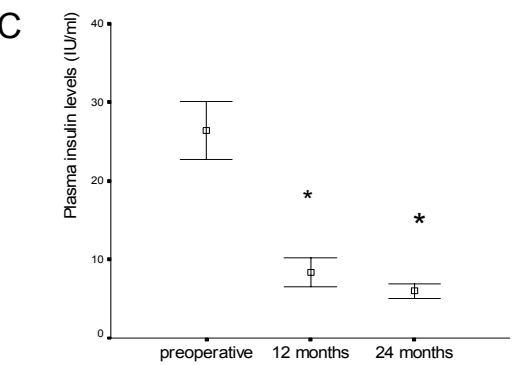

Figure 3.1. Restrictive surgery leads to a strong increase in circulating ghrelin levels (a) and a decrease in plasma leptin (b) and insulin (c) levels. Values are shown as mean \pm SEM. ${ }^{*} p<0.05$ compared to preoperative values. 


\section{Discussion}

As expected after restrictive bariatric surgery a decrease in BMI, excess weight, leptin and insulin was achieved two years postoperative. Ghrelin kinetics did not differ between adjustable gastric banding and VBG. Thus both techniques have similar effects on the amount of food ingested resulting in comparable stimulation of $\mathrm{Gr}$ cells. This study shows that circulating ghrelin levels rise after restrictive bariatric surgery indicating an increased ghrelin production by the stomach. In contrast others reported that ghrelin levels in patients subjected to restrictive surgery did not change after one year ${ }^{18}$. Another study investigating postoperative ghrelin levels revealed that one year after surgery ghrelin levels were higher in patients who received restrictive surgery than after gastric bypass surgery ${ }^{19}$.

When different bariatric surgical techniques are evaluated, gastric bypass surgery compared to restrictive bariatric techniques tends to be more effective $^{10,11,20}$. This is in line with the paradoxical finding that patients after gastric bypass, despite low food intake, have extremely low ghrelin levels ${ }^{9,12,21,22}$. The mechanism for the disparity in behavior of ghrelin after the different surgical techniques is not yet elucidated. Recently Cummings et al. postulated that after gastric bypass surgery, as a consequence of the lack of food in the excluded stomach, a continuous stimulation of the ghrelin producing $\mathrm{Gr}$ cells occurs. This leads to an exhaustion of the Gr cells, resulting in very low circulating ghrelin levels, a hypothesis called the override inhibition theory ${ }^{9}$. These low levels of ghrelin after gastric bypass surgery could result in increased satiety. As shown here ghrelin levels rise after restrictive bariatric surgery. A possible explanation could be that in restrictive bariatric surgery passage of food through the stomach, although to a lesser extent, is still taking place. $\mathrm{Gr}$ cells are not exhausted and react with an increased production of ghrelin which could result in increased appetite in patients after restrictive surgery.

Ghrelin however is not the only satiety regulating hormone. Leptin and insulin reduce satiety, but in morbidly obese patients signaling functions of both hormones are considered to be defective ${ }^{1}$. Gastric bypass surgery leads to reduced circulating leptin and insulin concentrations ${ }^{22}$. This study, as well as other studies ${ }^{19,23}$, shows that also after restrictive surgery circulating leptin and insulin levels strongly decreased. Taken together the difference in effect between gastric bypass and restrictive surgery is only reflected by the difference in ghrelin levels, emphasizing the potential role of ghrelin. However one should bear in mind that no correlation was found between \%EWL and the difference in pre- and postoperative ghrelin levels, indicating that postoperative regulation of food intake is under the influence of multiple factors which still need investigating. 
In conclusion, in contrast to gastric bypass surgery, restrictive surgery leads to increased ghrelin levels which can be responsible for the superior effect of gastric bypass surgery. These results indicate that attention should be paid to the association between plasma ghrelin levels and efficacy of bariatric surgery. Surgical techniques bypassing the stomach as well as adding ghrelin lowering medication after restrictive surgery can increase satiety and thus contribute to a more successful treatment to conquer morbid obesity. 


\section{References}

1. Cummings DE, Schwartz MW. Genetics and pathophysiology of human obesity. Annu Rev Med 2003;54:453-71.

2. Kojima M, Hosoda H, Date Y, Nakazato M, Matsuo H, Kangawa K. Ghrelin is a growthhormone-releasing acylated peptide from stomach. Nature 1999;402:656-60.

3. Date Y, Kojima M, Hosoda H, Sawaguchi A, Mondal MS, Suganuma T, Matsukura S, Kangawa K, Nakazato M. Ghrelin, a novel growth hormone-releasing acylated peptide, is synthesized in a distinct endocrine cell type in the gastrointestinal tracts of rats and humans. Endocrinology 2000;141:4255-61.

4. Tschop M, Smiley DL, Heiman ML. Ghrelin induces adiposity in rodents. Nature 2000; 407:908-13.

5. Egido EM, Rodriguez-Gallardo J, Silvestre RA, Marco J. Inhibitory effect of ghrelin on insulin and pancreatic somatostatin secretion. Eur J Endocrinol 2002;146:241-4.

6. Tschop M, Weyer C, Tataranni PA, Devanarayan V, Ravussin E, Heiman ML. Circulating ghrelin levels are decreased in human obesity. Diabetes 2001;50:707-9.

7. van Dielen FM, van 't Veer C, Buurman WA, Greve JW. Leptin and soluble leptin receptor levels in obese and weight-losing individuals. J Clin Endocrinol Metab 2002;87:1708-16.

8. Jamdar SC, Soo E, Cao WF. Effect of glutathione deficiency on the adipocyte sn-glycerol-3phosphate acyltransferase. Biochim Biophys Acta 1998;1393:41-8.

9. Cummings DE, Weigle DS, Frayo RS, Breen PA, Ma MK, Dellinger EP, Purnell JQ. Plasma ghrelin levels after diet-induced weight loss or gastric bypass surgery. N Engl J Med 2002; 346:1623-30.

10. Colquitt J, Clegg A, Sidhu M, Royle P. Surgery for morbid obesity. Cochrane Database Syst Rev 2003:CD003641.

11. Kenler HA, Brolin RE, Cody RP. Changes in eating behavior after horizontal gastroplasty and Roux-en-Y gastric bypass. Am J Clin Nutr 1990;52:87-92.

12. Faraj M, Havel PJ, Phelis S, Blank D, Sniderman AD, Cianflone K. Plasma acylationstimulating protein, adiponectin, leptin, and ghrelin before and after weight loss induced by gastric bypass surgery in morbidly obese subjects. J Clin Endocrinol Metab 2003;88: 1594-602.

13. Mason EE. Vertical banded gastroplasty for obesity. Arch Surg 1982;117:701-6.

14. Sagar PM. Surgical treatment of morbid obesity. Br J Surg 1995;82:732-9.

15. Cadiere GB, Bruyns J, Himpens J, Favretti F. Laparoscopic gastroplasty for morbid obesity. Br J Surg 1994;81:1524.

16. Belachew M, Legrand MJ, Defechereux TH, Burtheret MP, Jacquet N. Laparoscopic adjustable silicone gastric banding in the treatment of morbid obesity. A preliminary report. Surg Endosc 1994;8:1354-6.

17. Purnell JQ, Weigle DS, Breen $P$, Cummings DE. Ghrelin levels correlate with insulin levels, insulin resistance, and high-density lipoprotein cholesterol, but not with gender, menopausal status, or cortisol levels in humans. J Clin Endocrinol Metab 2003;88:5747-52.

18. Hanusch-Enserer U, Brabant G, Roden M. Ghrelin concentrations in morbidly obese patients after adjustable gastric banding. N Engl J Med 2003;348:2159-60.

19. Leonetti F, Silecchia G, lacobellis G, Ribaudo MC, Zappaterreno A, Tiberti C, lannucci CV, Perrotta N, Bacci V, Basso MS, Basso N, Di Mario U. Different plasma ghrelin levels after laparoscopic gastric bypass and adjustable gastric banding in morbid obese subjects. J Clin Endocrinol Metab 2003;88:4227-31.

20. Hell E, Miller KA, Moorehead MK, Norman S. Evaluation of health status and quality of life after bariatric surgery: comparison of standard Roux-en-Y gastric bypass, vertical banded gastroplasty and laparoscopic adjustable silicone gastric banding. Obes Surg 2000; 10:214-9.

21. Geloneze B, Tambascia MA, Pilla VF, Geloneze SR, Repetto EM, Pareja JC. Ghrelin: a gutbrain hormone: effect of gastric bypass surgery. Obes Surg 2003;13:17-22. 
22. Holdstock C, Engstrom BE, Ohrvall M, Lind L, Sundbom M, Karlsson FA. Ghrelin and adipose tissue regulatory peptides: effect of gastric bypass surgery in obese humans. J Clin Endocrinol Metab 2003;88:3177-83.

23. van Dielen FM, van't Veer C, Schols AM, Soeters PB, Buurman WA, Greve JW. Increased leptin concentrations correlate with increased concentrations of inflammatory markers in morbidly obese individuals. Int J Obes Relat Metab Disord 2001;25:1759-66. 


\section{Chapter 4}

Leptin in morbid obese patients, no role for treatment of morbid obesity but important in the post operative immune response

Jeroen Nijhuis, Francois M.H. van Dielen, Wim A. Buurman, Jan Willem M. Greve Obes Surg. 2004;14:476-8 


\section{Abstract}

Leptin protects the organism for an energy deficit and can no longer be seen as a hormone which could be used therapeutically to prevent an energy surplus. However leptin may still have an impact in clinical medicine. Leptin was shown to have several important functions. The pleiotropic properties of leptin include a regulatory function in the immune system. Reviewing the effects of leptin on different parts of the immune system learns that the immune system is deregulated in an environment low in leptin. A strong reduction in leptin levels occurs in situations of starvation as seen after bariatric surgery. We postulate the hypothesis that the starvation induced postoperative decrease of leptin is causative to the more serious course of complications observed after bariatric surgery. 


\section{Introduction}

Approximately 30 years ago two genes believed to play a role in the development of obesity were discovered. They were called the ob and $\mathrm{db}$ genes. Mice lacking either the ob or the $\mathrm{db}$ gene (ob/ob and $\mathrm{db} / \mathrm{db}$ mice), develop severe obesity ${ }^{1}$. By means of parabiotic experiments it became clear that $\mathrm{db} / \mathrm{db}$ mice synthesize the molecule that ob/ob mice lacked, whereas $\mathrm{db} / \mathrm{db}$ mice are unable to respond to this molecule. It was hypothesized that the molecule coded for by the ob gene is a satiety factor which acts on a receptor encoded by the $\mathrm{db}$ gene. It lasted till the mid nineties until this molecule was identified. Friedman and co workers cloned the ob gene that encoded for a $16 \mathrm{kDa}$ protein named leptin (Greek: leptos $=$ thin) ${ }^{2}$. Treatment of ob/ob mice with leptin reduced body weight and increased activity. Leptin appeared to be mainly produced by adipocytes which explains the strong correlation between circulating leptin levels and $\mathrm{BMI}^{3}$.

The receptor for leptin was discovered shortly after the discovery of the ligand. The leptin receptor is a single membrane-spanning receptor related with the gp130 signal-transducing component of the IL-6 receptor ${ }^{4}$. In total six isoforms are currently described, obRa, Rb, Rc, Rd, Re and Rf. The obRe is a soluble receptor which is though to have a regulating function by controlling plasma leptin levels ${ }^{3,5}$. Ra-Rd and Rf are membrane bound receptors with similar extracellular and transmembrane domains. Only one isoform, the obRb, which has a long intracellular domain (306 amino acids), is considered to be the principal signaling molecule. However, there is suggestive evidence that short forms also have a signaling function ${ }^{6}$.

It is hypothesized that leptin via leptin receptors present in the arcuate nucleus of the hypothalamus can enhance the negative feedback mechanism which results in a decrease of energy intake. These receptors are situated on the catabolic proopiomelanocortin (POMC) and anabolic neuropeptide-Y/Agouti related protein (NPY/AgRP) neurons ${ }^{7}$. POMC is cleaved into melanocortins which receptors are present in brain areas that regulate food intake and autonomic activity. The catabolic neurons are activated by leptin and suppressed in states of genetically defective leptin signaling. The anabolic neurons are suppressed by leptin and activated in states of genetically defective leptin signaling ${ }^{8}$ (illustrated in Figure 4.1). These data led to the general acceptation of the hypothesis that leptin acts as satiety factor.

Leptin treatment of extremely obese and hyperphagic leptin deficient mice resulted in more active behavior, less food intake as well as weight loss in these animals. However, the crucial difference between the experimental leptin deficient mouse and the obese patient is the absence of circulating leptin in leptin deficient mice versus high levels of leptin in obese individuals. In parallel with insulin resistance it was hypothesized that morbid obese patients are 
leptin resistant, with the $\mathrm{db} / \mathrm{db}$ mice (lacking the long form of the leptin receptor) as an ultimate model. Unfortunately, in contrast to diabetes, in which insulin resistance can be treated by administration of excess insulin, administration of excess leptin does not result in substantial weight loss. Some articles describe weight stabilization or weight loss after leptin treatment in humans ${ }^{9}$. This effect however is minor and immediately reversed after cessation of the treatment. Currently the role of leptin is therefore no longer sought in preventing an energy surplus but in protecting the organism in situations of an energy deficit as seen in starvation ${ }^{10}$.

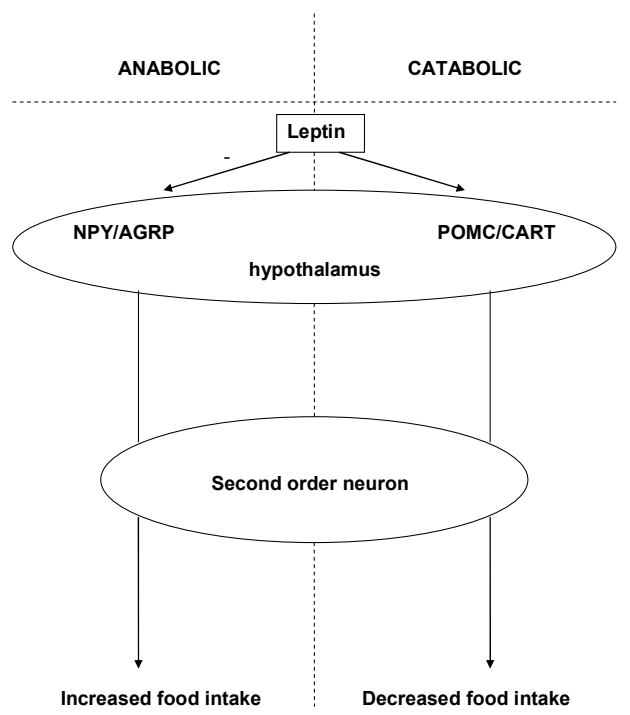

Figure 4.2 Regulation of satiety by leptin

Recently an additional role for leptin was postulated. Several authors described the resemblance of the immunological status of leptin deficient mice with that of starved wild type mice. The immunological abnormalities include impaired T-cell responses and thymic atrophy, which render these mice more susceptible to infections ${ }^{11}$. A parallel situation is seen in leptin deficient humans and patients suffering from anorexia nervosa ${ }^{12}$. Leptin deficient subjects are hyperphagic and therefore obese, whereas the low leptin levels seen in anorexia nervosa are due to fasting. Both subjects however have absent (leptin deficiency) or very low (starved) leptin levels, therefore a role for leptin and not solely the obesity status in the immune system is hypothesized. These findings shift our attention from the metabolic to the immunologic aspects of leptin. Especially in conditions where leptin levels are low or decreasing fast. 
Leptin is of interest for bariatric surgery because of its property to act as an acute phase protein. The molecular structure of leptin resembles that of the Interleukin-6 (IL-6) cytokine family ${ }^{13}$. Leptin however can by itself not induce an acute phase response like IL- $6^{14}$. In animal models of acute inflammation as well as in septic patients and postoperative patients, leptin levels are increased $^{15-19}$. The rise in leptin levels can be a direct result of increased levels of lipopolysaccharide (LPS), Tumor Necrosis Factor alpha (TNF- $\alpha$ ) and IL-1, since both LPS and these cytokines induce leptin production ${ }^{20-25}$.

Which implication has the hypothesis that leptin functions as an acute phase protein for bariatric surgery? Directly after bariatric surgery, leptin appears to act as a positive acute phase protein. However, within 48 hours the leptin levels decreased ${ }^{26-28}$. Suppression of the immune system as seen in patients suffering from anorexia nervosa (low leptin) and in leptin deficient mice (absent leptin) raises the question whether the strong decrease in leptin levels postoperatively could play a role in the pathogenesis of postoperative complications observed after bariatric surgery ${ }^{29}$.

\section{Subjects and methods}

\section{Subjects and samples}

All participants gave written informed consent. The study was approved by the local ethical committee of the Academic Hospital Maastricht.

A total of fifteen subjects admitted to the Surgical Department of the University Hospital Maastricht to undergo an operation for morbid obesity, were included in the study. The group comprised fourteen females and one male aged $37 \pm 6$ years with a mean BMI of $49.7 \pm 4.3 \mathrm{~kg} / \mathrm{m}^{2}$. These patients underwent a primary operation for morbid obesity (Vertical banded gastroplasty (VBG, $n=11$ ) or laparoscopic gastric banding using Lap-Band $(n=4))$. All subjects were otherwise healthy according to history, clinical examination and routine laboratory findings.

Blood samples were collected after at least eight hours fasting using evacuated blood collection tubes containing EDTA one day before surgery, and 24, 48 and 72 hours after surgery and processed as previously described ${ }^{30}$.

\section{Leptin immunoassay}

Plasma concentrations of leptin was determined using sandwich ELISA. For detection of plasma leptin levels plates (Nunc maxisorb, Nunc, Roskilde, Denmark) were coated overnight at four degrees Celcius with the murine antihuman leptin mAb 4G1. After blocking with 1\% BSA (Sigma, St. Louis, MO) 
in PBS, diluted plasma samples and a dilution series of recombinant human leptin, the standard curve, were added to the plate. Recombinant human leptin was purchased from R\&D systems (Minneapolis, MN). Bound leptin was detected by incubation with antihuman leptin mAb 4F8 followed by peroxidaseconjugated goat antimurine IgA (Caltag Laboratories, Burlingame, CA). 3,3',5,5'-tetramethylbenzidine (Kirkegaard \& Perry Laboratories, Gaithersburg, $M D$ ) was used as substrate for peroxidase, and color intensity was determined by measuring absorbency at $450 \mathrm{~nm}$. The detection limit of this leptin assay is $0.04 \mathrm{ng} / \mathrm{ml}$. Both mAb, 4G1 and 4F8, were kindly provided by Dr. R. Devos (Hoffmann La-Roche, Welwyn Garden City, UK).

All plasma samples were analyzed in the same run. The intra- and inter-assay coefficients of variance of the various assays were $<10 \%$.

\section{Statistical analysis}

All data are expressed as median with interquartile range. Due to the nonparametrically distributed data, preoperative and postoperative results were compared using repeated measurements ANOVA (analysis of variance). A pvalue less than 0.05 was considered statistically significant.

\section{Results}

Leptin levels where not increased at 24 hours after surgery. However, similar to previous studies a decrease in leptin was observed after three days in fourteen of the fifteen patients studied. Of these patients about $75 \%$ showed a decrease of more than $45 \%$. During the first three days, postoperative median leptin levels decrease from $77.8 \mathrm{ng} / \mathrm{ml}\left(1^{\text {st }}\right.$ quartile: $60.3,3^{\text {rd }}$ quartile: 105.0$)$ to $38.0 \mathrm{ng} / \mathrm{ml}\left(1^{\text {st }}\right.$ quartile: $25.1,3^{\text {rd }}$ quartile: 61.0$)(p<0.001)$ (Figure 4.2$)$. Normally plasma levels of $38 \mathrm{ng} / \mathrm{ml}$ correlate with a BMI of about $30^{3}$. BMI did not change during the first three days, indicating that in the postoperative period leptin is not simply a reflection of fat mass or BMI. 


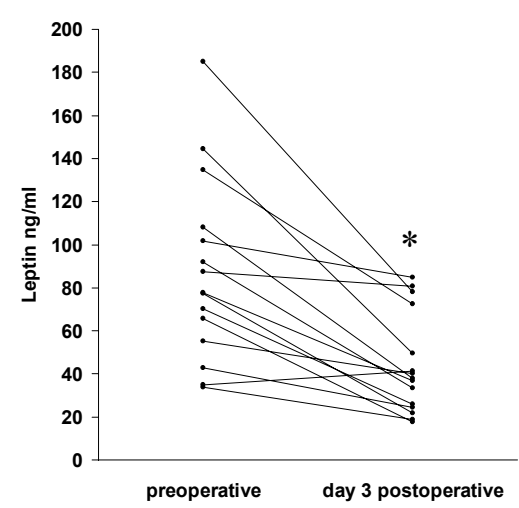

Figure 4.2. Leptin levels decrease rapidly after bariatric surgery. Leptin levels preoperative and 72 hours postoperative of 15 morbid obese patients are given. *: $p<0.05$.

\section{Discussion}

Inflammation and infection are part of the pathogenesis of most of the early postoperative complications like pulmonary emboli, wound infection and sepsis, suggesting that the immune system plays an essential role in the pathogenesis. Particularly in the context of postoperative septic complications, which have a more severe course in morbid obese patients compared to lean patients. A statement however, which is based on general surgical opinion and not on published studies. During the first days after bariatric surgery it is important to focus on the pleiotropic properties of leptin. Starvation leads to a rapid decrease of circulating leptin levels. This decrease in leptin, reflecting the metabolic state of the individual, results in a relative leptin deficiency which may cause a deregulation of the immune system.

We postulate that during the first two days postoperative, surgical stress and starvation have opposing effects on circulating leptin levels. Starvation leads to a decrease in leptin whereas surgical stress increases leptin ${ }^{31,32}$. After the second day of bariatric surgery, starvation dominates; the result is that the individual has to cope with a sharp decrease in leptin levels.

Leptin deficiency makes an organism more susceptible to septic shock, induced by LPS $^{33}$. Administration of leptin to deficient mice reversed this vulnerability. Another study reported that leptin deficient mice are also vulnerable to LPS induced hepatotoxicity ${ }^{34}$. Interestingly, the LPS induced mortality of mice lacking the leptin receptor ( $\mathrm{db} / \mathrm{db}$ mice) resembled that of wild type mice, despite the fact that they are as obese and diabetic as leptin deficient mice ${ }^{35}$. An explanation for this paradoxical finding may be the 
presence of soluble leptin receptors in $\mathrm{db} / \mathrm{db}$ mice. These receptors, when bound to leptin, can translocate to the membrane and trigger intracellular cascades, while signaling in the central nervous system is absent ${ }^{6,36}$.

Leptin deficient, $\mathrm{db} / \mathrm{db}$ as well as wild type mice pretreated with leptin antagonists were more susceptible to the lethal toxicity of TNF- $\alpha$ compared to wild type mice. Furthermore, leptin deficient mice treated with exogenous leptin were protected against the lethal toxicity of TNF- $\alpha$. Thus in a leptin deficient environment TNF- $\alpha$ is more toxic than in a normal environment, which can be reversed by administrating leptin ${ }^{37}$.

Taken together this leads to a hypothesis that leptin protects the organism against the auto-aggressive effects of the immune system. During sepsis increased leptin levels induced by mediators like TNF- $\alpha$, IL-1 and/or LPS ${ }^{20-24}$, may be involved in counteraction of the harmful effects of pro-inflammatory cytokines. The finding that higher leptin levels in septic patients are significantly related to a higher chance of survival supports this hypothesis ${ }^{17}$. The regulatory role of leptin on the cellular level is illustrated by the finding that macrophages, polymorphnuclear cells (PMN's) and natural killer cells (NK-cells) express the short (ob-Ra) and long (ob-Ra) leptin receptor ${ }^{38-43}$. Phagocytotic activity of macrophages from lean non-diabetic mice is enhanced by adding leptin ${ }^{39}$. In line with this observation is the reduced phagocytic function of macrophages in animals with low or absent leptin levels ${ }^{44,45}$. This also accounts for situations were leptin signaling is impaired by absence of leptin receptors ${ }^{44}$. Administration of leptin abrogated this difference in ob/ob mice (lacking leptin) but not in $\mathrm{db} / \mathrm{db}$ mice (lacking the ob-Rb receptor). This makes it plausible that leptin acts directly via ob-Rb on macrophages to improve phagocytic functioning. Compared to wild type mice leptin deficient mice are more vulnerable to LPS induced hepatotoxicity ${ }^{34}$. A further role for leptin in NK cell physiology was recently established. Tian et al. observed that in $\mathrm{db} / \mathrm{db}$ mice the total number of NK-cells in spleen, liver, peripheral blood and lung was reduced, while the NK-cells expression of CD69 (activation marker) was lower both at baseline and after poly I:C stimulation and activation. Leptin treatment of NK-cells of wild type mice increased both their basal and IL-15 or poly I:C stimulated lysis of splenocytes. A phenomenon absent in spleens of $\mathrm{db} / \mathrm{db}$ mice $^{46}$. Leptin also enhanced expression of indicators of NK-cell activity, such as IL-2 and perforin genes transcription of human NK-cells, further emphasizing the importance of leptin for normal NK-cell functioning ${ }^{43}$. Leptin enhances the oxidative and chemotactic response of human neutrophils in vitro $^{42,47}$. Hypothetically leptin deficiency leads to less production of reactive oxygen species (ROS) by PMNs. As a consequence an organism deficient in leptin will be less capable of killing bacteria by ROS production and subsequently more susceptible to invading micro-organisms. 
Pretreatment of murine macrophages with leptin results in higher LPS induced IL-6, IL-12 and TNF- $\alpha$ production, while leptin on itself was not capable to induce cytokine release ${ }^{44}$. In contrast, stimulation of human monocytes with leptin in absence of LPS led to increased TNF- $\alpha$ and IL-6 production $^{41,48}$. In line with these observations macrophages obtained from calorie restricted mice, which have low circulating leptin levels, released less IL-6 and IL-12 after LPS stimulation $^{49,50}$. Leptin deficient mice respond to LPS stimulation with lower plasma TNF- $\alpha$ and IL-6 levels, compared to wild type mice ${ }^{44,49}$. In the same experiments, plasma levels of the anti-inflammatory cytokines IL-10 and IL-1Ra were also lower in leptin deficient mice. The latter was confirmed by stimulation of murine monocytes (RAW cell line) with both LPS and leptin, resulting in an increased IL-1Ra production ${ }^{33,38}$. These results lead to the question why leptin deficient mice, which produce less TNF- $\alpha$, are not protected from LPS induced mortality. Normal mice are thought to die from LPS by large amounts circulating of proinflammatory mediators like TNF- $\alpha$. A possible explanation for this paradoxical finding can be that the decreased IL-1Ra and IL-10 release renders the leptin deficient mouse more vulnerable even to lower doses of TNF- $\alpha$. This is supported by the finding that leptin deficient or $\mathrm{db} / \mathrm{db}$ mice are more vulnerable to exogenous TNF- $\alpha$ administration ${ }^{37}$. Other groups have found contrasting data, showing increased TNF- $\alpha$ levels at baseline in leptin deficient an $\mathrm{db} / \mathrm{db}$ mice as well as after stimulation by LPS or Cecal Ligation and Puncture (CLP) in starved wild type mice ${ }^{49,51,52}$. At this stage there is no explanation for these contrasting results. However, in line with the experiments discussed in this paragraph, also these mice were more susceptible to LPS or CLP induced septic shock.

Not only the innate immunity responsible for the acute phase reaction but also the aquired immunity is affected by leptin. Lymphocytes express the functional leptin receptor, which indicates that leptin can have an effect on these cells ${ }^{53,54}$. A deficient T-cell function is seen in leptin deficient mice, which is corrected after leptin administration. This T-cell dysfunction is illustrated by a reduced delayed type hypersensitivity, thymic atrophy and a lower number of circulating lymphocytes ${ }^{55-57}$. Similar defects are reported in humans who lack the ob gene $^{12}$. Farooqi et al. showed that leptin deficiency leads to a complete suppression of the Th1 immune response and to a lesser extent suppression of the Th2 response ${ }^{58}$. In conditions in which leptin levels are low but not absent, like in starvation, plasma levels of IL-4 are increased, indicating a dominance of the Th2 immune response ${ }^{59,60}$. This was confirmed in vitro in wild type murine T-lymphocytes harvested after starvation, which produce more IL-4 and less IFN- ${ }^{60}$. Currently no in vivo data exist on the effect of high plasma leptin levels on T-cell differentiation as seen in morbid obese individuals. In vitro data show that human macrophages and T-lymphocytes as well as murine T-lymphocytes treated with leptin react with an increased production of the Th-1 cytokines 
IFN- $\gamma$ and IL-2 and a decreased production of the Th-2 cytokine IL- $4^{41,53,54,61}$. These data suggest that in an environment abundant in leptin, Th1 cytokines are upregulated, while during fasting the Th2 cytokines dominate. The impact on the immune system of a dominant Th2 immune response during states of low leptin is not known, but we consider that this imbalance in Th1/Th2 status plays a role in the increased susceptibility to LPS, TNF- $\alpha$ or infection induced sepsis.

Low leptin levels are unfavorable for an organism, leading to a less efficient innate and acquired immune response. These considerations also can be put in the perspective of surgery in the cachectic patient, which also have a higher incidence of postoperative complications ${ }^{62}$. Several studies have shown that leptin is decreased in cachexia as seen in cancer patients to levels as low as $3 \mathrm{ng} / \mathrm{ml}^{63-67}$. Such low leptin levels can suppress the immune system and favor postoperative complications.

In summary, after bariatric surgery there is an increased risk of more serious complications, in which the immune system plays a central role. This is the result of the interplay between the energy balance and the immune system, in which leptin is the crucial mediator. Starvation as seen after bariatric surgery, results in strongly reduced leptin levels. The relative loss of leptin in such patients is considered to impair the immune system rendering the morbid obese patient more prone to develop postoperative complications. This leads to the question whether leptin can be used as a pharmacological intervention, to support the immune system in the postoperative period after bariatric surgery, the only proven effective treatment of morbid obesity ${ }^{68}$. 


\section{References}

1. Coleman DL. Obese and diabetes: two mutant genes causing diabetes-obesity syndromes in mice. Diabetologia 1978;14:141-8.

2. Zhang Y, Proenca R, Maffei M, Barone M, Leopold L, Friedman JM. Positional cloning of the mouse obese gene and its human homologue. Nature 1994;372:425-32.

3. van Dielen FM, van 't Veer C, Buurman WA, Greve JW. Leptin and soluble leptin receptor levels in obese and weight-losing individuals. J Clin Endocrinol Metab 2002;87:1708-16.

4. Tartaglia LA, Dembski M, Weng X, Deng N, Culpepper J, Devos R, Richards GJ, Campfield LA, Clark FT, Deeds J, Muir C, Sanker S, Moriarty A, Moore KJ, Smutko JS, Mays GG, Wool EA, Monroe CA, Tepper RI. Identification and expression cloning of a leptin receptor, OB-R. Cell 1995;83:1263-71.

5. Huang L, Wang Z, Li C. Modulation of circulating leptin levels by its soluble receptor. J Biol Chem 2001;276:6343-9.

6. Murakami T, Yamashita T, lida M, Kuwajima M, Shima K. A short form of leptin receptor performs signal transduction. Biochem Biophys Res Commun 1997;231:26-9.

7. $\quad$ Ahima RS, Flier JS. Leptin. Annu Rev Physiol 2000;62:413-37.

8. Cummings DE, Schwartz MW. Genetics and pathophysiology of human obesity. Annu Rev Med 2003;54:453-71.

9. Dagogo-Jack S. Human leptin regulation and promise in pharmacotherapy. Curr Drug Targets 2001;2:181-95.

10. Havel PJ. Peripheral signals conveying metabolic information to the brain: short-term and long-term regulation of food intake and energy homeostasis. Exp Biol Med (Maywood) 2001; 226:963-77.

11. Faggioni $R$, Feingold $K R$, Grunfeld $C$. Leptin regulation of the immune response and the immunodeficiency of malnutrition. Faseb J 2001;15:2565-71.

12. Ozata M, Ozdemir IC, Licinio J. Human leptin deficiency caused by a missense mutation: multiple endocrine defects, decreased sympathetic tone, and immune system dysfunction indicate new targets for leptin action, greater central than peripheral resistance to the effects of leptin, and spontaneous correction of leptin-mediated defects. J Clin Endocrinol Metab 1999;84:3686-95.

13. Zhang F, Basinski MB, Beals JM, Briggs SL, Churgay LM, Clawson DK, DiMarchi RD, Furman TC, Hale JE, Hsiung HM, Schoner BE, Smith DP, Zhang XY, Wery JP, Schevitz RW. Crystal structure of the obese protein leptin-E100. Nature 1997;387:206-9.

14. Kaibara A, Moshyedi A, Auffenberg T, Abouhamze A, Copeland EM, 3rd, Kalra S, Moldawer LL. Leptin produces anorexia and weight loss without inducing an acute phase response or protein wasting. Am J Physiol 1998;274:R1518-25.

15. Gualillo O, Eiras S, Lago F, Dieguez C, Casanueva FF. Elevated serum leptin concentrations induced by experimental acute inflammation. Life Sci 2000;67:2433-41.

16. Torpy DJ, Bornstein SR, Chrousos GP. Leptin and interleukin-6 in sepsis. Horm Metab Res 1998;30:726-9.

17. Bornstein SR, Licinio J, Tauchnitz R, Engelmann L, Negrao AB, Gold P, Chrousos GP. Plasma leptin levels are increased in survivors of acute sepsis: associated loss of diurnal rhythm, in cortisol and leptin secretion. J Clin Endocrinol Metab 1998;83:280-3.

18. Arnalich F, Lopez J, Codoceo R, Jim nez M, Madero R, Montiel C. Relationship of plasma leptin to plasma cytokines and human survivalin sepsis and septic shock. J Infect Dis 1999; 180:908-11.

19. Wallace AM, Sattar N, McMillan DC. The co-ordinated cytokine/hormone response to acute injury incorporates leptin. Cytokine 2000;12:1042-5.

20. Grunfeld C, Zhao C, Fuller J, Pollack A, Moser A, Friedman J, Feingold KR. Endotoxin and cytokines induce expression of leptin, the ob gene product, in hamsters. J Clin Invest 1996; 97:2152-7. 
21. Sarraf P, Frederich RC, Turner EM, Ma G, Jaskowiak NT, Rivet DJ, 3rd, Flier JS, Lowell BB, Fraker DL, Alexander HR. Multiple cytokines and acute inflammation raise mouse leptin levels: potential role in inflammatory anorexia. J Exp Med 1997;185:171-5.

22. Finck BN, Johnson RW. Tumor necrosis factor-alpha regulates secretion of the adipocytederived cytokine, leptin. Microsc Res Tech 2000;50:209-15.

23. Janik JE, Curti BD, Considine RV, Rager HC, Powers GC, Alvord WG, Smith JW, 2nd, Gause BL, Kopp WC. Interleukin 1 alpha increases serum leptin concentrations in humans. J Clin Endocrinol Metab 1997;82:3084-6.

24. Zumbach MS, Boehme MW, Wahl P, Stremmel W, Ziegler R, Nawroth PP. Tumor necrosis factor increases serum leptin levels in humans. J Clin Endocrinol Metab 1997;82:4080-2.

25. Faggioni R, Fantuzzi G, Fuller J, Dinarello CA, Feingold KR, Grunfeld C. IL-1 beta mediates leptin induction during inflammation. Am J Physiol 1998;274:R204-8.

26. Montalban C, Del Moral I, Garcia-Unzueta MT, Villanueva MA, Amado JA. Perioperative response of leptin and the tumor necrosis factor alpha system in morbidly obese patients. Influence of cortisol inhibition by etomidate. Acta Anaesthesiol Scand 2001;45:207-12.

27. Maruna P, Gurlich R, Fried M, Frasko R, Chachkhiani I, Haluzik M. Leptin as an acute phase reactant after non-adjustable laparoscopic gastric banding. Obes Surg 2001;11:609-14.

28. Cho YM, Kim MS, Shin CS, Park do J, Park KS, Yang HK, Lee KU, Cho BY, Lee HK, Kim SY. Dynamic change in plasma leptin level during the perioperative period. Horm Res 2003; 59:100-4.

29. Byrne TK. Complications of surgery for obesity. Surg Clin North Am 2001;81:1181-93, vii-viii.

30. van Dielen FM, Buurman WA, Hadfoune M, Nijhuis J, Greve JW. Macrophage inhibitory factor, plasminogen activator inhibitor-1, other acute phase proteins, and inflammatory mediators normalize as a result of weight loss in morbidly obese subjects treated with gastric restrictive surgery. J Clin Endocrinol Metab 2004;89:4062-8.

31. Chan JL, Heist K, DePaoli AM, Veldhuis JD, Mantzoros CS. The role of falling leptin levels in the neuroendocrine and metabolic adaptation to short-term starvation in healthy men. $\mathrm{J}$ Clin Invest 2003;111:1409-21.

32. Hernandez C, Simo R, Chacon P, Sabin P, Baena JA, Castellanos JM, Planas M. Influence of surgical stress and parenteral nutrition on serum leptin concentration. Clin Nutr 2000; 19:61-4.

33. Faggioni R, Fantuzzi G, Gabay C, Moser A, Dinarello CA, Feingold KR, Grunfeld C. Leptin deficiency enhances sensitivity to endotoxin-induced lethality. Am J Physiol 1999;276: R136-42.

34. Li Z, Lin H, Yang S, Diehl AM. Murine leptin deficiency alters Kupffer cell production of cytokines that regulate the innate immune system. Gastroenterology 2002;123:1304-10.

35. Madiehe AM, Mitchell TD, Harris RB. Hyperleptinemia and reduced TNF-alpha secretion cause resistance of $\mathrm{db} / \mathrm{db}$ mice to endotoxin. Am J Physiol Regul Integr Comp Physiol 2003; 284:R763-70.

36. Barrenetxe J, Palacios R, Barber A, Lostao MP. Functional expression of the short isoform of the murine leptin receptor Ob-Rc (muB1.219) in Xenopus laevis oocytes. J Physiol Biochem 2003;59:119-26.

37. Takahashi N, Waelput W, Guisez Y. Leptin is an endogenous protective protein against the toxicity exerted by tumor necrosis factor. J Exp Med 1999;189:207-12.

38. Gabay C, Dreyer M, Pellegrinelli N, Chicheportiche R, Meier CA. Leptin directly induces the secretion of interleukin 1 receptor antagonist in human monocytes. J Clin Endocrinol Metab 2001;86:783-91.

39. Gainsford T, Willson TA, Metcalf D, Handman E, McFarlane C, Ng A, Nicola NA, Alexander WS, Hilton DJ. Leptin can induce proliferation, differentiation, and functional activation of hemopoietic cells. Proc Natl Acad Sci U S A 1996;93:14564-8.

40. Tsiotra PC, Pappa V, Raptis SA, Tsigos C. Expression of the long and short leptin receptor isoforms in peripheral blood mononuclear cells: implications for leptin's actions. Metabolism 2000;49:1537-41. 
41. Zarkesh-Esfahani H, Pockley G, Metcalfe RA, Bidlingmaier M, Wu Z, Ajami A, Weetman AP, Strasburger CJ, Ross RJ. High-dose leptin activates human leukocytes via receptor expression on monocytes. J Immunol 2001;167:4593-9.

42. Caldefie-Chezet F, Poulin A, Tridon A, Sion B, Vasson MP. Leptin: a potential regulator of polymorphonuclear neutrophil bactericidal action? J Leukoc Biol 2001;69:414-8.

43. Zhao Y, Sun R, You L, Gao C, Tian Z. Expression of leptin receptors and response to leptin stimulation of human natural killer cell lines. Biochem Biophys Res Commun 2003;300: 247-52.

44. Loffreda S, Yang SQ, Lin HZ, Karp CL, Brengman ML, Wang DJ, Klein AS, Bulkley GB, Bao C, Noble PW, Lane MD, Diehl AM. Leptin regulates proinflammatory immune responses. Faseb J 1998;12:57-65.

45. Salman H, Bergman M, Bessler H, Alexandrova S, Straussberg R, Zahavi I, Djaldetti M. Effect of three days starvation on the phagocytic activity of rat peritoneal macrophages. Acta Haematol 1998;100:17-21.

46. Tian Z, Sun R, Wei H, Gao B. Impaired natural killer (NK) cell activity in leptin receptor deficient mice: leptin as a critical regulator in NK cell development and activation. Biochem Biophys Res Commun 2002;298:297-302.

47. Caldefie-Chezet F, Poulin A, Vasson MP. Leptin regulates functional capacities of polymorphonuclear neutrophils. Free Radic Res 2003;37:809-14.

48. Santos-Alvarez J, Goberna R, Sanchez-Margalet V. Human leptin stimulates proliferation and activation of human circulating monocytes. Cell Immunol 1999;194:6-11.

49. Sun D, Muthukumar AR, Lawrence RA, Fernandes G. Effects of calorie restriction on polymicrobial peritonitis induced by cecum ligation and puncture in young C57BL/6 mice. Clin Diagn Lab Immunol 2001;8:1003-11.

50. Dong W, Selgrade MK, Gilmour IM, Lange RW, Park P, Luster MI, Kari FW. Altered alveolar macrophage function in calorie-restricted rats. Am J Respir Cell Mol Biol 1998;19:462-9.

51. Faggioni R, Moser A, Feingold KR, Grunfeld C. Reduced leptin levels in starvation increase susceptibility to endotoxic shock. Am J Pathol 2000;156:1781-7.

52. Yamakawa T, Tanaka S, Yamakawa Y, Kiuchi Y, Isoda F, Kawamoto S, Okuda K, Sekihara $\mathrm{H}$. Augmented production of tumor necrosis factor-alpha in obese mice. Clin Immunol Immunopathol 1995;75:51-6.

53. Martin-Romero C, Santos-Alvarez J, Goberna R, Sanchez-Margalet V. Human leptin enhances activation and proliferation of human circulating T lymphocytes. Cell Immunol 2000; 199:15-24.

54. Lord GM, Matarese G, Howard JK, Baker RJ, Bloom SR, Lechler RI. Leptin modulates the Tcell immune response and reverses starvation-induced immunosuppression. Nature 1998; 394:897-901.

55. Howard JK, Lord GM, Matarese G, Vendetti S, Ghatei MA, Ritter MA, Lechler RI, Bloom SR. Leptin protects mice from starvation-induced lymphoid atrophy and increases thymic cellularity in ob/ob mice. J Clin Invest 1999;104:1051-9.

56. Chandra RK. Cell-mediated immunity in genetically obese C57BL/6J ob/ob) mice. Am J Clin Nutr 1980;33:13-6.

57. Mandel MA, Mahmoud AA. Impairment of cell-mediated immunity in mutation diabetic mice (db/db). J Immunol 1978;120:1375-7.

58. Farooqi IS, Matarese G, Lord GM, Keogh JM, Lawrence E, Agwu C, Sanna V, Jebb SA, Perna F, Fontana S, Lechler RI, DePaoli AM, O'Rahilly S. Beneficial effects of leptin on obesity, $T$ cell hyporesponsiveness, and neuroendocrine/metabolic dysfunction of human congenital leptin deficiency. J Clin Invest 2002;110:1093-103.

59. Fraser DA, Thoen J, Reseland JE, Forre O, Kjeldsen-Kragh J. Decreased CD4+ lymphocyte activation and increased interleukin-4 production in peripheral blood of rheumatoid arthritis patients after acute starvation. Clin Rheumatol 1999;18:394-401.

60. Sanna V, Di Giacomo A, La Cava A, Lechler RI, Fontana S, Zappacosta S, Matarese G. Leptin surge precedes onset of autoimmune encephalomyelitis and correlates with development of pathogenic T cell responses. J Clin Invest 2003;111:241-50. 
61. Siegmund B, Lehr HA, Fantuzzi G. Leptin: a pivotal mediator of intestinal inflammation in mice. Gastroenterology 2002;122:2011-25.

62. Windsor JA, Hill GL. Weight loss with physiologic impairment. A basic indicator of surgical risk. Ann Surg 1988;207:290-6.

63. Brown DR, Berkowitz DE, Breslow MJ. Weight loss is not associated with hyperleptinemia in humans with pancreatic cancer. J Clin Endocrinol Metab 2001;86:162-6.

64. Mantovani G, Maccio A, Mura L, Massa E, Mudu MC, Mulas C, Lusso MR, Madeddu C, Dessi A. Serum levels of leptin and proinflammatory cytokines in patients with advanced-stage cancer at different sites. J Mol Med 2000;78:554-61.

65. Simons JP, Schols AM, Campfield LA, Wouters EF, Saris WH. Plasma concentration of total leptin and human lung-cancer-associated cachexia. Clin Sci (Lond) 1997;93:273-7.

66. Aleman MR, Santolaria F, Batista N, de La Vega M, Gonzalez-Reimers E, Milena A, Llanos $\mathrm{M}$, Gomez-Sirvent JL. Leptin role in advanced lung cancer. A mediator of the acute phase response or a marker of the status of nutrition? Cytokine 2002;19:21-6.

67. Gomez-Ambrosi J, Zabalegui N, Bing C, Tisdale MJ, Trayhurn P, Williams G. Weight loss in tumour-bearing mice is not associated with changes in resistin gene expression in white adipose tissue. Horm Metab Res 2002;34:674-7.

68. Clinical Guidelines on the Identification, Evaluation, and Treatment of Overweight and Obesity in Adults--The Evidence Report. National Institutes of Health. Obes Res 1998;6 Suppl 2:51S-209S. 


\section{Chapter 5}

Endothelial activation markers and their key

regulators after restrictive bariatric surgery,

a 2 year follow-up study

Jeroen Nijhuis, Francois M.H. van Dielen, Suomi M.G. Fouraschen, Maartje A.J. van den Broek, Sander Rensen, Wim A. Buurman, Jan Willem M. Greve

Obesity (Silver Spring). 2007;15:1395-1399 


\section{Abstract}

\section{Background}

Increased plasma levels of endothelial activation markers in obese subjects reflect the positive association between cardiovascular diseases and obesity. The pro-inflammatory state associated with obesity is thought to play a major role in endothelial cell activation in morbid obese individuals. Previous studies demonstrated that long term weight loss after bariatric surgery is accompanied by a decreased pro-inflammatory state. However, little is known about the long term effects of bariatric surgery on endothelial cell activation.

\section{Methods}

Plasma levels of sICAM-1, sE-selectin and SVCAM-1, all markers of endothelial cell activation and of their regulators adiponectin and resistin were measured at different time points postoperatively in 26 consecutive patients that underwent restrictive surgery, with a follow-up of two years.

\section{Results}

During the first six months after bariatric surgery, sE-selectin levels decreased. Despite substantial weight loss, sICAM-1 and sVCAM-1 plasma levels did not decrease significantly. After 24 months, sICAM-1 levels were significantly decreased while sE-selectin levels were further decreased. However, sVCAM-1 levels remained elevated. Adiponectin levels did not change significantly during the first six months after bariatric surgery, whereas resistin levels increased. After 24 months, adiponectin levels were similar to normal weight controls, but resistin levels remained high.

\section{Conclusion}

Reductions in plasma levels of different markers of endothelial activation after bariatric surgery show different temporal patterns, suggesting that distinct mechanisms are involved in their regulation. Although not all endothelial activation markers normalize after bariatric surgery, our findings suggest that bariatric surgery can reduce endothelial activation on the long term. 


\section{Introduction}

Inflammation of the vascular wall is a crucial step in the pathophysiology of atherosclerosis which causes endothelial cells to express a wide variety of endothelial adhesion molecules, including Endothelial selectin (E-selectin), Vascular Cell Adhesion Molecule-1 (VCAM-1) and Intercellular Adhesion Molecule-1 (ICAM-1). In order to limit the inflammatory process, these adhesion molecules are rapidly removed from the cell surface, which occurs by proteolytic cleavage and shedding ${ }^{1,2}$. The elevated circulating levels of products of proteolytic cleavage and shedding of adhesion molecules correlate with atherosclerosis ${ }^{1}$. Furthermore, plasma levels of soluble forms of ICAM-1 (sICAM-1), VCAM-1 (sVCAM-1) and E-selectin (sE-selectin) are increased in obesity ${ }^{3,4}$.

Recently, two proteins, adiponectine and resistin, which could affect expression of endothelial activation markers by endothelial cells, were discovered. Adiponectin and resistin have opposite actions on endothelial cells and plasma levels are respectively decreased and increased in human obesity ${ }^{5,6}$. The adipokine adiponectin downregulates expression of ICAM-1, E-selectin and VCAM-1, while resistin, which in humans is secreted by inflammatory cells ${ }^{7}$, upregulates these adhesion molecules ${ }^{8,9}$.

Weight loss in obese and morbid obese individuals results in improvement of endothelial function ${ }^{10}$ and decreased circulating inflammatory markers ${ }^{11,12}$. This study was conducted to analyze the effects of weight loss after bariatric surgery on the levels of endothelial activation markers and their key regulators. Together with circulating plasma markers of endothelial activation (sICAM-1, sE-selectin and sVCAM-1), plasma levels of mediators of endothelial activation (adiponectin and resistin) were studied in a follow-up of 24 months, reflecting the degree of endothelial cell activation during weight loss after bariatric surgery.

\section{Subjects and methods}

\section{Subjects and samples}

All participants gave written informed consent. The study was approved by the local ethical committee of the Academic Hospital Maastricht.

A total of 26 consecutive subjects, admitted to the Surgical Department of the University Hospital Maastricht to undergo an operation for morbid obesity, were included in the study. The group comprised 23 female and three male individuals, aged $38 \pm 9$ years with a mean BMl of $46.3 \pm 6.0 \mathrm{~kg} / \mathrm{m}^{2}$. These patients underwent a primary operation for morbid obesity (Vertical banded 
gastroplasty (VBG, $n=12$ ) or laparoscopic gastric banding using Lap-Band $(n=14))$. All subjects were selected to be otherwise healthy according to history, clinical examination and whenever possible laboratory findings, which means that no overt signs of type 2 diabetes mellitus, hypertension (diastolic blood pressure: $82.12 \pm 8.82 \mathrm{mmHg}$ ) and other cardiovascular diseases were present. Moreover, the individuals did not use any medications apart from oral anticonceptives.

ten healthy lean subjects (eight female and two male) aged $35 \pm 14$ years, with a mean BMI of $22.5 \pm 3.5$ served as control group to provide reference values (values depicted as dotted lines in Figure 5.1.).

Blood samples were collected after at least eight hours fasting using evacuated blood collection tubes containing EDTA one day before surgery, and 3, 6, 12 and 24 months after surgery and processed as previously described ${ }^{11}$.

\section{Immunoassays}

Plasma concentrations of sICAM-1 and sE-selectin were determined using sandwich ELISAs as described elsewhere ${ }^{11,13}$. Plasma sVCAM-1, adiponectin and resistin concentrations were measured using ELISA development kits (R\&D systems, Minneapolis, MN). All plasma samples were analyzed in the same run. The intra- and inter-assay coefficients of variance of the various assays were $<10 \%$.

\section{Statistical analysis}

All data are expressed as mean $\pm S D$. Due to the non-parametrically distributed data, preoperative and postoperative results were compared using repeated measurements ANOVA (analysis of variance). A p-value less than 0.05 was considered statistically significant.

\section{Results}

\section{Weight loss after surgery}

Restrictive bariatric surgery resulted in a significant loss of BMI from $46.3 \pm 6.0 \mathrm{~kg} / \mathrm{m}^{2}$ to $34.7 \pm 6.6 \mathrm{~kg} / \mathrm{m}^{2} \quad(p<0.01)$ during the two year follow-up period, which was not influenced by the restrictive bariatric surgical techniques used (Figure 5.1). During the first six months, a striking decrease in BMI and $\%$ EWL was observed, amounting to a remarkable mean 142 grams body weight loss per day, which decreased to a mean weight loss of 53 grams per day (6-12 months). Patients reached a stable weight after one year. 
BMI

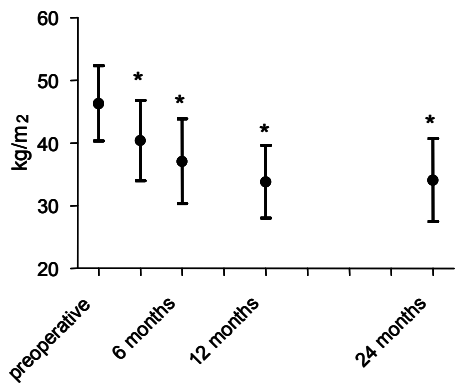

adiponectin

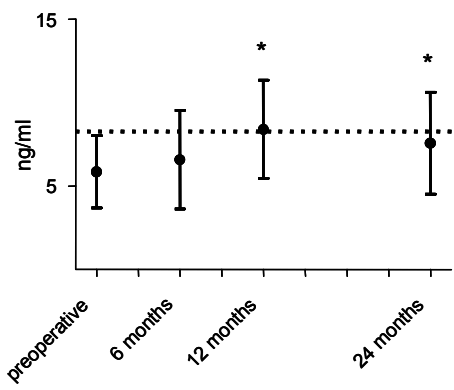

resistin

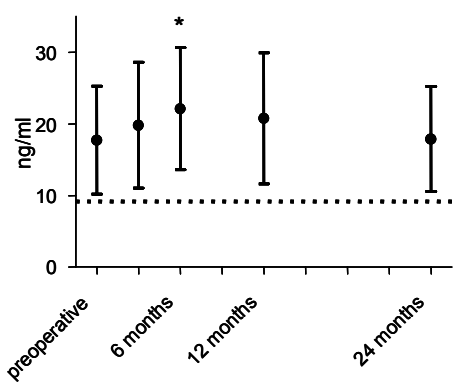

sICAM-1

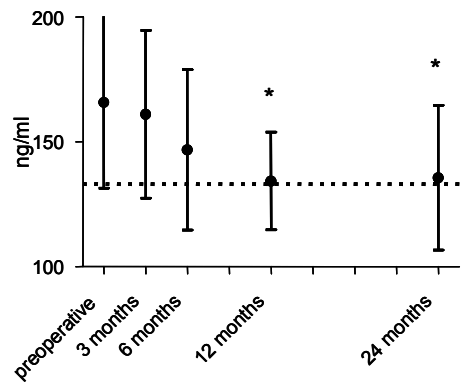

sVCAM-1

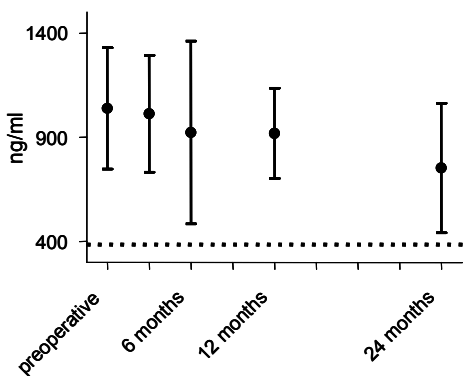

sE-selectin

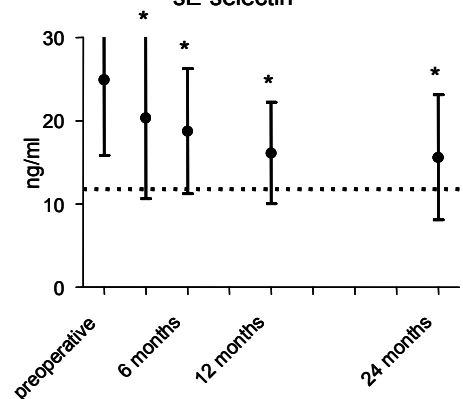

Figure 5.1 BMI of 26 morbidly obese subjects was determined preoperatively as well as after gastric restrictive surgery. BMI decreased after gastric restrictive surgery. Effect of weight loss due to gastric restrictive surgery on plasma levels of endothelial activation markers sICAM-1, sVCAM-1, sE-selectin, and their regulators adiponectin and resistin in 26 morbidly obese subjects. During the first months after bariatric surgery, adiponectin concentrations did not increase significantly whereas resistin levels did increase. After 12 months, adiponectin levels were significantly increased while resistin levels dropped to preoperative values. In contrast to plasma sE-selectin levels, sICAM-1 and SVCAM-1 plasma levels were still elevated during the first months after bariatric surgery. In the long term sE-selectin levels further declined and sICAM-1 levels decreased significantly but sVCAM-1 concentrations remained elevated. The dotted line represents control values. Mean values and standard deviations are for sICAM-1 $133.2+22.7 \mathrm{ng} / \mathrm{ml}$, for adiponectine $8.27+4.6 \mu \mathrm{g} / \mathrm{ml}$, for sVCAM-1 $354.6+108.2 \mathrm{ng} / \mathrm{ml}$, for resistin $9.15+2.2 \mathrm{ng} / \mathrm{ml}$ and for sE-selectin $11.35+4.7 \mathrm{ng} / \mathrm{ml}$.

* Significantly changed compared to preoperative values. 


\section{Effect of weight loss on endothelial activation markers}

Previously, we reported that inflammatory markers such as the acute phase protein lipopolysaccharide binding protein (LBP), CRP, and soluble TNF $\alpha$ receptors did not decrease during the first six months after bariatric surgery, even though the individuals lose substantial amounts of weight ${ }^{11}$. In line with this, circulating levels of the adhesion molecules sICAM-1 and SVCAM-1 remained elevated (Figure 5.1). In contrast, plasma levels of $s E$-selectin rapidly declined during the first six months (Figure 5.1).

In the long term (12-24 months) after bariatric surgery, levels of circulating inflammatory markers decreased ${ }^{11}$. Likewise, plasma sICAM-1 and sE-selectin levels further decreased to levels comparable to those measured in healthy controls (from $165.8 \pm 32.4$ to $136.8 \pm 30.7 \mathrm{ng} / \mathrm{ml}(p<0.05)$ and from $23.8 \pm 9.5$ to $15.4 \pm 7.3 \mathrm{ng} / \mathrm{ml}(p<0.05)$, respectively). sVCAM-1 levels showed a trend to decrease from $1039.1 \pm 290.2$ to $753.0 \pm 311.4 \mathrm{ng} / \mathrm{ml}$, but remained elevated as compared to healthy controls. The decrease of endothelial activation markers did not correlate with the decrease in weight after bariatric surgery.

\section{Effect of weight loss on regulators of endothelial activation}

Despite substantial weight loss directly after bariatric surgery, only minimal changes in plasma adiponectin and resistin levels were seen. In the stable weight phase, after 12 months, adiponectin plasma levels had increased significantly from $6.4 \pm 3.6$ to $7.6 \pm 3.0 \mu \mathrm{g} / \mathrm{ml}(p<0.05)$ (Figure 5.1). After 24 months, however, adiponectin levels did not differ significantly from preoperative levels. Plasma resistin levels increased significantly during the period of substantial weight loss, from $17.7 \pm 7.5$ to $22.1 \pm 7.3 \mathrm{ng} / \mathrm{ml}$ after six months $(p<0.05)$, but decreased to preoperative values once stable weight was achieved (Figure 5.1).

\section{Discussion}

Cardiovascular diseases are common in morbid obese individuals. Endothelial cell activation is thought to play a causative role in the development of cardiovascular diseases. In this study we have monitored levels of endothelial cell activation markers and their main regulators in morbid obese individuals up to two years after bariatric surgery. During the first six months after bariatric surgery, plasma sICAM-1 and SVCAM-1 concentrations remained high. In contrast, sE-selectin, decreased significantly during this period. This suggests that endothelial cells remain in an activated state during this period, although the effects of weight loss are already reflected in components of the endothelial activation state. Since plasma adiponectin levels did not change and resistin 
levels even increased during the first months after bariatric surgery, it is unlikely that these mediators of endothelial activation in vitro are responsible for the partial reduction of endothelial cell activation. Instead, inflammatory mediators may be responsible for this effect. In a previous report, we hypothesized that a severe catabolic state, brought about by substantial weight loss, could be responsible for metabolic stress, resulting in an ongoing inflammatory state during the first months after bariatric surgery ${ }^{11}$. This may explain why the reduction in endothelial cell activation is initially only minor. In this respect it is also noteworthy that, similar to the endothelial activation markers, there are marked differences with respect to the degree of normalization of inflammatory mediators during the first months after surgery. PAI-1 and the acute phase protein a1-acid glycoprotein (AGP) levels, like sEselectin levels, decrease rapidly, whereas sICAM-1 and SVCAM-1 levels, like LBP and CRP levels, remain elevated. These findings suggest that there is no uniform mechanism by which weight loss leads to decreased endothelial activation and inflammation, although parallel mechanisms may operate in both processes.

Once weight stabilization was reached (approximately 12-24 months postoperatively) the inflammatory condition diminished. In line with this, we report substantially decreased levels of the endothelial activation markers sICAM-1 and sE-selectin as well as increased plasma adiponectin concentrations 12-24 months after operation. On the other hand, resistin and sVCAM-1 levels remained elevated. A possible explanation can be that the subjects in our study were still obese, even at 24 months after gastric restrictive surgery (mean BMI of $34.7 \mathrm{~kg} / \mathrm{m}^{2}$ ). It has been shown that obese individuals have elevated resistin levels ${ }^{14}$, which can explain the high levels of resistin 2 years after surgery. Analogous to this, sVCAM-1 levels in obese subjects are higher than those in normal weight controls, as also shown by Vazquez et al. ${ }^{15}$.

Although almost exclusively secreted by adipocytes, adiponectin levels in obese individuals are lower than levels in normal weight control subjects and increase after weight loss ${ }^{16}$. The low-grade inflammatory state associated with obesity is thought to be responsible for the decreased adiponectin production ${ }^{17}$. Therefore, the ongoing inflammation during the first months after bariatric surgery may suppress an increase in adiponectin levels, despite substantial weight loss. After stable weight is achieved, the low-grade inflammation attenuates and adiponectin levels increase accordingly.

Resistin upregulates endothelial activation markers via a NF-KB or AP-1 dependent pathway ${ }^{9}$. Adiponectin downregulates the expression of adhesion molecules through cAMP dependent inhibition of NF-KB signaling ${ }^{8}$. Moreover, endothelial activation markers have been reported to be upregulated by pro- 
inflammatory cytokines ${ }^{13}$. This can explain the prolonged increase of sICAM-1 and sVCAM-1, but not the rapid decrease of sE-selectin during the first months after bariatric surgery. One possible explanation for the observed discrepancy is the source of the different activation markers. sICAM-1 is not exclusively secreted by endothelial cells. The observed increased plasma concentrations of resistin could imply that monocytes are activated during the first few months after bariatric surgery. Monocytes are also capable of producing SICAM- $1^{18}$, which could explain the prolonged increased plasma levels of sICAM-1 after bariatric surgery. Another possibility for the observed discrepancy could be the observation that $\mathrm{SE}$-selectin plasma levels are more sensitive than SVCAM-1 and SICAM-1 plasma levels for the hyperinsulinemic state in individuals with impaired glucose tolerance ${ }^{19}$. Directly after bariatric surgery insulin levels rapidly decrease ${ }^{20}$ which might explain the rapid decrease of $\mathrm{SE}$-selectin levels during the first months after bariatric surgery, while SICAM-1 and SVCAM-1 plasma levels are still increased.

In summary, levels of endothelial activation markers diminish after bariatric surgery induced weight loss, leading to a decreased pro-atherogenic state. This underscores the importance of bariatric surgery in reducing major comorbidities of morbid obesity, like cardiovascular disease. 


\section{References}

1. Blankenberg S, Barbaux S, Tiret L. Adhesion molecules and atherosclerosis. Atherosclerosis 2003;170:191-203.

2. von Asmuth EJ, Smeets EF, Ginsel LA, Onderwater JJ, Leeuwenberg JF, Buurman WA. Evidence for endocytosis of E-selectin in human endothelial cells. Eur J Immunol 1992; 22:2519-26.

3. Ferri C, Desideri G, Valenti M, Bellini C, Pasin M, Santucci A, De Mattia G. Early upregulation of endothelial adhesion molecules in obese hypertensive men. Hypertension 1999;34:568-73.

4. Straczkowski M, Lewczuk P, Dzienis-Straczkowska S, Kowalska I, Stepien A, Kinalska I. Elevated soluble intercellular adhesion molecule-1 levels in obesity: relationship to insulin resistance and tumor necrosis factor-alpha system activity. Metabolism 2002;51:75-8.

5. Faraj M, Havel PJ, Phelis S, Blank D, Sniderman AD, Cianflone K. Plasma acylationstimulating protein, adiponectin, leptin, and ghrelin before and after weight loss induced by gastric bypass surgery in morbidly obese subjects. J Clin Endocrinol Metab 2003;88: 1594-602.

6. Vozarova de Courten B, Degawa-Yamauchi M, Considine RV, Tataranni PA. High serum resistin is associated with an increase in adiposity but not a worsening of insulin resistance in Pima Indians. Diabetes 2004;53:1279-84.

7. Patel L, Buckels AC, Kinghorn IJ, Murdock PR, Holbrook JD, Plumpton C, Macphee CH, Smith SA. Resistin is expressed in human macrophages and directly regulated by PPAR gamma activators. Biochem Biophys Res Commun 2003;300:472-6.

8. Ouchi N, Kihara S, Arita $Y$, Okamoto $Y$, Maeda K, Kuriyama H, Hotta K, Nishida M, Takahashi M, Muraguchi M, Ohmoto Y, Nakamura T, Yamashita S, Funahashi T, Matsuzawa Y. Adiponectin, an adipocyte-derived plasma protein, inhibits endothelial NF-kappaB signaling through a cAMP-dependent pathway. Circulation 2000;102:1296-301.

9. Verma S, Li SH, Wang CH, Fedak PW, Li RK, Weisel RD, Mickle DA. Resistin promotes endothelial cell activation: further evidence of adipokine-endothelial interaction. Circulation 2003;108:736-40.

10. Gokce N, Vita JA, McDonnell M, Forse AR, Istfan N, Stoeckl M, Lipinska I, Keaney JF, Jr., Apovian CM. Effect of medical and surgical weight loss on endothelial vasomotor function in obese patients. Am J Cardiol 2005;95:266-8.

11. van Dielen FM, Buurman WA, Hadfoune M, Nijhuis J, Greve JW. Macrophage inhibitory factor, plasminogen activator inhibitor-1, other acute phase proteins, and inflammatory mediators normalize as a result of weight loss in morbidly obese subjects treated with gastric restrictive surgery. J Clin Endocrinol Metab 2004;89:4062-8.

12. Cottam DR, Mattar SG, Barinas-Mitchell E, Eid G, Kuller L, Kelley DE, Schauer PR. The chronic inflammatory hypothesis for the morbidity associated with morbid obesity: implications and effects of weight loss. Obes Surg 2004;14:589-600.

13. Leeuwenberg JF, Smeets EF, Neefjes JJ, Shaffer MA, Cinek T, Jeunhomme TM, Ahern TJ, Buurman WA. E-selectin and intercellular adhesion molecule-1 are released by activated human endothelial cells in vitro. Immunology 1992;77:543-9.

14. Azuma K, Katsukawa F, Oguchi S, Murata M, Yamazaki H, Shimada A, Saruta T. Correlation between serum resistin level and adiposity in obese individuals. Obes Res 2003;11: 997-1001.

15. Vazquez LA, Pazos F, Berrazueta JR, Fernandez-Escalante C, Garcia-Unzueta MT, Freijanes J, Amado JA. Effects of changes in body weight and insulin resistance on inflammation and endothelial function in morbid obesity after bariatric surgery. $\mathrm{J}$ Clin Endocrinol Metab 2005;90:316-22.

16. Yang WS, Lee WJ, Funahashi T, Tanaka S, Matsuzawa Y, Chao CL, Chen CL, Tai TY, Chuang LM. Weight reduction increases plasma levels of an adipose-derived antiinflammatory protein, adiponectin. J Clin Endocrinol Metab 2001;86:3815-9.

17. Lihn AS, Pedersen SB, Richelsen B. Adiponectin: action, regulation and association to insulin sensitivity. Obes Rev 2005;6:13-21. 
18. Rice GE, Munro JM, Corless C, Bevilacqua MP. Vascular and nonvascular expression of INCAM-110. A target for mononuclear leukocyte adhesion in normal and inflamed human tissues. Am J Pathol 1991;138:385-93.

19. Matsumoto K, Miyake S, Yano M, Ueki Y, Tominaga Y. High serum concentrations of soluble E-selectin in patients with impaired glucose tolerance with hyperinsulinemia. Atherosclerosis 2000;152:415-20.

20. Polyzogopoulou EV, Kalfarentzos F, Vagenakis AG, Alexandrides TK. Restoration of euglycemia and normal acute insulin response to glucose in obese subjects with type 2 diabetes following bariatric surgery. Diabetes 2003;52:1098-103. 


\section{Chapter 6}

Neutrophil activation in morbid obesity, chronic activation of acute inflammation

Jeroen Nijhuis, Sander S.M. Rensen, Yanti Slaats, Francois M.H. van Dielen, Wim A. Buurman, Jan Willem M. Greve 


\section{Abstract}

\section{Background}

Recent studies show that morbid obesity is associated with activation of the innate immune response. Neutrophil activation is a fundamental process in the innate immune response. Therefore, the activation state of neutrophils in morbidly obese subjects and the effect of bariatric surgery on neutrophil activation was evaluated.

\section{Methods}

Neutrophil activation was assessed by measuring circulating concentrations of myeloperoxidase (MPO) and calprotectin in 37 morbidly obese and nine control subjects (ELISA). Moreover, membrane expression of $\mathrm{CD} 66 \mathrm{~b}$ on circulating neutrophils was measured using flow cytometry in a group of seven morbidly obese and six control subjects. Immunohistochemical detection of MPO was performed in adipose and muscle tissue.

\section{Results}

Plasma MPO and calprotectin levels were significantly increased in morbidly obese subjects as compared to healthy controls, $27.1 \pm 10.8$ vs. $17.3 \pm 5.5 \mathrm{ng} / \mathrm{ml}(p<0.001)$ and $115.5 \pm 43.5$ vs. $65.1 \pm 23.1 \mathrm{ng} / \mathrm{ml}(p<0.001)$ for MPO and calprotectin respectively. In line, CD66b expression was significantly increased in morbidly obese individuals, $177.3 \pm 43.7$ vs. $129.7 \pm 9.2$ (mean fluorescence intensity) $(p<0.01)$. Bariatric surgery resulted in decreased calprotectin, but not MPO plasma levels. Adipose and muscle tissue did not contain enhanced numbers of MPO expressing cells in morbidly obese individuals.

\section{Discussion}

These results point out that enhanced numbers of activated neutrophils are circulating in morbidly obese subjects. The reported data support the finding that the innate immune system is activated in morbidly obese individuals. Moreover, since neutrophils have a short lifespan, this indicates that the chronic inflammatory condition associated with morbid obesity is characterized by a continuous activation of the innate immune system. 


\section{Introduction}

The inflammatory condition associated with obesity is considered to play a major role in the pathogenesis of obesity-related morbidities like cardiovascular disease and type 2 diabetes mellitus ${ }^{1}$. Several inflammatory molecules have been shown to be involved. For instance, tumor necrosis factor alpha (TNF- $\alpha$ ) plasma levels are increased in morbidly obese patients ${ }^{2,3}$ and TNF- $\alpha$ knockout mice do not develop insulin resistance after diet induced obesity ${ }^{4}$. Moreover, selective upregulation of IKB kinase beta (IKK- $\beta$ ), an inducer of nuclear factor kappa B (NF-kB) in liver results in decreased insulin sensitivity ${ }^{5}$.

So far most studies have focused on the role of macrophage activation and accumulation in adipose tissue, which has been shown to contribute significantly to insulin resistance ${ }^{6}$. However, it appears that there is a more general activation of the immune system. For instance, levels of acute phase proteins (C-reactive protein (CRP) and $\alpha_{1}$-acid glycoprotein (AGP)) are increased in morbid obesity and decreased after surgery-induced weight loss ${ }^{3}$. Moreover, circulating levels of endothelial activation markers are increased in obesity, indicating an activation of endothelial cells ${ }^{7}$. Furthermore, the complement system is activated in morbid obesity which decreases after weight loss ${ }^{8}$. Collectively, these findings indicate that the immune system is activated in obesity.

Neutrophils represent one of the most prominent components of the innate immune system displaying strong phagocytic and anti-microbial activity. Their anti-microbial activity is mainly based on specific proteins stored in granules or in the cytoplasm, such as myeloperoxidase (MPO) and calprotectin. MPO is a potent enzyme stored in the azurophilic granules of neutrophils which is secreted upon neutrophil activation. MPO generates numerous reactive oxidants and radicals which cause oxidative damage to proteins, lipoproteins, lipids and DNA of target cells ${ }^{9}$. These characteristics of MPO are also important in the relation of MPO with cardiovascular disease. Zheng et al. showed that apolipoprotein A1 (ApoA1), the major lipoprotein of high density lipoprotein (HDL), is a specific target for MPO in atheroma, which could lead to plaque instability $^{10}$. Moreover, the product of MPO controlled catalysis of hydrogen peroxide, hypochlorous acid, is thought to play a central role in the etiology of atherosclerosis ${ }^{11}$. Calprotectin is a cytoplasmic, bacteriostatic protein which is released upon activation ${ }^{12}$. Neutrophil activation is also accompanied by translocation of the glycoprotein CD66b from the secondary granules to the outer cell membrane and is involved in adhesion of neutrophils to E-selectin on the activated endothelium ${ }^{13}$.

Earlier studies have shown that whereas the number of neutrophils remains unchanged in morbidly obese patients, expression of CD62L, an adhesion molecule on the neutrophil surface, was depressed ${ }^{14}$. Expression of other 
activation markers by neutrophils, such as the Fc receptor CD16 and the adhesion molecule CD11b as well as plasma levels of the activation marker elastase were similar between obese patients and normal weight controls ${ }^{14,15}$. Therefore the current views are that neutrophils may be slightly less activated and not activated in the morbidly obese individual. However, other studies reported that the total number of circulating neutrophils was increased in obese individuals $^{16,17}$. In addition, evidence for a role of MPO in the development of obesity in mice was recently reported. Overexpression of MPO in transgenic mice led to enhanced weight gain on a high fat $\operatorname{diet}^{18}$. Given these results and the notion that other components of the innate immune system are activated in morbidly obese subjects, we set out to evaluate the activation state of neutrophils in morbidly obese subjects. Here, it is reported that, in line with the activation of the innate immune response in morbid obesity, increased numbers of activated neutrophils are circulating in morbidly obese individuals.

\section{Subjects and methods}

\section{Subjects and samples}

All participants gave written informed consent. The study was approved by the local ethical committee of the Academic Hospital Maastricht.

To compare the neutrophil activation markers MPO and calprotectin between morbidly obese individuals and normal weight control subjects, a total of 37 morbidly obese patients were compared to nine normal weight control subjects (study 1A). CD66b expression on neutrophils was studied in seven morbidly obese subjects and compared to CD66b expression on neutrophils of six normal weight controls (study $1 \mathrm{~B}$ ). The effect of bariatric surgery on neutrophil activation was studied in 15 consecutive subjects, admitted to the Department of Surgery of the University Hospital Maastricht to undergo an operation for morbid obesity (study 2). Characteristics of the different study groups are depicted in Table 6.1. All subjects were selected to be otherwise healthy according to history, clinical examination and whenever possible laboratory findings, which means that no overt signs of type 2 diabetes mellitus, hypertension, non alcoholic fatty liver disease and other cardiovascular diseases were present. Moreover, patients using anti-inflammatory medication like aspirin, statins and fibrates were excluded.

For study $1 \mathrm{~A}$ and 2, blood samples were collected after at least eight hours fasting using evacuated blood collection tubes containing EDTA and processed as previously described ${ }^{3}$. In study $1 \mathrm{~B}$ whole blood samples were used. All samples were processed immediately for fluorescent activated cell sorting (FACS). 


\section{Immunoassays}

Plasma concentrations of MPO and calprotectin were determined using sandwich ELISAs (HyCult biotechnology, Uden, the Netherlands). All plasma samples were analyzed in the same run. The intra- and inter-assay coefficients of variance of the various assays were $<10 \%$.

\section{FACS analysis}

FACS analysis to detect CD66b expression on neutrophils was performed using the following protocol. $100 \mu \mathrm{l}$ whole blood (EDTA) was incubated with a fluorescein-isothiocyanate (FITC) labeled antibody against CD66b. PBS and a FITC labeled isotype antibody were used as negative control. After 30 minutes of incubation in the dark, erythrocytes were lyzed and the vials were centrifuged at $400 \mathrm{~g}$. The supernatant was discarded and the cells were washed twice with PBS- $0.1 \%$ BSA. Finally, cells were resuspended in $1 \%$ paraformaldehyde solution and FACS analysis was performed the same day on the FACSCalibur using Cellquest software (Becton Dickinson, Franklin lakes, $\mathrm{NJ})$. Data are expressed as mean fluorescence intensity.

\section{Immunohistochemistry}

Slices of four micrometers of formalin fixed, paraffin embedded visceral adipose (omentum) and muscle (rectus abdominus) tissue were stained for neutrophil infiltration using an antibody directed against MPO. In short, slides were deparaffinized, rehydrated and incubated for 15 minutes in methanol$0.6 \% \mathrm{H}_{2} \mathrm{O}_{2}$ to block endogenous peroxidases. Thereafter, slides were incubated with $10 \%$ goat serum in TBS- $0.1 \%$ BSA to prevent aspecific binding of the secondary antibody. After washing with TBS, slides were incubated with rabbit anti human MPO (1:1000). Goat anti rabbit IgG antibody labeled with HRP was used as a secondary antibody. AEC (3-Amino-9-ethylcarbazole) was used as substrate for peroxidase. Hematoxillin was used as a counterstaining.

\section{Reagents and materials}

Bovine serum albumin (BSA) was purchased from Sigma (St. Louis, MO). FITC labeled antibodies against $\mathrm{CD66b}$ (clone $80 \mathrm{H} 3$ ) and the isotype control were purchased from Serotec (Kidlington, England). Polyclonal rabbit anti human MPO was purchased from Dako (Glostrup, Denmark).

\section{Statistical analysis}

All data are expressed as mean $\pm S D$. In study $1 A$ and $1 B$, due to unpaired and non-parametrically distributed data, results were compared using the Mann- 
Whitney test. In study two, due to paired and non-parametrically distributed data, results were compared using the Wilcoxon sign rank test. A p-value less than 0.05 was considered statistically significant.

\section{Results}

\section{Plasma markers of neutrophil activation are increased in morbid obesity}

Table 6.1 summarizes the patient characteristics of the morbidly obese and normal weight controls studied.

Table 6.1 Characteristics of the study populations.

\begin{tabular}{lcccccc}
\hline & \multicolumn{2}{c}{$\begin{array}{c}\text { Study Group 1A } \\
\text { morbidly }\end{array}$} & $\begin{array}{c}\text { Study Group 1B } \\
\text { controls } \\
\text { obese }(\mathrm{n}=37)\end{array}$ & $\begin{array}{c}\text { morbidly } \\
(\mathrm{n}=9)\end{array}$ & $\begin{array}{c}\text { obese }(\mathrm{n}=7) \\
\text { controls }\end{array}$ & $\begin{array}{c}\text { Study Group 2 } \\
\text { preoperative postoperative }\end{array}$ \\
\hline $\mathrm{BMI}\left(\mathrm{kg} / \mathrm{m}^{2}\right)$ & $46.0 \pm 6.0$ & $22.8 \pm 3.0$ & $43.8 \pm 6.7$ & $22.8 \pm 2.6$ & $46.0 \pm 4.9$ & $36.2 \pm 7.4$ \\
Age $(\mathrm{yr})$ & $37 \pm 10$ & $31 \pm 11$ & $47 \pm 7$ & $44 \pm 12$ & $36 \pm 10$ & \\
Sex $($ male/female $)$ & $5 / 32$ & $2 / 7$ & $3 / 4$ & $3 / 3$ & $1 / 14$ & \\
\hline
\end{tabular}

Plasma MPO and calprotectin levels were compared between morbidly obese and normal weight controls in study 1A. In study 1B CD66b expression was studied and morbidly obese subjects were compared to normal weight controls. The effect of bariatric surgery on plasma MPO and calprotectin levels was studied in study 2 .

The plasma levels of the neutrophil activation markers MPO and calprotectin were measured in morbidly obese and normal weight controls (study group 1A). Both circulating MPO and calprotectin levels were significantly increased in morbidly obese subjects as compared to healthy controls. The levels of MPO were $27.1 \pm 10.8 \mathrm{ng} / \mathrm{ml}$ in the morbidly obese group whereas normal weight controls showed plasma levels of $17.3 \pm 5.5 \mathrm{ng} / \mathrm{ml}(p<0.001)$. For calprotectin, plasma levels were $115.5 \pm 43.5 \mathrm{ng} / \mathrm{ml}$ in the morbidly obese group, whereas plasma levels of normal weight controls were $65.1 \pm 23.1 \mathrm{ng} / \mathrm{ml} \quad(p<0.001)$ (Figure 6.1).

\section{CD66b expression on neutrophils is increased in morbidly obese individuals}

The activation marker of circulating neutrophils, CD66b, was assessed using flow cytometry. CD66b was measured in a smaller group of seven morbidly obese and six normal weight healthy controls (see for characteristics Table 6.1, study group 1B). Like MPO and calprotectin plasma levels, CD66b expression 
was significantly increased in morbidly obese individuals, $177.3 \pm 43.7$ vs. $129.7 \pm 9.2(p<0.01)$ (Figure 6.2).
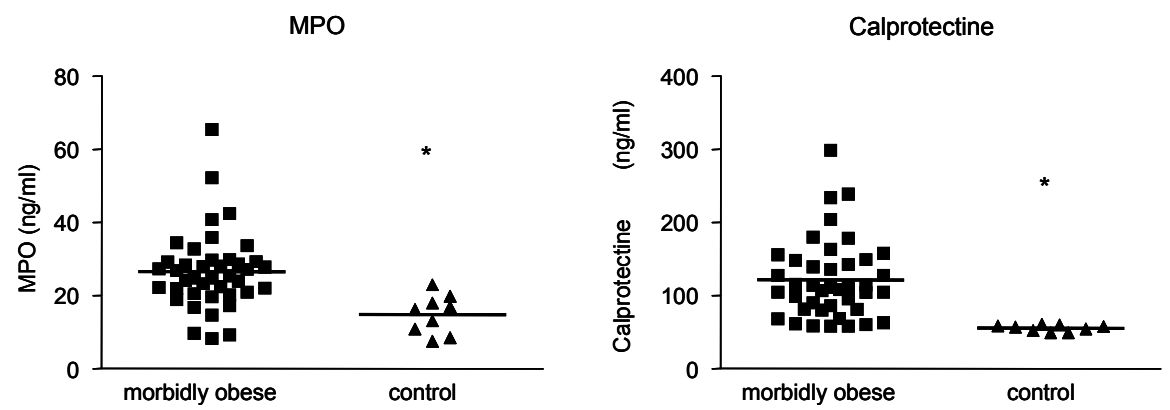

Figure 6.1 Circulating MPO (A) and Calprotectin (B) levels in morbidly obese and normal weight subjects (study group 1A). The levels of MPO were $27.1 \pm 10.8 \mathrm{ng} / \mathrm{ml}$ in the morbidly obese group whereas normal weight controls showed plasma levels of $17.3 \pm 5.5 \mathrm{ng} / \mathrm{ml}$ $(p<0.001)$. For calprotectin, plasma levels were $115.5+43.5 \mathrm{ng} / \mathrm{ml}$ in the morbidly obese group, whereas plasma levels of normal weight controls were $65.1+23.1 \mathrm{ng} / \mathrm{ml}$ $(p<0.001)$

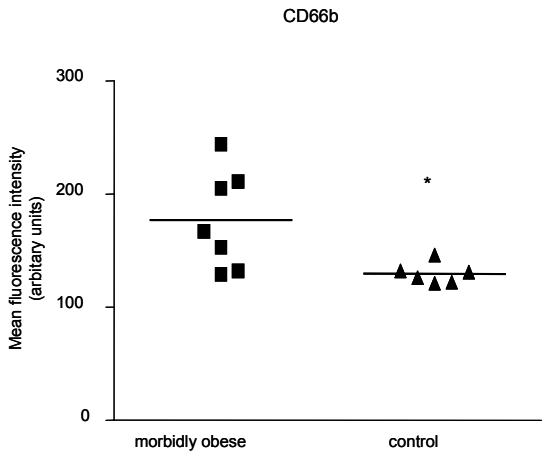

Figure 6.2 CD66b expression on the neutrophil cell membrane quantified by mean fluorescence intensity in morbidly obese and normal weight subjects (study group 1B). CD66b expression was significantly increased in morbidly obese individuals, $177.3 \pm 43.7$ vs. $129.7 \pm 9.2(p<0.01)$.

\section{The effect of bariatric surgery on plasma markers of neutrophil activation (study group 2)}

Weight loss after bariatric surgery is associated with decreased plasma levels of inflammatory mediators. Interestingly, MPO levels remained unchanged after bariatric surgery $(19.7 \pm 4.1 \mathrm{ng} / \mathrm{ml}$ preoperative and $21.5 \pm 6.8 \mathrm{ng} / \mathrm{ml}$ two years postoperative). On the other hand, two years after bariatric surgery, calprotectin levels decreased (eleven out of 15 patients) significantly from a 
mean of $119.6 \pm 31.5$ to a mean of $93.9 \pm 42.7 \mathrm{ng} / \mathrm{ml}(\mathrm{p}<0.001)$. (Figure 6.3). The outliers of the calprotectin group were not identical with the outliers in the MPO group.

MPO

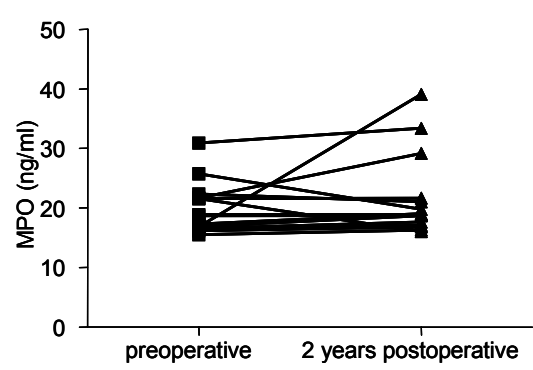

Calprotectin

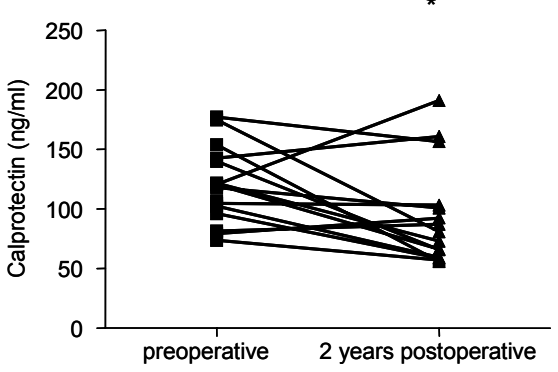

Figure 6.3 Effect of bariatric surgery on circulating plasma MPO and calprotectin levels. Preoperative and two year postoperative plasma levels of MPO and calprotectin were measured (study group 2).Two years after bariatric surgery, MPO levels remained unchanged after bariatric surgery $(19.7 \pm 4.1 \mathrm{ng} / \mathrm{ml}$ preoperative and $21.5 \pm 6.8 \mathrm{ng} / \mathrm{ml} 2$ years postoperative). Interestingly, calprotectin levels decreased (11 out of 15 patients) significantly from a mean of $119.6 \pm 31.5$ to a mean of $93.9 \pm 42.7 \mathrm{ng} / \mathrm{ml}$ $(p<0.001)$.

\section{Absence of neutrophils in adipose and muscle tissue}

To determine if the increased neutrophil activation is accompanied by enhanced neutrophil infiltration of adipose or muscle tissue, immunohistochemical staining for MPO was performed. From 17 morbidly obese subjects, subcutaneous and visceral adipose tissue as well as skeletal muscle was stained for polymorphonuclear cells. In seven of these patients, plasma levels of calprotectin and MPO were measured as part of study $1 \mathrm{~A}$ and shown to be increased. MPO positive cells were detected solely in blood vessels of adipose tissue and skeletal muscle tissue.

\section{Discussion}

The inflammatory condition in morbidly obese subjects is characterized by activation of several components of the innate immune response. This is illustrated by increased plasma levels of acute phase proteins, endothelial cell activation markers, complement factors and cytokines derived from activated macrophages. Remarkably little is known about the activation of neutrophils, a central component in innate immunity, in obesity. Thus far available data suggests that neutrophils are less activated in morbid obesity ${ }^{14,15}$. This is in contrast to the overt evidence that the innate immune system is activated in 
morbid obesity. Therefore, we set out to determine the degree of neutrophil activation using the plasma levels of calprotectin and MPO and neutrophil membrane expression of CD66b. MPO and calprotectin are primarily secreted by neutrophils although a minor secretion by activated monocytes cannot be excluded $^{9,12,19}$. CD66b on the other hand is specifically expressed on the outer cell membrane of granulocytes and its expression is enhanced upon activation of the cells making CD66b a suitable marker for neutrophil activation.

We show increased plasma levels of MPO and calprotectin in morbidly obese patients strongly indicating neutrophil activation. The observed increased neutrophil specific CD66b expression also strongly supports neutrophil activation in morbid obesity. A possible mechanism for the activation of neutrophils could be the increased plasma levels of leptin and TNF- $\alpha$ observed in morbid obesity. Leptin has been reported to activate neutrophils via indirect induction of TNF- $\alpha$ secretion by monocytes ${ }^{20}$.

Our findings contrast with the study of Cottam et al., who reported a lower CD62L expression on neutrophils of morbidly obese individuals as compared to neutrophils of normal weight controls ${ }^{14}$. They concluded that neutrophils of morbidly obese patients are less capable of activation and migration to target tissues rendering such patients more susceptible to inflammatory diseases.

In morbidly obese patients, enhanced numbers of macrophages have been reported in adipose tissue ${ }^{6}$. In this context, the relation of activation of neutrophils with neutrophil infiltration of adipose and muscle tissue was investigated. Positive staining for MPO containing neutrophils in both adipose and skeletal muscle tissue was confined to blood vessels, which was similar in both tissues, indicating that increased plasma MPO levels originate from other sources.

Interestingly, MPO is associated with cardiovascular diseases, since elevated plasma MPO levels have been reported to predict the presence of coronary artery disease ${ }^{9}$. In addition, it has been shown that LDL receptor knockout mice overexpressing MPO, given a high fat diet, had increased aortic lesions and were more obese than their LDL receptor knockout littermates ${ }^{18}$. The latter was thought to result from effects of MPO on lipid metabolism.

Interestingly both plasma MPO levels and obesity are considered independent risk factors for cardiovascular disease. Increased plasma levels of MPO as observed in the present study could therefore imply an additional risk for obese individuals for cardiovascular diseases. In another perspective, the causative role of MPO in cardiovascular disease and obesity provides opportunities for treatment options aimed at decreasing oxidative damage with anti-oxidants and related drugs ${ }^{21}$, a topic that needs further study.

Bariatric surgery results in marked weight loss as well as decreased plasma levels of inflammatory mediators ${ }^{3,7}$. Therefore it was hypothesized that bariatric surgery would also result in decreased plasma levels of MPO and calprotectin. 
The decreased plasma levels of calprotectin indeed indicate that neutrophils are less activated two years after bariatric surgery. Interestingly, similar to earlier observations that several parts of the inflammatory cascade do not decrease after substantial weight loss ${ }^{3,7}$, MPO levels remained elevated two years after bariatric surgery. The continuous obese status could explain these findings.

In summary, we show that increased numbers of activated neutrophils are circulating in morbidly obese individuals. Bariatric surgery partly reduced neutrophil activation. These findings support the notion that morbid obesity is associated with activation of the innate immune response. Interestingly, the innate immune response is an acute inflammatory response, while obesity is considered a chronic inflammatory status. Therefore, obesity appears to be characterized by a chronic stimulation of the acute inflammatory response. 


\section{References}

1. Cottam DR, Mattar SG, Barinas-Mitchell E, Eid G, Kuller L, Kelley DE, Schauer PR. The chronic inflammatory hypothesis for the morbidity associated with morbid obesity: implications and effects of weight loss. Obes Surg 2004;14:589-600.

2. Kopp HP, Kopp CW, Festa A, Krzyzanowska K, Kriwanek S, Minar E, Roka R, Schernthaner G. Impact of weight loss on inflammatory proteins and their association with the insulin resistance syndrome in morbidly obese patients. Arterioscler Thromb Vasc Biol 2003; 23:1042-7.

3. van Dielen FM, Buurman WA, Hadfoune M, Nijhuis J, Greve JW. Macrophage inhibitory factor, plasminogen activator inhibitor-1, other acute phase proteins, and inflammatory mediators normalize as a result of weight loss in morbidly obese subjects treated with gastric restrictive surgery. J Clin Endocrinol Metab 2004;89:4062-8.

4. Ventre J, Doebber T, Wu M, MacNaul K, Stevens K, Pasparakis M, Kollias G, Moller DE. Targeted disruption of the tumor necrosis factor-alpha gene: metabolic consequences in obese and nonobese mice. Diabetes 1997;46:1526-31.

5. Cai D, Yuan M, Frantz DF, Melendez PA, Hansen L, Lee J, Shoelson SE. Local and systemic insulin resistance resulting from hepatic activation of IKK-beta and NF-kappaB. Nat Med 2005;11:183-90.

6. Weisberg SP, McCann D, Desai M, Rosenbaum M, Leibel RL, Ferrante AW, Jr. Obesity is associated with macrophage accumulation in adipose tissue. J Clin Invest 2003;112: 1796-808.

7. Vazquez LA, Pazos F, Berrazueta JR, Fernandez-Escalante C, Garcia-Unzueta MT, Freijanes J, Amado JA. Effects of changes in body weight and insulin resistance on inflammation and endothelial function in morbid obesity after bariatric surgery. J Clin Endocrinol Metab 2005;90:316-22.

8. Hanusch-Enserer U, Cauza E, Spak M, Dunky A, Rosen HR, Wolf H, Prager R, Eibl MM. Acute-phase response and immunological markers in morbid obese patients and patients following adjustable gastric banding. Int J Obes Relat Metab Disord 2003;27:355-61.

9. Nicholls SJ, Hazen SL. Myeloperoxidase and cardiovascular disease. Arterioscler Thromb Vasc Biol 2005;25:1102-11.

10. Zheng L, Nukuna B, Brennan ML, Sun M, Goormastic M, Settle M, Schmitt D, Fu X, Thomson L, Fox PL, Ischiropoulos H, Smith JD, Kinter M, Hazen SL. Apolipoprotein A-I is a selective target for myeloperoxidase-catalyzed oxidation and functional impairment in subjects with cardiovascular disease. J Clin Invest 2004;114:529-41.

11. Yang J, Cheng $Y$, Ji R, Zhang $C$. A novel model of inflammatory neointima formation reveals a potential role of myeloperoxidase in neointimal hyperplasia. Am J Physiol Heart Circ Physiol 2006.

12. Striz I, Trebichavsky I. Calprotectin - a pleiotropic molecule in acute and chronic inflammation. Physiol Res 2004;53:245-53.

13. Skubitz KM, Kuroki M, Jantscheff P, Skubitz AP, Grunert F. CD66b. J Biol Regul Homeost Agents 1999;13:242-3.

14. Cottam DR, Schaefer PA, Shaftan GW, Velcu L, Angus LD. Effect of surgically-induced weight loss on leukocyte indicators of chronic inflammation in morbid obesity. Obes Surg 2002;12:335-42.

15. Adeyemi E, Benedict $\mathrm{S}$, Abdulle A. A comparison of plasma polymorphonuclear leucocyte elastase levels in obese and lean individuals. J Int Med Res 1998;26:252-6.

16. Dixon JB, O'Brien PE. Obesity and the white blood cell count: changes with sustained weight loss. Obes Surg 2006;16:251-7.

17. Pratley RE, Wilson C, Bogardus C. Relation of the white blood cell count to obesity and insulin resistance: effect of race and gender. Obes Res 1995;3:563-71.

18. Castellani LW, Chang JJ, Wang X, Lusis AJ, Reynolds WF. Transgenic mice express human MPO -463G/A alleles at atherosclerotic lesions, developing hyperlipidemia and obesity in 463G males. J Lipid Res 2006;47:1366-77. 
19. Ghanim H, Aljada A, Hofmeyer D, Syed T, Mohanty P, Dandona P. Circulating mononuclear cells in the obese are in a proinflammatory state. Circulation 2004;110:1564-71.

20. Zarkesh-Esfahani H, Pockley AG, Wu Z, Hellewell PG, Weetman AP, Ross RJ. Leptin indirectly activates human neutrophils via induction of TNF-alpha. J Immunol 2004;172: 1809-14.

21. Ivanovski O, Szumilak D, Nguyen-Khoa T, Ruellan N, Phan O, Lacour B, Descamps-Latscha $\mathrm{B}$, Drueke TB, Massy ZA. The antioxidant $\mathrm{N}$-acetylcysteine prevents accelerated atherosclerosis in uremic apolipoprotein E knockout mice. Kidney Int 2005;67:2288-94. 


\section{Chapter 7}

Insulin sensitivity during the first months after

restrictive bariatric surgery, inconsistency

between HOMA-IR and steady state plasma glucose (SSPG) levels

Francois M.H. van Dielen, Jeroen Nijhuis, Nicolaas C. Schaper, Janneke Wiebolt, Afra Koks, Fred. J. Prakken, Sander S.M. Rensen, Wim A. Buurman, Jan Willem M. Greve 


\section{Abstract}

\section{Background}

The low-grade inflammatory condition present in morbid obesity is thought to play a causative role in the pathophysiology of insulin resistance (IR). Bariatric surgery fails to improve this inflammatory condition during the first months after surgery, although on the long term surgery results in resolution of the inflammation. Considering the close relation between inflammation and IR, a study was conducted in which insulin sensitivity was measured during the first months after bariatric surgery.

\section{Methods}

Insulin sensitivity was measured using homeostasis model assessment insulin resistance (HOMA$\mathrm{IR}$ ) and steady state plasma glucose (SSPG) levels in eleven subjects prior to surgery and when $26 \%$ excess weight loss (EWL) (approximately two months after bariatric surgery) was reached. Moreover, plasma levels of leptin, acute phase proteins and TNF- $\alpha$ receptors were measured.

\section{Results}

SSPG levels after $26 \%$ EWL did not differ from SSPG levels before surgery $(14.3 \pm 5.4$ vs. $14.4 \pm 2.7 \mathrm{mmol} / \mathrm{I})$, whereas HOMA-IR values decreased significantly $(3.59 \pm 1.99$ vs. $2.09 \pm 1.02)$. In line with earlier studies plasma levels of inflammatory parameters did not improve, whereas leptin levels decreased.

\section{Conclusion}

During the first months after restrictive bariatric surgery a discrepancy was observed between HOMA-IR and SSPG levels. In contrast to SSPG levels HOMA-IR values showed improvement of insulin sensitivity. These results point out that HOMA-IR as surrogate marker of insulin sensitivity cannot be used during the first months after bariatric surgery. Moreover, the present data show that during the first months after restrictive bariatric surgery insulin sensitivity did not improve, leaving the patient at risk for the co-morbidities associated with IR. 


\section{Introduction}

Bariatric surgery is considered to be the best treatment option for morbid obesity and its co-morbidities ${ }^{1}$. In the long term bariatric surgery not only results in improved body weight but also reduces the low-grade inflammatory condition associated with morbid obesity ${ }^{2}$. The low-grade inflammatory condition is thought to play a causative role in the pathophysiology of insulin resistance. Supportive data for this hypothesis was generated in a study which showed that treatment of subjects suffering from insulin resistance with the anti-inflammatory drug acetylsalicylic acid resulted in improved insulin sensitivity ${ }^{3,4}$. In line, previous studies have shown increased insulin sensitivity and reduced inflammation in the long term after bariatric surgery ${ }^{5,6}$.

Interestingly, prior data show, that despite substantial weight loss, several parameters of the low-grade inflammatory condition did not decrease during the first months after bariatric surgery ${ }^{5}$. Plasma adiponectin and resistin as well as acute phase proteins and tumor necrosis factor alpha (TNF- $\alpha$ ) receptor levels remained unchanged at three months after surgery. This lead us to investigate insulin sensitivity of morbidly obese subjects before and at approximately two months after surgery when patients had lost $25 \%$ of excess weight in relation with inflammatory parameters.

\section{Materials and methods}

In total eleven consecutive patients admitted to the surgical department of the university hospital Maastricht for surgical treatment of morbid obesity, participated in the study. Seven patients underwent vertical banded gastroplasty (VBG) and four subjects a Lap-Band operation. In the study group, the subjects were otherwise healthy according to history, clinical examination and routine laboratory tests. In particular none of the studied subjects had evidence of diabetes mellitus or inflammatory disease or were taking medication known to influence glucose metabolism. The morbidly obese patients were studied with the SSPG test prior to gastric restrictive surgery (baseline) and after $25 \%$ excess weight loss (EWL). Characteristics of the study population are presented in Table 7.1. The study was approved by the ethical committee of the university hospital Maastricht, the Netherlands. All subjects gave written informed consent. 
Table 7.1 Characteristics of the study population.

\begin{tabular}{lcc}
\hline Variables & $\begin{array}{c}\text { Preoperative } \\
(\mathrm{n}=11)\end{array}$ & $\begin{array}{c}26 \% \mathrm{EWL} \\
(\mathrm{n}=11)\end{array}$ \\
\hline Sex (female/male) & $9 / 2$ & \\
Age $(\mathrm{yr})$ & $40.4 \pm 7.6$ & $39.4 \pm 3.4^{*}$ \\
BMl $\left(\mathrm{kg} / \mathrm{m}^{2}\right)$ & $44.6 \pm 3.3$ & $0.93 \pm 0.1$ \\
Waist hip ratio & $0.97 \pm 0.08$ & $14.9 \pm 3.3$ \\
Weight loss $(\mathrm{kg})$ & & $5.5 \pm 0.7$ \\
Fasting glucose (mmol/l) & $5.4 \pm 0.6$ & $7.4 \pm 4.5^{*}$ \\
Fasting insulin (mU/l) & $14.8 \pm 7.8$ & $2.09+1.02^{*}$ \\
HOMA-IR & $3.59 \pm 1.99$ & $53 \pm 26$ \\
Days after surgery & & \\
\hline
\end{tabular}

${ }^{*} p<0.05$ compared to the preoperative situation.

\section{Steady State Plasma Glucose test}

Insulin sensitivity was determined by using SSPG levels, described by Reaven et al. ${ }^{7,8}$. This insulin suppression test determines a steady state plasma glucose (SSPG) concentration as a measure for insulin mediated glucose uptake and highly correlates $(r>0.90)$ with the golden standard, the hyperinsulinemic euglycaemic clamp technique.

In short after a 12-hours overnight fast, body weight and body height were measured. Subjects were studied supine in a hospital bed. Catheters were placed in both antecubital veins to enable infusion of glucose, insulin and octreotide as well as venous blood sampling. During an acclimatisation period of thirty minutes an automatic blood pressure measurement (Dinamap, Criticon Inc., Tampa, FI) was performed. Octreotide (Sandostatin, kindly provided for by Novartis Pharma B.V. Arnhem, the Netherlands), a somatostatin analogue, was administered intravenously by using a syringe infusion pump (Treonic IP4, Vickers Medical, England) at $5.0 \mu \mathrm{g} / \mathrm{min}$, preceded by a bolus of $25 \mu \mathrm{g}$. Due to the expected severe insulin resistance in the study population a higher infusion rate was used than described by Pei and Reaven ${ }^{9}$. In both the pre- and postoperative measurements of SSPG the same octreotide concentration was used decreasing change of confounding the results due to high octreotide plasma concentrations. Insulin (Actrapid, Novo-Nordisk, Bagsærd, Denmark) was infused at a rate of $25 \mathrm{mU} / \mathrm{m}^{2} / \mathrm{min}$ by a second syringe pump. Glucose was infused via a volumetric pump (IVAC 591, IVAC Corporation, San Diego, $\mathrm{CA}$ ) at $240 \mathrm{mU} / \mathrm{m}^{2} / \mathrm{min}$. Before the test as well as on different time points during the test venous blood samples were taken. The mean plasma level of glucose at $150,160,170$ and 180 minutes was defined as SSPG level. SSPG levels provide an indirect measure for insulin resistance.

Plasma glucose was determined by a glucose oxidase method (YSI model 2300 Stat, Yellow Springs Industries, Yellow Springs, OH). Blood samples for 
determining inflammatory mediators and insulin were immediately put on melting ice and plasma was prepared by centrifugation at $1,400 \mathrm{~g}$ for ten minutes at $4^{\circ} \mathrm{C}$. The plasma was spun again at $2,700 \mathrm{~g}$ for 10 minutes at $4^{\circ} \mathrm{C}$ and recovered plasma was stored in aliquots at $-80^{\circ} \mathrm{C}$ until measurement.

\section{Reagents, materials and assays}

Plasma concentrations of soluble TNF- $\alpha$ receptors, leptin, lipopolysaccharid binding protein (LBP), C-reactive protein (CRP), $\alpha_{1}$-acid glycoprotein (AGP) and insulin were measured using sandwich ELISA's. TNF- $\alpha$ receptors (55 and 75), leptin, LBP, CRP and AGP were measured as described elsewhere ${ }^{5}$. Plasma insulin concentrations were measured using a commercial available ELISA (Mercodia AB, Uppsala, Sweden).

All plasma samples were measured in the same run, except for plasma insulin concentrations. When plasma concentrations exceeded the upper detection limit of the assay, samples were additionally diluted and analyzed in a separate run with an overlap. The intra- and inter-assay coefficients of variance of the assays were smaller than $10 \%$.

\section{Statistical analysis}

Data were expressed as mean \pm standard deviation. The Wilcoxon sign-rank test was used to analyze differences.

\section{Results}

\section{Effect of weight loss on metabolic and inflammatory mediators}

After bariatric surgery, $26 \pm 4 \%$ excess weight loss (EWL) was reached in $53 \pm 26$ days resulting in BMI loss from $43.9 \pm 3.6 \mathrm{~kg} / \mathrm{m}^{2}$ (preoperative) to $39.4 \pm 3.4 \mathrm{~kg} / \mathrm{m}^{2}$.

As shown in Table 7.1, fasting plasma glucose levels before surgery were in a normal range $(<5.6 \mathrm{mmol} / \mathrm{l})$, with increased fasting plasma insulin levels $(14.8 \pm 7.8 \mathrm{mU} / \mathrm{l})$ resulting in increased HOMA-IR (3.59 \pm 1.99$)$. Fasting plasma glucose levels at $26 \%$ EWL were similar to preoperative values. In contrast, fasting insulin plasma levels as well as HOMA-IR decreased after surgery $(7.4 \pm 4.5 \mathrm{mU} / \mathrm{l}$ and $2.09 \pm 1.02$ respectively).

Figure 7.1 shows pre- and postoperative steady state plasma insulin (SSPI) levels and SSPG. Because SSPI levels were not significantly different between the two conditions $(p=0.76)$, pre- and postoperative SSPG levels could be compared. Preoperative glucose levels increased to reach the SSPG concentration (mean of plasma glucose levels from $t=150$ to $t=180$ ) of 
$14.4 \pm 2.7 \mathrm{mmol} / \mathrm{l}$. This concentration is much higher compared to the SSPG levels found in healthy subjects $(4.1 \pm 0.4 \mathrm{mmol} / \mathrm{l})$, indicating reduced preoperative insulin sensitivity in our morbidly obese subjects. These data represent the lower $30^{\text {th }}$ percentile of insulin resistance as measured by the group of Reaven in 490 healthy volunteers ${ }^{10}$.

A

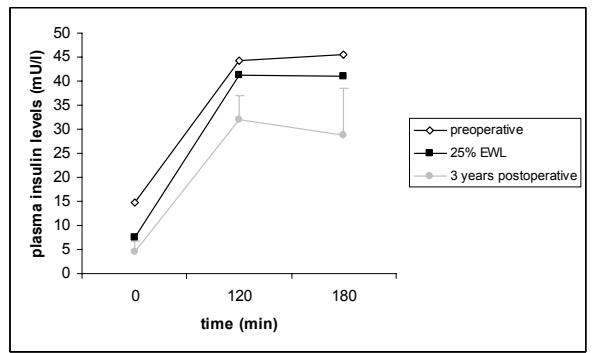

B

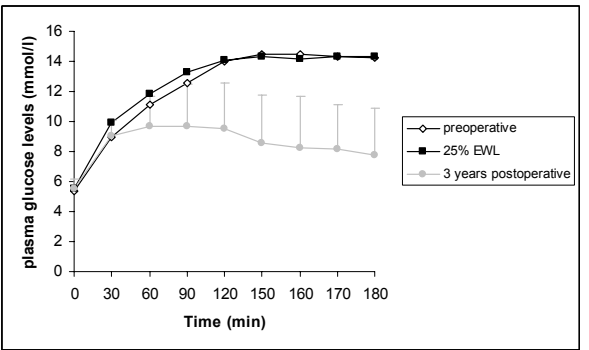

Figure 7.1 Preoperative SSPI values (Figure 7.1A) did not significantly differ compared to $26 \%$ EWL $(14.4 \pm 2.7$ vs. $14.3 \pm 5.4 \mathrm{mmol} / \mathrm{l})$, therefore pre and postoperative SSPG levels could be compared. SSPG levels did not decrease in the first months after restrictive bariatric surgery, indicating that during the first months after surgery insulin sensitivity did not improve.

Interestingly, the mean SSPG concentration before surgery was not significantly different to the mean SSPG concentration after bariatric surgery at $26 \%$ EWL $(14.3 \pm 5.3 \mathrm{mmol} /)$.

In the long term after bariatric surgery SSPG levels improve substantially $(8.2 \pm 3.2 \mathrm{mmol} / \mathrm{l})$ according to data in a group of individuals three years after bariatric surgery ${ }^{11}$ (grey lines in Figure 7.1). However, compared to the preoperative and $25 \%$ EWL group, SSPI levels in the group three years after bariatric surgery were lower $(43.6 \pm 10.0$ vs. $28.7 \pm 9.8 \mathrm{mU} / \mathrm{l})$. The preoperative BMI of this study population was $47.4 \pm 6.4 \mathrm{~kg} / \mathrm{m}^{2}$, at approximately three years after bariatric surgery, patients had reached a BMI of $31.3 \pm 4.9 \mathrm{~kg} / \mathrm{m}^{2}(70 \%$ $\mathrm{EWL}$ ). Fasting plasma glucose and insulin levels were within the normal range $(5.5 \pm 0.6 \mathrm{mmol} / \mathrm{l}$ and $4.5 \pm 2.9 \mathrm{mU} / \mathrm{l}$ respectively) resulting in normal HOMA-IR values $(1.11 \pm 0.55)$.

As reported earlier plasma leptin levels decreased significantly, whereas circulating levels of acute phase proteins (CRP, AGP and LBP) and TNF- $\alpha$ receptors did not change despite the substantial weight loss at timepoint $26 \%$ $\mathrm{EWL}^{5}$ (Table 7.2). 
Table 7.2 Levels of inflammatory mediators at $\mathrm{t}=0$ during the SSPG test of both study groups.

\begin{tabular}{lcc}
\hline Variables & $\begin{array}{c}\text { Preoperative } \\
(\mathrm{n}=11)\end{array}$ & $\begin{array}{c}26 \% \mathrm{EWL} \\
(\mathrm{n}=11)\end{array}$ \\
\hline Leptin $(\mathrm{ng} / \mathrm{ml})$ & $67.0 \pm 31.5$ & $26.9 \pm 14.3^{*}$ \\
CRP $(\mu \mathrm{g} / \mathrm{ml})$ & $20.3 \pm 12.1$ & $21.9 \pm 17.1$ \\
AGP $(\mathrm{ng} / \mathrm{ml})$ & $12.1 \pm 7.7$ & $10.3 \pm 5.2$ \\
LBP $(\mu \mathrm{g} / \mathrm{ml})$ & $36.2 \pm 16.9$ & $35.1 \pm 11.6$ \\
Soluble TNFR55 $(\mathrm{ng} / \mathrm{ml})$ & $0.6 \pm 0.21$ & $0.67 \pm 0.2$ \\
Soluble TNFR75 $(\mathrm{ng} / \mathrm{ml})$ & $1.07 \pm 0.43$ & $1.34 \pm 0.47$
\end{tabular}

${ }^{*} p<0.05$ compared to the preoperative situation. Only plasma leptin levels decreased significantly after surgery, illustrating the ongoing inflammatory state in the first months after bariatric surgery.

\section{Discussion}

This study shows that in line with prior studies, the inflammatory condition did not improve during the first two months after bariatric surgery. A possible explanation could be metabolic stress induced by a severe catabolic state, brought about by substantial weight loss. This is supported by the observations that anorexia nervosa is also characterized by a low-grade inflammatory condition. Normalizing the catabolic state of patients suffering from anorexia nervosa by refeeding improves the inflammatory state ${ }^{12,13}$.

Considering the close relation between inflammation and insulin resistance, insulin sensitivity was measured during the first months after surgery using SSPG levels. Interestingly, SSPG levels did not decrease two months after surgery, I indicating that the patients still suffered from insulin resistance despite substantial weight loss. Although values could not be compared, due to significantly lower SSPI levels in the study group three year after surgery, data in the study group three years after bariatric surgery are strongly suggestive for improved SSPG levels in the long term after bariatric surgery. Low SSPI levels could lead to underestimation of the SSPG levels, which would imply that SSPG levels would decrease further with increasing SSPI levels. Further supporting the suggestion that insulin sensitivity improved in the long term after bariatric surgery are the HOMA-IR values, which are within the normal range. In contrast, HOMA-IR levels decreased significantly in the first months after surgery. This was mainly due to reduced fasting plasma insulin levels after surgery. Circulating fasting plasma glucose levels did not change significantly during the two months period. These results indicate that during the first months after bariatric surgery HOMA-IR should not be used as surrogate marker of insulin sensitivity. These findings also give rise to the hypothesis that observed differences between HOMA-IR and SSPG can be accounted for by the storage capacity of the liver for macronutrients. When losing weight rapidly hepatocytes will loose stored macronutrients earlier than skeletal muscle cells 
or adipocytes, leading to increased insulin sensitivity of hepatocytes compared to skeletal muscle cells or adipocytes. Before surgery, liver gluconeogenesis results in increased insulin production. This leads in non type II diabetic morbidly obese patients, with insulin resistance, to increased fasting plasma insulin levels and normal or slightly increased fasting plasma glucose levels. We consider that directly after surgery, when the stored macronutrients content of the liver decreases rapidly, insulin sensitivity increases and gluconeogenesis decreases resulting in decreased fasting plasma insulin levels.

A study using the euglycemic hyperinsulinemic clamp technique to measure insulin sensitivity has been performed after gastric bypass surgery and biliopancreatic diversion (BPD) ${ }^{14}$. Interestingly, six months after gastric bypass surgery insulin resistance did not decrease. In contrast, insulin resistance was significantly improved six months after BPD, which, as shown in another study, could be recovered within four weeks after $\mathrm{BPD}^{15}$. Taken together the present study and other data show that techniques mainly based on restriction, unlike malabsorptive procedures, do not immediately reduce peripheral insulin sensitivity. In general, gastric bypass surgery is considered restrictive, with only a minor malabsorptive component ${ }^{16}$. It is thought that incretins like glucagon like peptide-1 (GLP-1) and gastrointestinal polypeptide (GIP) play a central role in the observed differences ${ }^{15}$. Malabsorptive surgery results both in bypassing the foregut and in supplying the distal ileum with undigested food. Consequently secretion of GIP and GLP-1 is altered ${ }^{17}$. Both GIP and GLP-1 are known to increase insulin sensitivity and secretion ${ }^{18}$ and therefore malabsorptive surgery is thought to be more effective in increasing insulin sensitivity than purely restrictive procedures.

A possible explanation for the unchanged SSPG levels in the first months after bariatric surgery could be insufficient weight loss. At $26 \%$ EWL the subjects did loose approximately $15 \mathrm{~kg}$, but the BMI remained in the morbid obese spectrum $\left(39.4 \mathrm{~kg} / \mathrm{m}^{2}\right)$. It is suggested that peripheral insulin sensitivity only starts to improve after a certain setpoint which has not been reached in the study population. Another explanation could imply the severe catabolic state associated with substantial weight loss in the first months after bariatric surgery. In line with this hypothesis are studies showing decreased insulin sensitivity in adipose tissue during fasting ${ }^{19,20}$.

In conclusion, these results show that, in line with the low-grade inflammatory condition, in the first months after restrictive bariatric surgery, despite substantial weight loss, insulin resistance does not improve. On the long term after bariatric surgery insulin sensitivity improved, emphasizing the role of bariatric surgery in the treatment of insulin resistance in morbidly obese patients. Interestingly, SSPG levels remained unchanged, while HOMA-IR decreased in the first months after bariatric surgery questioning the scientific 
base for the use of HOMA-IR as a surrogate marker of insulin sensitivity during the first months after restrictive bariatric surgery. 


\section{References}

1. Buchwald H, Avidor Y, Braunwald E, Jensen MD, Pories W, Fahrbach K, Schoelles K. Bariatric surgery: a systematic review and meta-analysis. Jama 2004;292:1724-37.

2. Cottam DR, Mattar SG, Barinas-Mitchell E, Eid G, Kuller L, Kelley DE, Schauer PR. The chronic inflammatory hypothesis for the morbidity associated with morbid obesity: implications and effects of weight loss. Obes Surg 2004;14:589-600.

3. Hundal RS, Petersen KF, Mayerson AB, Randhawa PS, Inzucchi S, Shoelson SE, Shulman GI. Mechanism by which high-dose aspirin improves glucose metabolism in type 2 diabetes. J Clin Invest 2002;109:1321-6.

4. Yuan M, Konstantopoulos N, Lee J, Hansen L, Li ZW, Karin M, Shoelson SE. Reversal of obesity- and diet-induced insulin resistance with salicylates or targeted disruption of Ikkbeta. Science 2001;293:1673-7.

5. van Dielen FM, Buurman WA, Hadfoune M, Nijhuis J, Greve JW. Macrophage inhibitory factor, plasminogen activator inhibitor-1, other acute phase proteins, and inflammatory mediators normalize as a result of weight loss in morbidly obese subjects treated with gastric restrictive surgery. J Clin Endocrinol Metab 2004;89:4062-8.

6. Hansen EN, Torquati A, Abumrad NN. Results of bariatric surgery. Annu Rev Nutr 2006; 26:481-511.

7. Shen SW, Reaven GM, Farquhar JW. Comparison of impedance to insulin-mediated glucose uptake in normal subjects and in subjects with latent diabetes. J Clin Invest 1970;49:2151-60.

8. Reaven GM, Olefsky JM. Relationship between heterogeneity of insulin responses and insulin resistance in normal subjects and patients with chemical diabetes. Diabetologia 1977; 13:201-6.

9. Pei D, Jones CN, Bhargava R, Chen YD, Reaven GM. Evaluation of octreotide to assess insulin-mediated glucose disposal by the insulin suppression test. Diabetologia 1994;37:843-5.

10. Yeni-Komshian H, Carantoni M, Abbasi F, Reaven GM. Relationship between several surrogate estimates of insulin resistance and quantification of insulin-mediated glucose disposal in 490 healthy nondiabetic volunteers. Diabetes Care 2000;23:171-5.

11. Nijhuis J, van Dielen FM, Schaper NC, Wiebolt J, Koks A, Prakken FJ, Rensen SS, Buurman WA, Greve JW. Short-term Overfeeding Induces Insulin Resistance in Weight-stable Patients After Bariatric Surgery. Obes Surg 2008.

12. Allende LM, Corell A, Manzanares J, Madruga D, Marcos A, Madrono A, Lopez-Goyanes A, Garcia-Perez MA, Moreno JM, Rodrigo M, Sanz F, Arnaiz-Villena A. Immunodeficiency associated with anorexia nervosa is secondary and improves after refeeding. Immunology 1998;94:543-51.

13. Nakai $Y$, Hamagaki S, Takagi R, Taniguchi A, Kurimoto F. Plasma concentrations of tumor necrosis factor-alpha (TNF-alpha) and soluble TNF receptors in patients with anorexia nervosa. J Clin Endocrinol Metab 1999;84:1226-8.

14. Muscelli E, Mingrone G, Camastra S, Manco M, Pereira JA, Pareja JC, Ferrannini E. Differential effect of weight loss on insulin resistance in surgically treated obese patients. Am J Med 2005;118:51-7.

15. Guidone C, Manco M, Valera-Mora E, laconelli A, Gniuli D, Mari A, Nanni G, Castagneto M, Calvani M, Mingrone G. Mechanisms of recovery from type 2 diabetes after malabsorptive bariatric surgery. Diabetes 2006;55:2025-31.

16. Johnson W, DeMaria E. Surgical treatment of obesity. Curr Treat Options Gastroenterol 2006;9:167-74.

17. Patriti A, Facchiano E, Sanna A, Gulla N, Donini A. The enteroinsular axis and the recovery from type 2 diabetes after bariatric surgery. Obes Surg 2004;14:840-8.

18. Vilsboll T, Holst JJ. Incretins, insulin secretion and Type 2 diabetes mellitus. Diabetologia 2004;47:357-66. 
19. Jensen MD, Haymond MW, Gerich JE, Cryer PE, Miles JM. Lipolysis during fasting. Decreased suppression by insulin and increased stimulation by epinephrine. J Clin Invest 1987;79:207-13.

20. Buijs MM, Burggraaf J, Wijbrandts $C$, de Kam ML, Frolich M, Cohen AF, Romijn JA, Sauerwein HP, Meinders AE, Pijl H. Blunted lipolytic response to fasting in abdominally obese women: evidence for involvement of hyposomatotropism. Am $\mathrm{J}$ Clin Nutr 2003;77:544-50. 
${ }_{1004} 1$ 


\section{Chapter 8}

Short term overfeeding induces insulin resistance in weight stable patients after bariatric surgery

Jeroen Nijhuis, Francois M.H. van Dielen, Nicolaas C. Schaper, Janneke Wiebolt, Afra Koks, Fred. J. Prakken, Sander S.M. Rensen, Wim A. Buurman, Jan Willem M. Greve

Obes Surg. 2008;18:300-5. 


\section{Abstract}

\section{Background}

Short time overfeeding of rats rapidly leads to insulin resistance (IR). A study with healthy human volunteers, which we suggest are less susceptible for developing IR after short time overfeeding, did not show these effects on IR. Therefore a study population of weight stable, formerly morbidly obese subjects (body mass index (BMI) $31.3 \mathrm{~kg} / \mathrm{m}^{2}$ ), which were treated with bariatric surgery approximately three years ago was selected.

\section{Methods}

Eleven subjects were submitted to a seven days overfeeding study, resulting in a $53 \%$ increase in caloric intake $(1227 \pm 394.4$ to $1879.2 \pm 298.4 \mathrm{kCal} /$ day). During normal diet and after overfeeding, insulin sensitivity was measured using steady state plasma glucose (SSPG) levels. At these time points, BMI and waist/hip ratio together with plasma levels of inflammatory markers (C-reactive protein (CRP), alpha-1 acid glycoprotein (AGP), lipopolysaccharide binding protein (LBP) and tumor necrosis factor alpha (TNF- $\alpha$ ) receptors) and plasma leptin values were also measured.

\section{Results}

SSPG levels after overfeeding increased from $8.2 \pm 3.2$ to $10.6 \pm 2.6 \mathrm{mmol} / \mathrm{l}(p<0.05)$, indicating decreased insulin sensitivity after overfeeding. Fasting plasma insulin, glucose, circulating levels of inflammatory markers as well as BMI and waist/hip ratio remained unchanged.

\section{Conclusion}

This study shows that overfeeding in a group of weight stable formerly morbidly obese subjects three years after bariatric surgery results in decreased insulin sensitivity. The mechanisms behind decreased insulin sensitivity induced by overfeeding are poorly understood, but the present results reveal that a unique human model is available to study these mechanisms, leading to a better understanding of the pathophysiology of IR. 


\section{Introduction}

The mechanisms that underlie insulin resistance in morbid obesity are in part unraveled. Increased fat mass and accumulation of fat in organs pivotal to glucose metabolism are thought to play a role. Moreover, the low-grade inflammatory condition associated with morbid obesity is also considered to be central to the pathophysiology of insulin resistance in morbid obesity ${ }^{1}$.

Recently increased food intake accompanying morbid obesity is considered to be involved. Rats subjected to an overfeeding diet were shown to develop insulin resistance within seven days ${ }^{2}$. However, a study with human volunteers failed to show this effect of overfeeding on insulin sensitivity ${ }^{3}$. Selection of the study population could be the cause of the discrepancy between these studies. The population selected consisted of physically active healthy men with a mean BMI of $21.5 \mathrm{~kg} / \mathrm{m}^{2}$. We considered that such normal weight subjects have sufficient buffer capacity to cope with increased food intake.

Therefore, to investigate the effect of overfeeding on insulin sensitivity, a study population was selected consisting of former morbidly obese patients treated with bariatric surgery. These weight stable subjects are still mildly obese and had developed insulin resistance in the past, while being morbidly obese, which subsided after surgery ${ }^{4}$.

\section{Research design and methods}

Eleven consecutive subjects were included, two males and nine females. These subjects were on average 3.4 years after their surgical treatment for morbid obesity. Nine patients underwent vertical banded gastroplasty and two patients received a Lap-Band, both gastric restrictive procedures. At the moment of the experiment, all subjects had reached a stable body weigh for at least one year. The subjects were healthy according to history, clinical examination and routine laboratory tests. In particular none of the studied subjects had evidence of diabetes mellitus or inflammatory disease or were taking medication known to influence glucose metabolism. Characteristics of the study population are presented in Table 8.1. The study was approved by the ethical committee of the University Hospital Maastricht, the Netherlands. All subjects gave written informed consent. 
Table 8.1 Characteristics and physiological parameters of the subjects during normal diet and after the overfeeding experiment.

\begin{tabular}{lccc}
\hline Variables & $\begin{array}{c}\text { Normal diet } \\
\mathrm{n}=11\end{array}$ & $\begin{array}{c}\text { After overfeeding } \\
\mathrm{n}=11\end{array}$ & $P$-value \\
\hline Sex (female/male) & $9 / 2$ & & \\
Age $(\mathrm{yr})$ & $39 \pm 18.5$ & & \\
Weight $(\mathrm{kg})$ & $89.0 \pm 18.9$ & $89.8 \pm 19.5$ & $\mathrm{NS}^{*}$ \\
$\mathrm{BMI}\left(\mathrm{kg} / \mathrm{m}^{2}\right)$ & $31.3 \pm 4.9$ & $31.5 \pm 5.1$ & $\mathrm{NS}$ \\
Waist/hip ratio & $0.9 \pm 0.1$ & $0.9 \pm 0.1$ & $\mathrm{NS}$ \\
$\%$ EWL & $70 \pm 13.8$ & & \\
Weight loss $(\mathrm{kg})$ & $47 \pm 6.7$ & & \\
Fasting glucose (mmol/l) & $5.5 \pm 0.6$ & $5.5 \pm 0.6$ & $\mathrm{NS}$ \\
Fasting insulin (mU/l) & $4.5 \pm 2.9$ & $4.7 \pm 1.1$ & $\mathrm{NS}$ \\
HOMA-IR & $1.11 \pm 0.55$ & $1.14 \pm 0.30$ & $\mathrm{NS}$ \\
Days after surgery & $1228 \pm 394$ & & \\
Energy intake (kcal/day) & $1227 \pm 394.4$ & $1879.2 \pm 298.4$ & $p=0.005$ \\
Carbohydrate intake (grams/day) & $134.0 \pm 32.3$ & $214 \pm 32.9$ & $p=0.005$ \\
Mean arterial pressure $(\mathrm{mmHg})$ & $92.5 \pm 12.9$ & $93.0 \pm 9.9$ & $\mathrm{NS}$ \\
\hline
\end{tabular}

* Not Significant

\section{Steady State Plasma Glucose (SSPG) measurement}

Insulin sensitivity was determined by using SSPG levels, described by Reaven et al. ${ }^{5,6}$ This insulin suppression test determines a SSPG concentration as a measure for insulin mediated glucose uptake and highly correlates $(r>0.90)$ with the golden standard, the hyperinsulinemic euglycaemic clamp technique. In short after a 12-hour overnight fast, body weight and body height were measured. Subjects were studied supine in a hospital bed. Catheters were placed in both antecubital veins to enable infusion of glucose, insulin and octreotide as well as venous blood sampling. During an acclimatisation period of thirty minutes an automatic blood pressure measurement (Dinamap, Criticon Inc., Tampa, Fl) was performed. Octreotide (Sandostatin, kindly provided by Novartis Pharma B.V. Arnhem, the Netherlands), a somatostatin analogue, was administered intravenously by using a syringe infusion pump (Treonic IP4, Vickers Medical, England) at $5.0 \mu \mathrm{g} / \mathrm{min}$, preceded by a bolus of $25 \mu \mathrm{g}$. A higher infusion rate was used than described by Pei and Reaven ${ }^{7}$. In both the measurements during normal diet and measurements after overfeeding equal octreotide concentrations were used, decreasing the risk of confounding due to high octreotide plasma concentrations. Insulin (Actrapid, Novo-Nordisk, Bagsærd, Denmark) was infused at a rate of $25 \mathrm{mU} / \mathrm{m}^{2} / \mathrm{min}$ by a second syringe pump. Glucose was infused via a volumetric pump (IVAC 591, IVAC Corporation, San Diego, CA) at $240 \mathrm{mU} / \mathrm{m}^{2} / \mathrm{min}$. Before the test as well as on different time points during the test venous blood samples were taken. The mean plasma level of glucose at 150,160, 170 and 180 minutes was defined as SSPG level. 
Plasma glucose was determined by a glucose oxidase method (YSI model 2300 Stat, Yellow Springs Industries, Yellow Springs, OH). Blood samples for determining inflammatory mediators and insulin were immediately put on melting ice and plasma was prepared by centrifugation at $1,400 \mathrm{~g}$ for ten minutes at $4^{\circ} \mathrm{C}$. The plasma was spun again at $2,700 \mathrm{~g}$ for ten minutes at $4^{\circ} \mathrm{C}$ and recovered plasma was stored in aliquots at $-80^{\circ} \mathrm{C}$ until measurement.

\section{Study protocols}

All subjects were studied twice. Six subjects were studied while on their normal diet after gastric restrictive surgery and subsequently after one week of additional feeding. In the other five subjects the inverse sequence was used. To minimize the effects of the first SSPG test on the second, the mean interval between the two tests was 18 days (range 13-24 days).

The feeding supplement consisted of three packets daily of $200 \mathrm{ml}$ liquid nourishment (Resource Energy Drink by Novartis Nutrition, the Netherlands), with a total energy content of $900 \mathrm{kcal}$ containing $113 \mathrm{gram}$ carbohydrates and 35 gram fat per day.

In the week before the SSPG test, subjects were requested to keep a three day food-intake diary (registration was performed a one, three and five days before the test) to calculate total energy intake during additional feeding and during their habitual diet. Participant received detailed written and oral instructions on how to fill in the diaries. They were also asked to take the supplement between their usual meals in order to reduce satiety effects and to return all empty packets, in order to evaluate the amount of extra feeding consumed. The nutrient intake from food records were analyzed by using international food composition tables.

\section{Reagents, materials and assays}

Plasma concentrations of soluble TNF- $\alpha$ receptors, leptin, lipopolysaccharid binding protein (LBP), C-reactive protein (CRP), $\alpha_{1}$-acid glycoprotein (AGP) and insulin concentrations were measured using sandwich ELISA's. TNF- $\alpha$ receptors (55 and 75), leptin, LBP, CRP and AGP were measured as described elsewhere $^{8}$. Plasma insulin concentrations were measured using a commercially available ELISA (Mercodia AB, Uppsala, Sweden).

All plasma samples were measured in the same run, except for plasma insulin concentrations. When plasma concentrations exceeded the upper detection limit of the assay, samples were additionally diluted and analyzed in a separate run with an overlap. The intra- and inter-assay coefficients of variance of the assays were smaller than $10 \%$. 


\section{Statistical analysis}

Data were expressed as mean \pm standard deviation. The Wilcoxon sign-rank test was used to analyse differences. A p-value of less than 0.05 was denoted as statistically significant.

\section{Results}

\section{$\mathrm{BMI}$ and metabolic parameters of the study group}

The preoperative BMI of the study population was $47.4 \pm 6.4 \mathrm{~kg} / \mathrm{m}^{2}$. At the time of the overfeeding experiment, at approximately three years after bariatric surgery, patients had reached a BMI of $31.3 \pm 4.9 \mathrm{~kg} / \mathrm{m}^{2}(70 \%$ excess body weight loss $(E W L))$. Fasting plasma glucose and insulin levels were within the normal range and did not change after overfeeding. In the year before the overfeeding experiment the weight remained stable. Interestingly, the short period of overfeeding did not lead to a change in body weight or waist-hip ratio.

\section{Effect of additional feeding on insulin sensitivity in weight stable patients treated with restrictive bariatric surgery}

As shown in Table 8.1, overfeeding led to a $53 \%$ increase in daily calorie intake and a $59 \%$ increase in carbohydrate intake (both $p=0.005$ ). As assessed by food records, this additional feeding did not lead to changes in other dietary habits (food as well as liquid intake) in the period of extra food intake.

Figure 8.1. shows steady state plasma insulin (SSPI) levels and SSPG levels during normal diet and after overfeeding. Because, SSPI levels were not different between the two conditions, SSPG levels could be compared during normal diet and after overfeeding. The mean SSPG concentration during normal diet was $8.2 \pm 3.2 \mathrm{mmol} / \mathrm{l}$. SSPG concentrations were significantly higher following a period of overfeeding $(10.6 \pm 2.6 \mathrm{mmol} / \mathrm{l}, \mathrm{p}<0.05)$. These data clearly show that insulin sensitivity is reduced by high caloric intake. SSPG levels increased after overfeeding, both in the group subjected to measurements after overfeeding as well as in the group subjected to measurements before the overfeeding. This implies that the effect of overfeeding on insulin sensitivity is rapidly lost after a short washout period.

Interestingly, HOMA-IR, a surrogate marker for insulin sensitivity, remained unchanged after overfeeding.

Analysis of plasma levels of leptin and other inflammatory mediators revealed that overfeeding for seven days did not affect these parameters (Table 8.2). 
A

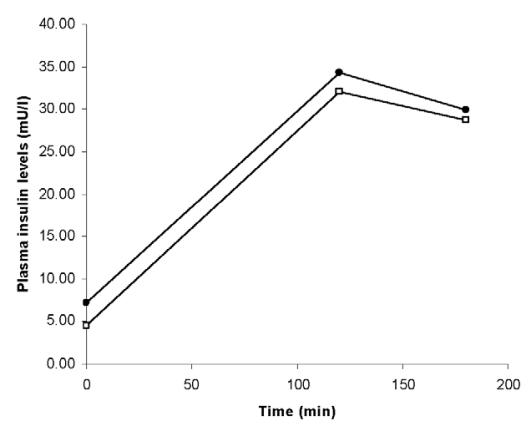

B

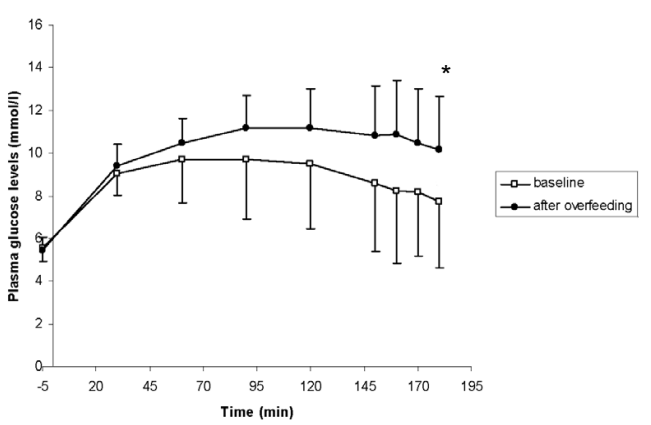

Figure 8.1 SSPI and SSPG levels during the experiment.

Due to similar SSPI levels (Figure 8.1A), SSPG values of both conditions can be compared. During normal diet the SSPG values (figure $1 \mathrm{~b}$ ) are significantly lower $\left({ }^{*}: P<0.05\right)$ than after overfeeding $(8.2 \pm 3.2$ vs. $10.6 \pm 2.6 \mathrm{mmol} / \mathrm{l})$, indicating that overfeeding results in decreased insulin sensitivity.

Table 8.2 Levels of inflammatory mediators at $\mathrm{t}=0$ during the SSPG test of both study groups.

\begin{tabular}{lccl}
\hline Variables & $\begin{array}{c}\text { Normal diet } \\
\mathrm{n}=11\end{array}$ & $\begin{array}{c}\text { After overfeeding } \\
\mathrm{n}=11\end{array}$ & $P$-value \\
\hline Leptin $(\mathrm{ng} / \mathrm{ml})$ & $15.7 \pm 16.3$ & $18.3 \pm 17.6$ & $\mathrm{NS}^{*}$ \\
CRP $(\mu \mathrm{g} / \mathrm{ml})$ & $2.3 \pm 2.2$ & $1.9 \pm 1.3$ & $\mathrm{NS}$ \\
AGP $(\mathrm{ng} / \mathrm{ml})$ & $10.5 \pm 8.1$ & $8.5 \pm 7.9$ & $\mathrm{NS}$ \\
LBP $(\mu \mathrm{g} / \mathrm{ml})$ & $12.7 \pm 5.2$ & $15.6 \pm 4.4$ & $\mathrm{NS}$ \\
Soluble TNFR55 $(\mathrm{ng} / \mathrm{ml})$ & $0.72 \pm 0.27$ & $0.58 \pm 0.21$ & $\mathrm{NS}$ \\
Soluble TNFR75 $(\mathrm{ng} / \mathrm{ml})$ & $1.26 \pm 0.66$ & $0.98 \pm 0.66$ & $\mathrm{NS}$ \\
\hline
\end{tabular}

* Not Significant. Despite decreased insulin sensitivity, inflammatory mediators remained unchanged.

\section{Discussion}

The influence of additional carbohydrate intake (total energy intake of $900 \mathrm{kcal}$ per day) on insulin resistance using SSPG level measurement was assessed in weight stable patients, 1.5-4.5 years after gastric restrictive surgery. Insulin sensitivity decreased significantly after one week of additional feeding. The additional feeding led to a $59 \%$ increase in carbohydrate intake, without affecting fasting plasma glucose levels and circulating inflammatory mediators. In addition, no major changes in body weight were observed showing that increased caloric intake has a strong influence on insulin sensitivity in the population of morbidly obese subjects who have lost a significant amount of weight. These findings emphasize that bariatric surgery should not be considered a temporary intervention but should be implemented life long. A 
similar study, which shows increased insulin resistance after a two week overfeeding regimen, has been performed in Pima Indians ${ }^{9}$. The interesting finding in our study is that, unlike the study in Pima Indians, insulin sensitivity is decreased without weight gain. This shifts the attention towards the effects of macronutrient intake on insulin sensitivity, and provides for an unique model to study the effects of macronutrient intake on insulin sensitivity, without the confounding effect of weight gain.

Although SSPG levels showed that insulin sensitivity decreased, HOMA-IR failed to show this effect. In this respect our study also differs from the study in Pima Indians in which fasting insulin levels increased. Unpublished data from our group revealed that this discrepancy between SSPG levels and HOMA-IR values also occurred during the first month after bariatric surgery, where SSPG data clearly shows that insulin sensitivity is not decreased, whereas HOMA-IR improved significantly. Metabolic stress either due to fasting or a caloric challenge is a common feature in both conditions, which raises the question if HOMA-IR as a surrogate marker for insulin sensitivity can be used during periods of metabolic stress. These findings also give rise to the hypothesis that observed differences between HOMA-IR and SSPG can be accounted for by the storage capacity of the liver for macronutrients. During the first stage of overfeeding macronutrients are stored in skeletal muscle and adipose tissue. As a result peripheral insulin sensitivity as measured by SSPG or hyperinsulinemic euglycemic clamp techniques decreases. Skeletal muscle cells and adipocytes can still cope with the surplus of macronutrients in the first week of overfeeding and therefore the liver is relatively spared during the first week of massive overfeeding leading to normal fasting insulin and glucose plasma levels.

Several mechanisms have been proposed to underlie insulin sensitivity in obese individuals. Currently, research mainly focuses on increased fat mass and accompanying changes in adipocytokine secretion and inflammation. Interestingly, induction of insulin resistance by overfeeding did not result in increased plasma levels of acute phase proteins and the TNF- $\alpha$ receptors showing that insulin sensitivity can decrease without overt changes in inflammatory parameters, normally closely correlated to insulin resistance. The results of the present study show that, in the absence of inflammation, increased nutrient intake (caloric challenge) could also play a role in the pathophysiology of obesity induced insulin resistance. One of the processes thought to play a major role in overfeeding induced insulin resistance is oxidative stress. Recently it was reported that a single glucose and fat challenge can induce oxidative stress in $\operatorname{man}^{10-12}$. In line, oxidative stress has recently been shown to be a causative factor in the pathophysiology of insulin resistance $^{13}$. 
Recently also ER-stress and the unfolded protein response have been linked to IR and obesity. Obesity is thought to increase the metabolic workload for cells resulting in accumulation of reactive oxygen species and intermediary metabolites, which activate the unfolded protein response ${ }^{14,15}$. Activation of the serine kinase c-Jun aminoterminal kinase (JNK1) induced by ER-stress suppresses insulin signaling ${ }^{16}$. Although it has been shown that obesity and oxidative stress can lead to ER stress no studies have shown a direct effect of overfeeding on ER stress, therefore studies are needed to unravel the role of ER stress in overfeeding induced insulin resistance.

Plasma levels of the satiety hormone leptin also remained unchanged, whereas reported data shows increased levels of leptin after overfeeding ${ }^{2,17}$. Leptin acts as an adipostat and although the study population substantially increases its caloric intake the total amount of calories is still below average $(1879 \mathrm{kCal} /$ day $)$, which consequently does not lead to a rise in plasma leptin levels.

Interestingly, the present study and the study in Pima indians ${ }^{9}$ shows decreased insulin sensitivity after overfeeding, while an overfeeding study in normal weight, physically active, healthy controls did not result in insulin resistance $^{3}$. A reason for this difference could be the genetic background and/or metabolic alterations of the study population. For the present study former morbidly obese individuals in the stable weight phase after bariatric surgery were included. This population was known to suffer from insulin resistance before surgery, which was significantly improved at the time stable weight was achieved ${ }^{18}$. Compared to normal weight healthy controls this population could be metabolically altered, possibly under genetic control, during the process of becoming morbidly obese, resulting in an altered response to overfeeding. Moreover, this population is still obese and therefore has an increased risk of developing insulin resistance. In order to clarify the difference between the response to overfeeding in both groups, further studies are needed.

In conclusion, the present study shows that increased food intake (caloric challenge) in the stable weight phase after bariatric surgery leads to decreased insulin sensitivity without weight gain. This implies that a unique human model is available to study mechanisms behind insulin resistance induced by overfeeding without the confounding effect of weight gain. 


\section{References}

1. Cottam DR, Mattar SG, Barinas-Mitchell E, Eid G, Kuller L, Kelley DE, Schauer PR. The chronic inflammatory hypothesis for the morbidity associated with morbid obesity: implications and effects of weight loss. Obes Surg 2004;14:589-600.

2. Wang J, Obici S, Morgan K, Barzilai N, Feng Z, Rossetti L. Overfeeding rapidly induces leptin and insulin resistance. Diabetes 2001;50:2786-91.

3. Ohannesian JP, Marco CC, Najm PS, Goldstein BJ, Caro JF, Kolaczynski JW. Small weight gain is not associated with development of insulin resistance in healthy, physically active individuals. Horm Metab Res 1999;31:323-5.

4. Guidone C, Manco M, Valera-Mora E, laconelli A, Gniuli D, Mari A, Nanni G, Castagneto M, Calvani M, Mingrone G. Mechanisms of recovery from type 2 diabetes after malabsorptive bariatric surgery. Diabetes 2006;55:2025-31.

5. Reaven GM, Silvers A, Farquhar JW. Study of the relationship between plasma insulin concentration and efficiency of glucose uptake in normal and mildly diabetic subjects. Diabetes 1970;19:571-8.

6. Shen SW, Reaven GM, Farquhar JW. Comparison of impedance to insulin-mediated glucose uptake in normal subjects and in subjects with latent diabetes. J Clin Invest 1970;49:2151-60.

7. Pei D, Jones CN, Bhargava R, Chen YD, Reaven GM. Evaluation of octreotide to assess insulin-mediated glucose disposal by the insulin suppression test. Diabetologia 1994;37: 843-5.

8. van Dielen FM, Buurman WA, Hadfoune M, Nijhuis J, Greve JW. Macrophage inhibitory factor, plasminogen activator inhibitor-1, other acute phase proteins, and inflammatory mediators normalize as a result of weight loss in morbidly obese subjects treated with gastric restrictive surgery. J Clin Endocrinol Metab 2004;89:4062-8.

9. Mott DM, Lillioja S, Bogardus C. Overnutrition induced decrease in insulin action for glucose storage: in vivo and in vitro in man. Metabolism 1986;35:160-5.

10. Dhindsa S, Tripathy D, Mohanty P, Ghanim H, Syed T, Aljada A, Dandona P. Differential effects of glucose and alcohol on reactive oxygen species generation and intranuclear nuclear factor-kappaB in mononuclear cells. Metabolism 2004;53:330-4.

11. Mohanty P, Hamouda W, Garg R, Aljada A, Ghanim H, Dandona P. Glucose challenge stimulates reactive oxygen species (ROS) generation by leucocytes. J Clin Endocrinol Metab 2000;85:2970-3.

12. Mohanty P, Ghanim H, Hamouda W, Aljada A, Garg R, Dandona P. Both lipid and protein intakes stimulate increased generation of reactive oxygen species by polymorphonuclear leukocytes and mononuclear cells. Am J Clin Nutr 2002;75:767-72.

13. Houstis N, Rosen ED, Lander ES. Reactive oxygen species have a causal role in multiple forms of insulin resistance. Nature 2006;440:944-8.

14. Rutkowski DT, Kaufman RJ. A trip to the ER: coping with stress. Trends Cell Biol 2004; 14:20-8.

15. Harding HP, Zhang Y, Zeng H, Novoa I, Lu PD, Calfon M, Sadri N, Yun C, Popko B, Paules R, Stojdl DF, Bell JC, Hettmann T, Leiden JM, Ron D. An integrated stress response regulates amino acid metabolism and resistance to oxidative stress. Mol Cell 2003;11:619-33.

16. Ozcan U, Cao Q, Yilmaz E, Lee AH, Iwakoshi NN, Ozdelen E, Tuncman G, Gorgun C, Glimcher LH, Hotamisligil GS. Endoplasmic reticulum stress links obesity, insulin action, and type 2 diabetes. Science 2004;306:457-61.

17. Chin-Chance C, Polonsky KS, Schoeller DA. Twenty-four-hour leptin levels respond to cumulative short-term energy imbalance and predict subsequent intake. J Clin Endocrinol Metab 2000;85:2685-91.

18. Hansen EN, Torquati A, Abumrad NN. Results of bariatric surgery. Annu Rev Nutr 2006; 26:481-511. 


\section{Chapter 9}

Discussion and summary 
116 Chapter 9 


\section{Mechanisms by which bariatric surgery increases insulin sensitivity}

Bariatric surgery has been shown to be an effective treatment option for morbid obesity and its co-morbidities, as insulin resistance ${ }^{1}$. Possible mechanisms by which bariatric surgery increases insulin sensitivity were reviewed in Chapter 2. The first part of this review discussed the theories regarding the effect of bariatric surgery on incretin secretion. As is generally recognized, bariatric malabsorptive surgery causes anatomical changes of the alimentary tract. These changes are thought to alter plasma incretin levels and consequently affect insulin secretion and action. Several authors describe a mechanism by which plasma incretin levels could alter after malabsorptive surgery. Increased amounts of unprocessed nutrients in the ileum could result in increased glucagon like protein-1 (GLP-1) plasma levels and increased insulin secretion ${ }^{2,3}$. The effect of bariatric surgery on guthormones can not solely explain the effect on insulin resistance. In literature bariatric surgery is also reported to lead to decreased nutrient intake causing reduction of fat mass and intracellular load of fat metabolites. In this context, from data described in the literature on the effect of these metabolic and behavioral changes induced by bariatric surgery, several mechanisms by which bariatric surgery could increase insulin sensitivity and inflammation were proposed.

First, decreased nutrient intake is thought to lead to a reduced formation of reactive oxygen species (ROS), which are considered to be a causal factor in the pathophysiology of insulin resistance ${ }^{4}$. Moreover, it was suggested that reduced fat mass paralleling weight loss could result in alterations of circulating adipokine levels as well as less macrophage accumulation in adipose tissue. This and the proposed reduced formation of ROS might result in lower circulating levels of prodiabetogenic factors, like tumor necrosis factor alpha (TNF- $\alpha$ ) and interleukin-6 (IL-6), as well as in enhanced plasma levels of the insulin sensitizing hormone adiponectin ${ }^{5}$. Finally, it was hypothesized that bariatric surgery could also result in enhanced $\beta$-cell functioning by reducing lipid accumulation in the pancreas. In addition, the decreased accumulation of lipids in myocytes and hepatocytes is reported to result in improved intracellular insulin signaling in these tissues ${ }^{6}$.

Based on the review, the effect of bariatric surgery on the resolution of insulin resistance can best be explained by the anatomical changes leading to alterations in incretin levels and weight loss leading to decreased fat mass as well as intracellular lipid accumulation. 


\section{Experimental and clinical studies}

The remaining chapters of this thesis concerned studies in morbidly obese patients which were treated or had been treated with bariatric surgery, applying different topics in bariatric surgery. With regard to weight loss, surgical techniques which bypass a part of the gastrointestinal tract for digestion are superior ${ }^{1}$.

Next to malabsorption, postoperative plasma levels of satiety hormones may play a role in their effectiveness. Circulating levels of the orexigenic hormone ghreline are reported to decrease after gastric bypass surgery ${ }^{7}$. In Chapter 3 , circulating levels of ghrelin and plasma levels of the satiety hormones leptin and insulin were evaluated after restrictive bariatric surgery in a two year follow-up study. Plasma ghrelin levels increased after vertical banded gastroplasty (VBG) or gastric banding surgery, whereas circulating insulin and leptin concentrations decreased. Gastric bypass was reported to result in lower plasma insulin and leptin levels and decreased plasma ghreline levels ${ }^{7,8}$. This led to the hypothesis, that differences in postoperative circulating ghrelin levels partly clarify the superior effect of gastric bypass surgery.

The satiety hormone leptin was studied in Chapter 4 in the context of the immune system. From reported data on the immunoregulatory role of leptin, it was deduced that low circulating leptin concentrations might lead to abnormal responses of the immune system. Directly after bariatric surgery, morbidly obese patients are in a fasting state, suggestive for lower plasma leptin levels. Therefore, plasma levels of leptin during the first days after restrictive bariatric surgery were measured, presented and discussed. While even in morbidly obese patients leptin and body mass index (BMI) are closely correlated, circulating leptin levels strongly decreased in the first days after bariatric surgery, whereas the BMI did not change. Assuming that leptin has an immunoregulatory role it was hypothesized that such substantially decreased plasma leptin levels could explain the increased postoperative complication rate described after bariatric surgery.

Further studies are necessary to elucidate this hypothesis.

In the next chapters of this thesis, the inflammatory aspect of morbid obesity was studied. Recently, increased plasma levels of acute phase proteins (Creactive protein (CRP), alpha-1 acid glycoprotein (AGP) and lipopolysaccharide binding protein (LBP)) and cytokine receptors were reported in morbid obesity ${ }^{9}$. These observations imply activation of the innate immune response in morbid obesity. The low-grade inflammatory condition was further characterized in Chapters 5 and 6. 
Circulating levels of endothelial activation markers as well as plasma levels of regulators of endothelial activation were subject of study in Chapter 5. Moreover, the effect of bariatric surgery on these inflammatory parameters was evaluated. Compared to healthy normal weight individuals, increased plasma levels of endothelial activation markers soluble endothelial selectin (sEselectin), soluble vascular cell adhesion molecule-1 (sVCAM-1) and soluble intercellular adhesion molecule-1 (sICAM-1) were found in morbidly obese patients. In addition, circulating resistin levels were increased, whereas adiponectin levels were decreased. Resistin is known to activate endothelial cells, while adiponectin is reported to down regulate endothelial activation ${ }^{10}$. These results show activation of endothelial cells in morbidly obese individuals. Bariatric surgery resulted in substantially decreased levels of the endothelial activation markers SICAM-1 and sE-selectin and increased plasma adiponectin at 12-24 months after surgery. Interestingly, resistin and sVCAM-1 levels remained elevated. A possible explanation for the latter observation may be the fact that the subjects in our study were still obese, even at 24 months after gastric restrictive surgery (mean BMI of $34.7 \mathrm{~kg} / \mathrm{m}^{2}$ ).

During the first six months after bariatric surgery, plasma sICAM-1 and sVCAM-1 concentrations remained unchanged, while sE-selectin levels decreased significantly. This suggests that endothelial cells remain activated, although the effects of weight loss are already reflected in sE-selectin levels. This is in line with previous reports, showing an ongoing inflammatory state during the first months after bariatric surgery, which was explained by metabolic stress caused by a severe catabolic state, brought about by substantial weight loss $^{9}$. This assumption is supported by the observation that anorexia nervosa patients are also characterized by a low-grade inflammatory condition, which improves after refeeding these patients ${ }^{11}$. In this respect it is also noteworthy that, similar to the inflammatory markers studied in this thesis, there are marked differences with respect to the degree of normalization of inflammatory mediators during the first months after surgery reported in other studies. PAI-1 and AGP levels decrease rapidly, whereas LBP and CRP levels, remain elevated ${ }^{9}$. These findings suggest that there is no single mechanism by which weight loss leads to decreased endothelial activation and inflammation, although parallel mechanisms may operate in both processes.

Neutrophils are also a major cellular component of the innate immune system. Therefore neutrophil activation in morbidly obese patients as well as the effect of bariatric surgery on circulating neutrophil activation markers was studied (Chapter 6). Plasma levels of the neutrophil activation markers myeloperoxidase (MPO) and calprotectin were measured preoperative and two years postoperative. MPO and calprotectin plasma levels were increased as compared to normal weight healthy controls. The increased levels of MPO and 
calprotectin indicate neutrophil activation in morbidly obese patients. However, MPO and calprotectin production from monocytes could not be excluded. Monocytes have been shown to be activated in morbidly obese individuals and could therefore contribute to increased plasma levels of MPO and calprotectin. Therefore, the fraction of circulating neutrophils with enhanced CD66b expression, a specific marker of neutrophil activation, was compared between morbidly obese and normal weight control subjects ${ }^{12,13}$. Fluorescent flowcytometry revealed that CD66b expression of neutrophils was increased in morbid obesity.

Decreased plasma levels of calprotectin were found two years after bariatric surgery, whereas circulating MPO levels remained unchanged. As mentioned before, the obese condition of these patients might explain the unchanged plasma levels some inflammatory parameters, like MPO, after bariatric surgery. The results from chapter 5 and 6 lead to the hypothesis that the low-grade inflammatory condition is characterized by activation of the innate immune response. Interestingly, the innate immune response is an acute response, whereas morbid obesity is a chronic disease. It is therefore concluded, that morbid obesity is associated with chronic stimulation of an acute inflammatory response.

As mentioned previously, the low-grade inflammatory condition does not decrease during the first months after surgery, despite substantial weight loss. Inflammation has been reported to be causally related to insulin resistance an important co-morbidity associated with morbid obesity ${ }^{5}$. Therefore, insulin sensitivity as well as the inflammatory condition were evaluated in the first months after restrictive bariatric surgery (Chapter 7 ). At the time point that $25 \%$ EWL was reached, insulin sensitivity was not improved, as quantified with SSPG levels. In line, inflammatory parameters were not decreased at this time point. Paradoxically, HOMA-IR values, calculated using fasting insulin and glucose plasma levels, suggested increased insulin sensitivity. This study points out that in the first months after restrictive bariatric surgery, despite substantial weight loss, insulin resistance does not improve and levels of most inflammatory mediators remained high. Interestingly, SSPG levels remained unchanged, while HOMA-IR decreased in the first months after bariatric surgery, questioning the scientific base for the use of HOMA-IR as a surrogate marker of insulin sensitivity during the first months after restrictive bariatric surgery.

Next to inflammation and oxidative stress, increased food intake is also thought to play a role in the pathophysiology of obesity induced insulin resistance. The detrimental effects of increased food intake on insulin sensitivity was shown in rats, which were subjected to a seven day overfeeding period, resulting in 
lower insulin sensitivity, a finding which is not supported by a human study ${ }^{14,15}$. The selection of study subjects in the latter study could be responsible for the discrepancy seen between both studies. Normal weight physical active healthy men were included in the human study. We considered that these subjects may have sufficient buffer capacity to cope with increased food intake. Therefore, a study population was selected with a history of high food intake and insulin resistance (Chapter 8 ). This population consisted of stable weight, mildly obese subjects who had lost weight from prior bariatric surgery (three years postoperatively). In this population a seven days overfeeding period resulted in decreased insulin sensitivity, showing that insulin resistance can be induced by overfeeding in specific groups. This implies that a unique human model is available to study mechanisms behind insulin resistance (IR) induced by overfeeding.

\section{Future directions}

In this thesis several hypothesis were tested, but more importantly studies presented in this thesis also generated new research questions. In this paragraph three questions are further discussed. The first question is how substantially decreased plasma leptin levels after bariatric surgery could explain the increased postoperative complication rate. A point of departure for future research might be the observation that leptin, produced by cells of the stomach, influence duodenal cholecystokinin (CCK) production as well as vagal afferent satiety signaling ${ }^{16}$. These findings broaden the perspective of leptin from a centrally acting satiety hormone to leptin as a peripheral paracrine hormone regulating satiety. Interestingly, oral administration of high fat nutrition is reported to inhibit inflammation in the splanchic area via increased CCK release, vagal CCK receptors and efferent vagal acetylcholine release, inhibiting activation of gut homing macrophages ${ }^{17}$. Hypothetically, also leptin could, via its receptors on the afferent vagal nerve, activate the efferent vagal nerve and inhibit macrophage activation. Therefore, the absence of food in the stomach after bariatric surgery and low circulating leptin levels could via CCK signaling lead to decreased inhibition of gut derived macrophages. This may possibly interfere with inflammatory processes needed for normal postoperative recovery of the bariatric patient, since these patients are thought to be more susceptible to develop postoperative complications ${ }^{18}$.

From the data of Chapter 5 and 6 the hypothesis was deduced that morbid obesity is associated with a continuous stimulation of an acute inflammatory response. Due to reported data showing activation of leucocytes after macronutrient intake it is thought that continuous overfeeding, which 
accompanies morbid obesity, could explain the chronic activation of the inflammatory response ${ }^{19}$. Future research should focus on this aspect. Measuring the activation state of circulating leucocytes using the overfeeding model described in Chapter 8 answers the question if this model also is suitable for studying overfeeding induced inflammation. However, according to Chapter 8 overfeeding for seven days does not lead to increased plasma levels of inflammatory proteins. Increasing the overfeeding period might provide information to explain this discrepancy.

Finally, a research question which should be addressed in the future is to elucidate the mechanisms behind insulin resistance induced by overfeeding as described in Chapter 8. Future studies focusing on oxidative and endoplasmatic reticulum (ER) stress should be performed, using the model described in Chapter 8. The assumption that oxidative stress might be involved in the pathophysiology of insulin resistance is based on a number of studies reporting increased oxidative stress in circulating leucocytes ${ }^{20,21}$ following increased ingestion of macronutrients. In addition, reported data show that oxidative stress plays a causal role in the pathophysiology of insulin resistance ${ }^{4}$. Besides oxidative stress, ER stress has also been associated in literature with obesity and insulin resistance. Obesity is thought to increase the metabolic workload for cells, resulting in accumulation of reactive oxygen species and intermediary metabolites, which activate the unfolded protein response. Therefore, it is not surprising, that obesity is shown to be accompanied by increased ER stress, which is reported to increase serine phosphorylation of the insulin receptor substrate-1 resulting in insulin resistance ${ }^{22}$.

\section{Conclusion}

This thesis shows that morbid obesity is a systemic disease characterized by a low-grade inflammatory condition and co-morbidities like insulin resistance. Sustained resolution of the inflammation and co-morbidities can only be achieved by bariatric surgery, which should not be considered a temporary intervention but has to be implemented live long. 


\section{References}

1. Buchwald H, Avidor $\mathrm{Y}$, Braunwald $\mathrm{E}$, Jensen MD, Pories W, Fahrbach K, Schoelles K. Bariatric surgery: a systematic review and meta-analysis. Jama 2004;292:1724-37.

2. Rubino F, Gagner M, Gentileschi P, Kini S, Fukuyama S, Feng J, Diamond E. The early effect of the Roux-en-Y gastric bypass on hormones involved in body weight regulation and glucose metabolism. Ann Surg 2004;240:236-42.

3. Valverde I, Puente J, Martin-Duce A, Molina L, Lozano O, Sancho V, Malaisse WJ, Villanueva-Penacarrillo ML. Changes in glucagon-like peptide-1 (GLP-1) secretion after biliopancreatic diversion or vertical banded gastroplasty in obese subjects. Obes Surg 2005; 15:387-97.

4. Houstis N, Rosen ED, Lander ES. Reactive oxygen species have a causal role in multiple forms of insulin resistance. Nature 2006;440:944-8.

5. Shoelson SE, Lee J, Goldfine AB. Inflammation and insulin resistance. J Clin Invest 2006; 116:1793-801.

6. Schaffer JE. Lipotoxicity: when tissues overeat. Curr Opin Lipidol 2003;14:281-7.

7. Cummings DE, Weigle DS, Frayo RS, Breen PA, Ma MK, Dellinger EP, Purnell JQ. Plasma ghrelin levels after diet-induced weight loss or gastric bypass surgery. N Engl J Med 2002; 346:1623-30.

8. Stoeckli R, Chanda R, Langer I, Keller U. Changes of body weight and plasma ghrelin levels after gastric banding and gastric bypass. Obes Res 2004;12:346-50.

9. van Dielen FM, Buurman WA, Hadfoune M, Nijhuis J, Greve JW. Macrophage inhibitory factor, plasminogen activator inhibitor-1, other acute phase proteins, and inflammatory mediators normalize as a result of weight loss in morbidly obese subjects treated with gastric restrictive surgery. J Clin Endocrinol Metab 2004;89:4062-8.

10. Kawanami D, Maemura K, Takeda N, Harada T, Nojiri T, Imai Y, Manabe I, Utsunomiya K, Nagai R. Direct reciprocal effects of resistin and adiponectin on vascular endothelial cells: a new insight into adipocytokine-endothelial cell interactions. Biochem Biophys Res Commun 2004;314:415-9.

11. Allende LM, Corell A, Manzanares J, Madruga D, Marcos A, Madrono A, Lopez-Goyanes A, Garcia-Perez MA, Moreno JM, Rodrigo M, Sanz F, Arnaiz-Villena A. Immunodeficiency associated with anorexia nervosa is secondary and improves after refeeding. Immunology 1998;94:543-51.

12. Skubitz KM, Kuroki M, Jantscheff P, Skubitz AP, Grunert F. CD66b. J Biol Regul Homeost Agents 1999;13:242-3.

13. Lard LR, Mul FP, de Haas M, Roos D, Duits AJ. Neutrophil activation in sickle cell disease. J Leukoc Biol 1999;66:411-5.

14. Wang J, Obici S, Morgan K, Barzilai N, Feng Z, Rossetti L. Overfeeding rapidly induces leptin and insulin resistance. Diabetes 2001;50:2786-91.

15. Ohannesian JP, Marco CC, Najm PS, Goldstein BJ, Caro JF, Kolaczynski JW. Small weight gain is not associated with development of insulin resistance in healthy, physically active individuals. Horm Metab Res 1999;31:323-5.

16. Peters JH, Ritter RC, Simasko SM. Leptin and CCK selectively activate vagal afferent neurons innervating the stomach and duodenum. Am J Physiol Regul Integr Comp Physiol 2006;290:R1544-9.

17. Luyer MD, Greve JW, Hadfoune M, Jacobs JA, Dejong CH, Buurman WA. Nutritional stimulation of cholecystokinin receptors inhibits inflammation via the vagus nerve. J Exp Med 2005;202:1023-9.

18. Pieracci FM, Barie PS, Pomp A. Critical care of the bariatric patient. Crit Care Med 2006; 34:1796-804.

19. Aljada A, Mohanty P, Ghanim H, Abdo T, Tripathy D, Chaudhuri A, Dandona P. Increase in intranuclear nuclear factor kappaB and decrease in inhibitor kappaB in mononuclear cells after a mixed meal: evidence for a proinflammatory effect. Am J Clin Nutr 2004;79:682-90. 
20. Mohanty P, Hamouda W, Garg R, Aljada A, Ghanim H, Dandona P. Glucose challenge stimulates reactive oxygen species (ROS) generation by leucocytes. J Clin Endocrinol Metab 2000;85:2970-3.

21. Mohanty P, Ghanim H, Hamouda W, Aljada A, Garg R, Dandona P. Both lipid and protein intakes stimulate increased generation of reactive oxygen species by polymorphonuclear leukocytes and mononuclear cells. Am J Clin Nutr 2002;75:767-72.

22. Ozcan U, Cao Q, Yilmaz E, Lee AH, Iwakoshi NN, Ozdelen E, Tuncman G, Gorgun C, Glimcher LH, Hotamisligil GS. Endoplasmic reticulum stress links obesity, insulin action, and type 2 diabetes. Science 2004;306:457-61. 
Samenvatting 
$126 \mid$ Chapter 10 


\section{Samenvatting}

Gedurende de laatste decennia zijn de mensen in Nederland steeds dikker geworden. Zwaarlijvigheid (obesitas, Body Mass Index (BMI) $>30 \mathrm{~kg} / \mathrm{m}^{2}$ ) komt inmiddels bij 10,7\% van de volwassen bevolking voor, terwijl er wordt geschat dat $1,5 \%$ van de volwassen bevolking ernstig zwaarlijvig (morbide obesitas, BMI $>40 \mathrm{~kg} / \mathrm{m}^{2}$ ) is. (Morbide) obesitas brengt veel problemen met zich mee, onder andere psychosociale- en gezondheidsproblemen. Vergeleken met een groep mensen die een normaal gewicht hebben, is bij obese mensen de kans om type 2 diabetes mellitus (ouderdomssuiker) te krijgen 5-20 maal verhoogd. Omdat type 2 diabetes mellitus een belangrijke risicofactor is voor het ontwikkelen van hart- en vaatziekten is het niet verwonderlijk dat het risico voor het ontwikkelen van hart- en vaatziekten bij obese mensen met een factor 4-6 verhoogd is. Daarnaast is de kans om dikke darm- en borstkanker te ontwikkelen 4-6 maal hoger bij mensen met obesitas. De toename van obesitas gaat gepaard met een toename van het voorkomen van deze bijkomende ziekten, waardoor de kosten voor de gezondheidszorg stijgen. De directe en indirecte kosten worden geschat op respectievelijk 505 miljoen euro en 1,2 miljard euro per jaar ${ }^{1,2}$.

Vanwege de grote belasting van (morbide) obesitas op de gezondheidszorg is het noodzakelijk goede therapeutische en preventieve interventies te ontwikkelen. Vanuit de literatuur is bekend dat op de lange termijn een combinatie van psychotherapie, dieet en fysiotherapie resulteert in een gewichtsverlies van maximaal $10 \%$. Voor de obese populatie kan deze therapie afdoende zijn om naast de gewichtsproblematiek ook de bijkomende ziekten, zoals type 2 diabetes mellitus, te voorkomen. De meerderheid van de morbide obese populatie is echter onvoldoende gebaad bij deze maatregelen. De enige bewezen therapie voor de morbide obese patiënt is een operatieve techniek (bariatrische chirurgie). Om het gewenste effect te bereiken bestaan er grofweg twee verschillende vormen van bariatrische chirurgie. Restrictieve bariatrische chirurgie werkt voornamelijk door een verkleining van de oorspronkelijke maaginhoud. Voorbeelden van restrictieve chirurgie zijn de maagband, de vertical banded gastroplasty (VBG) en de gastric bypass operatie. Het andere operatietype is de malabsorptieve bariatrische chirurgie. Deze ingreep werkt doordat een deel van de darm wordt omgeleid, waardoor dit deel geen voedsel meer transporteert en dus ook geen voedingsstoffen kan opnemen. Zowel restrictieve als malabsorptieve technieken resulteren in aanzienlijk gewichtsverlies. Bovendien wordt het voorkomen van bijkomende ziekten door bariatrische chirurgie drastisch verminderdt ${ }^{3-6}$. 


\section{Mechanismen waarmee bariatrische chirurgie de insuline-gevoeligheid verbetert}

In Hoofdstuk 2 zijn de mogelijke mechanismen verantwoordelijk voor het effect van bariatrische chirurgie op het verbeteren van de insuline-gevoeligheid beschreven. De positieve invloed van bariatrische chirurgie op plasma spiegels van incretines werd het eerst behandeld in dit overzichtsartikel. Incretines worden door de dunne darm gemaakt. Het zijn hormonen die de uitscheiding en werking van insuline positief beïnvloeden. Een voorbeeld hiervan is Glucagon Like Peptide-1 (GLP-1) ${ }^{7}$. Insuline is een belangrijk hormoon in de glucose stofwisseling. Ongevoeligheid van cellen voor insuline (insuline resistentie) kan suikerziekte veroorzaken. De productie van incretines door de darm kan beïnvloed worden door een deel van de dunne darm niet meer in contact te laten komen met voedsel. Biliopancreatische diversie (BPD) en gastric bypass chirurgie zijn voorbeelden van bariatrisch chirurgische operaties waarbij door een deel van de darm geen voedsel meer loopt. Na deze vormen van chirurgie stijgen de GLP-1 plasma concentraties. Dit kan worden verklaard doordat er onverteerd voedsel direct in de kronkeldarm terechtkomt. Hierdoor worden de zogenaamde L-cellen gestimuleerd om GLP-1 te produceren ${ }^{8}$. De rol van incretines in het postoperatieve herstel van de insuline-gevoeligheid is nog niet volledig uitgezocht en daarom zijn verdere studies op dit gebied nodig. Het positieve effect van incretines op de insuline-gevoeligheid na bariatrische chirurgie kan niet volledig het effect van bariatrische chirurgie op de insuline gevoeligheid verklaren. Bariatrische chirurgie heeft meerdere gevolgen. Ten eerste is de inname van voedsel verminderd waardoor de vetmassa afneemt en de intracellulaire stapeling van vetten verminderd. In dit overzichtsartikel werd aan de hand van literatuurgegevens beschreven wat de gevolgen van deze veranderingen zijn voor de insuline-gevoeligheid van een individu. Daarnaast gaat morbide obesitas gepaard met oxidatieve stress. Dit kan worden verklaard door de verhoogde inname van voedsel ${ }^{9,10}$. Een vermindering van de inname van voedingsstoffen zou in deze context tot een vermindering van oxidatieve stress kunnen leiden. Sinds kort wordt gedacht dat oxidatieve stress insuline resistentie kan veroorzaken ${ }^{11}$. Verminderde voedselinname door bariatrische chirurgie zal mogelijk de insuline-gevoeligheid kunnen verbeteren. Bovendien heeft bariatrische chirurgie ook tot gevolg dat de vetmassa verminderd. De verhoogde vetmassa bij obesitas gaat gepaard met een verandering in het uitscheidingspatroon van adipokinen (door vetcellen uitgescheiden stoffen) en een ophoping van macrofagen in het vetweefsel $^{12}$. Enkele van deze adipokinen, zoals TNF- $\alpha$ en IL-6 verlagen de gevoeligheid voor insuline. Afname van de vetmassa zou dus de insulinegevoeligheid kunnen verhogen. Ten slotte gaat morbide obesitas gepaard met een verhoogde stapeling van vetten in lever- en spierweefsel wat de insuline- 
gevoeligheid verlaagd. Deze organen zijn belangrijk bij de glucose stofwisseling. $\mathrm{Na}$ bariatrische chirurgie vermindert de stapeling van metabolieten van vetzuren in deze organen, waardoor de insuline-gevoeligheid verbetert ${ }^{13}$.

\section{Experimentele en klinische studies}

In dit proefschrift zijn twee onderwerpen behandeld. De invloed van bariatrische chirurgie op verzadigingshormonen en het subklinische ontstekingsbeeld dat geassocieerd is met morbide obesitas en het effect van bariatrische chirurgie op dit ontstekingsbeeld.

In Hoofdstuk 3 is nader ingegaan op de invloed van restrictieve bariatrische chirurgie op concentraties van verzadigingshormonen. Gastric bypass chirurgie leidt tot meer gewichtsverlies dan een maagband of $\mathrm{VBG}^{6}$. Er wordt mede verondersteld dat postoperatieve plasma concentraties van verzadigingshormonen een rol spelen bij het verschil in gewichtsverlies tussen VBG en gastric bypass. Na gastric bypass chirurgie dalen de plasma spiegels van de verzadigingshormonen ghreline, leptine en insuline. Het was nog niet bekend of dit ook plaats vindt na restrictieve bariatrische chirurgie. Daarom is er een studie uitgevoerd, waarbij plasma concentraties van de verzadigingshormonen ghreline, insuline en leptine voor en twee jaar na een maagband of VBG operatie zijn gemeten. Plasma ghreline spiegels stegen na de operatie. Dit in tegenstelling tot de in de literatuur beschreven gedaalde plasma concentraties na gastric bypass chirurgie ${ }^{14}$. Circulerende insuline en leptine concentraties daalden wel, zoals dat ook gerapporteerd is na gastric bypass chirurgie. Ghreline is een orexigeen hormoon, het leidt tot een stijging van de eetlust. Gestegen plasma ghreline spiegels na een maagband en VBG operatie zouden kunnen leiden tot een verhoogde eetlust en minder gewichtsverlies.

Vanuit een andere invalshoek werd onderzoek gedaan naar het verzadigingshormoon leptine. Van dit hormoon is bekend dat het een immunoregulerende functie heeft, hetgeen nader wordt belicht in een overzichtsartikel in Hoofdstuk 4. In de internationale literatuur wordt vermeld dat leptine deficiëntie ofwel door ontbreken van het leptine gen ofwel door langdurig vasten (anorexia nervosa) gepaard gaat met identieke afwijkingen van het immuunsysteem. Hierdoor wordt algemeen aangenomen dat te lage plasma leptine spiegels ongunstig zijn voor een individu. Kort na baratrische chirurgie zullen de patiënten niet tot nauwelijks eten. Doordat leptine een verzadigingshormoon is, werd er verondersteld dat de plasma leptine spiegels dalen tijdens de eerste postoperatieve dagen. Om dit te onderzoeken werd er een studie uitgevoerd 
waarbij plasma leptine spiegels in de eerste dagen na de bariatrische ingreep zijn gemeten. Het resultaat was een sterke verlaging van plasma leptine spiegels gedurende de eerste dagen na bariatrische chirurgie. Waardoor de sterke samenhang tussen BMI en leptine spiegels die zelfs bij morbide obese patiënten nog aanwezig is verdwijnt. In deze periode is er sprake van een relatieve leptine deficiëntie omdat de concentratie van leptine in het plasma is hoger dan dat van een individu met een normaal gewicht. De sterk gedaalde leptine spiegels in de dagen na restrictieve bariatrische chirurgie zouden mogelijk het normale herstelproces na de ingreep kunnen verstoren. Verder onderzoek zal moeten uitwijzen wat de invloed is van postoperatieve leptine spiegels op het ontstaan en het beloop van complicaties na bariatrische chirurgie.

In de volgende hoofdstukken werd het ontstekingsbeeld dat geassocieerd is met morbide obesitas behandeld. In eerdere studies is aangetoond dat morbide obesitas gepaard gaat met hogere plasma spiegels van acute fase eiwitten. eiwitten van het complement systeem en cytokines ${ }^{15,16}$. Dit leidt tot de aanname dat de aangeboren afweer is geactiveerd in morbide obesitas. In dit proefschrift werd dit verder uitgewerkt door activering van endotheelcellen en neutrofielen, de twee belangrijkste cellulaire componenten van de aangeboren afweer, te bestuderen.

In Hoofdstuk 5 werd de mate van endotheelcel activering bepaald. Om dit te bepalen werd het plasma van morbide obese patiënten vergeleken met dat van gezonde controle personen met een normaal gewicht. In het plasma werden eiwitten gemeten die een maat zijn voor de mate van endotheelcel activering (sE-selectine, s-ICAM-1 en sVCAM-1). Daarnaast werden eiwitten gemeten die de endotheelcel activering reguleren (resistine en adiponectine). De bevindingen waren, dat in vergelijking met individuen met een normaal gewicht, plasma spiegels van sE-selectine, s-ICAM-1, sVCAM-1 hoger zijn bij morbide obese patiënten. Plasma resistine waarden zijn verhoogd, terwijl de circulerende adiponectine waarden verlaagd waren. Resistine verhoogt en adiponectine verlaagt de activeringsstatus van endotheelcellen. Samengevat geven deze resultaten aan dat endotheelcellen in de morbide obese patiënt meer geactiveerd zijn dan bij mensen met een normaal gewicht. In eerdere studies werd aangetoond dat de inflammatoire status afnam na bariatrische chirurgie $^{15}$. Analoog aan die gegevens laten de data in dit proefschrift zien dat twee jaar na de operatie de plasma waarden van sE-selectine en sICAM-1 ook zijn gedaald en dat na een jaar de plasma adiponectine spiegels stijgen. Daarentegen zijn de sVCAM-1 en resistine spiegels in het plasma niet veranderd ten opzichte van de preoperatieve plasma spiegels. Een mogelijke verklaring is dat de patiënten nog steeds aanzienlijk obees zijn. 
Alhoewel gewichtsverlies de inflammatoire status op de lange termijn doet afnemen, is dit op de korte termijn niet het geval. Dit is aangetoond in eerdere studies waarbij plasma spiegels van acute fase eiwitten en TNF- $\alpha$ receptoren niet daalden ondanks gewichtsverlies ${ }^{15}$. Adiponectine, resistine, sICAM-1 en sVCAM-1 plasma spiegels bleven gelijk of stegen ten opzichte van de preoperatieve plasma spiegels. Doordat de patiënten direct na de operatie veel minder kunnen eten, zal het lichaam de voedingsstoffen uit de eigen weefsels (vetweefsel, spierweefsel) moeten halen (katabolisme). Dit kan metabole stress veroorzaken en leiden tot het blijven bestaan van een ontstekingsbeeld ondanks aanmerkelijk gewichtsverlies. In lijn met deze aanname is de waarneming dat katabole anorexia nervosa patiënten ook een verhoogde inflammatoire status hebben, die vermindert als deze patiënten hervoed worden ${ }^{17}$.

In Hoofdstuk 6 werd de activering van neutrofiele granulocyten in morbide obese patiënten besproken. Hiervoor zijn de neutrofiel eiwitten MPO en calprotectine gemeten in het plasma van morbide obese patiënten en een gezonde controle groep met een normaal gewicht. Plasma spiegels van MPO en calprotectine geven de mate van neutrofielactivering aan. Beide waren verhoogd bij morbide obese individuen, wat zou kunnen duiden op activering van neutrofielen in morbide obese patiënten. Omdat MPO en calprotectine niet alleen door geactiveerde neutrofielen worden geproduceerd, maar ook voor een klein gedeelte door geactiveerde monocyten, is het voorkomen van het eiwit CD66b op de celmembraan van de neutrofiel gemeten. De aanwezigheid van CD66b op de celmembraan neemt toe bij activering van neutrofielen, maar is niet aanwezig op monocyten ${ }^{18}$. In de studie werd bij morbide obese patiënten een verhoogde CD66b aanwezigheid op de celmembraan gevonden vergeleken met gezonde proefpersonen met een normaal gewicht. Deze bevindingen maken het aannemelijk dat de fractie geactiveerde circulerende neutrofielen hoger is bij morbide obese patiënten.

Twee jaar na bariatrische chirurgie neemt de plasma calprotectine concentratie af. Dit geldt echter niet voor de MPO spiegels. De eerder genoemde verklaring dat bariatrische chirurgie weliswaar leidt tot aanmerkelijk gewichtsverlies, maar dat de patiënt nog steeds obees blijft, kan ook voor deze waarneming een verklaring zijn.

Zoals eerder vermeld neemt het ontstekingsbeeld in de eerste maanden na bariatrische chirurgie niet af $^{15}$. In de literatuur is beschreven dat er tussen ontstekingsstatus en insuline resistentie een sterk oorzakelijk verband bestaat ${ }^{19}$. Dit wordt ondersteund door studies met cellen waarbij TNF- $\alpha$ de insuline gevoeligheid van deze cellen doet afnemen ${ }^{20}$. Daarnaast wordt in een aantal studies, na behandeling met de ontstekingsremmer aspirine, een 
verbetering van de insuline gevoeligheid beschreven ${ }^{21,22}$. Vanwege de sterke relatie tussen ontsteking en insuline resistentie en het blijvende ontstekingsbeeld in de eerste maanden na bariatrische chirurgie, werd de insuline gevoeligheid van patiënten in de eerste maanden na bariatrische chirurgie bestudeerd (Hoofdstuk 7). Hiertoe werd de insuline gevoeligheid gemeten voor de operatie en ongeveer twee maanden na de operatie bij $25 \%$ excess weight loss (EWL) door middel van Steady State Plasma Glucose (SSPG) concentraties en homeostasis model assessment - insulin resistance (HOMAIR). Het resultaat van de studie was dat op beide tijdstippen de insuline gevoeligheid, gemeten met SSPG concentraties, laag bleef. Als echter de HOMA-IR als indicator voor insuline gevoeligheid werd gebruikt, was de insuline gevoeligheid verbeterd bij $25 \%$ EWL. Dit geeft aan dat de patiënt na bariatrische chirurgie nog insuline resistent blijft en dat tijdens de eerste maanden na bariatrische chirurgie de HOMA-IR als surrogaat marker voor insuline gevoeligheid niet bruikbaar is.

Zoals in deze discussie eerder werd vermeld spelen inflammatie en oxidatieve stress een belangrijke rol in het ontstaan van insuline resistentie. Oxidatieve stress kan worden geïnduceerd door een verhoogde inname van voedsel ${ }^{9,10}$ en leiden tot insuline resistentie. Bij studies in ratten is dit aangetoond, zeven dagen overvoeden leidt tot een verlaging van de insuline gevoeligheid ${ }^{23}$. In een studie bij mensen werd dit echter niet aangetoond ${ }^{24}$. In dit proefschrift wordt gesuggereerd, dat de selectie van proefpersonen voor deze studie een rol speelt in het niet kunnen veroorzaken van insuline resistentie door een verhoogde voedsel inname. Daarom is een populatie geselecteerd, waarvan verondersteld werd dat deze populatie genetisch en metabool gepredisponeerd is om insuline resistentie te ontwikkelen. Een groep proefpersonen werd geselecteerd die bestond uit mensen die 2-3 jaar na restrictieve bariatrische chirurgie een stabiel gewicht hadden bereikt, maar nog steeds obees zijn (Hoofdstuk 8). Het wordt algemeen aangenomen dat morbide obesitas gepaard gaat met een verminderde insuline gevoeligheid. De proefpersonen kregen per dag $650 \mathrm{kCal}$ extra boven op hun eigen dieet, hetgeen resulteerde in een verlaagde insuline gevoeligheid. Deze bevinding maakt duidelijk dat er een uniek humaan model beschikbaar is om de oorzaken achter overvoeding geïnduceerde insuline resistentie te onderzoeken.

\section{Toekomst}

Een mogelijk aanknopingspunt voor verder onderzoek is de waarneming dat CCK productie door het duodenum wordt beïnvloed door leptine, geproduceerd in de maag. Daarnaast wordt beschreven dat op de takken van de nervus 
vagus die naar de hersenen lopen (afferente vagale zenuwbanen) leptine en CCK receptoren aanwezig zijn ${ }^{25}$. Vetrijke voeding zou de leptine productie in de maag kunnen verhogen. Het geproduceerde leptine kan de afferente vagale zenuwbanen activeren via de leptine receptor of via de CCK receptor. Het signaal gaat dan via de afferente vagale zenuwbanen naar de hersenen en weer terug via efferente vagale zenuwbanen naar de darmen. De activatie van de efferente vagale zenuwbaan zorgt ervoor dat er acetylcholine geproduceerd wordt door de zenuwuiteinden. Hierdoor wordt de activering van macrofagen in de darm geremd en de inflammatie in de darmwand onderdrukt ${ }^{26}$. Een lage plasma leptine spiegel of een lage leptine productie van de maag na bariatrische chirurgie heeft tot gevolg dat de remmende werking van het zenuwstelsel op macrofagen in de darm wegvalt. Hierdoor zou theoretisch de kans op postoperatieve complicaties groter worden.

De bevindingen beschreven in de Hoofdstukken 5 en 6 laten zien dat morbide obesitas gepaard gaat met een activering van de aangeboren afweer. Het interessante is, dat de aangeboren afweer een acute ontstekingsrespons is, terwijl er bij obesitas sprake is van een chronisch ziektebeeld. Er werd daarom geconcludeerd dat morbide obesitas gekenmerkt wordt door een chronisch activering van een acute ontstekingsrespons. Verder onderzoek om dit uit te zoeken is nodig.

Door in het model beschreven in Hoofdstuk 8 de inflammatoire veranderingen in circulerende leucocyten te meten, kan bestudeerd worden of dit model ook geschikt is om de invloed van overvoeden op inflammatie te onderzoeken. Er kan zich een probleem voordoen als de studieduur zeven dagen blijt omdat er, zoals in Hoofdstuk 8 is te lezen, in het plasma geen inflammatoire veranderingen te meten waren. Het verlengen van de overvoedingstijd zou dit probleem kunnen verhelpen.

Uit Hoofdstuk 8 blijkt, dat het overvoeden van mensen kan leiden tot insuline resistentie. Dit leidt tot de vraagstelling welk mechanisme hiervoor verantwoordelijk is. In de toekomst zullen studies die zich richten op de rol van oxidatieve stress en endoplasmatisch reticulum (ER) stress een centrale rol moeten spleen om dit mechanisme op te helderen. De vooronderstelling dat oxidatieve stress een rol zou kunnen spelen in de pathofysiologie van insuline resistentie is onder andere gebaseerd op een aantal studies, waarin na het nemen van een verhoogde dosis macronutriënten de oxidatieve stress in circulerende leukocyten toeneemt ${ }^{9,10}$. Dat de rol van oxidatieve stress in de pathofysiologie van insuline resistentie een grote rol speelt wordt ook door studies in muizen bevestigd ${ }^{11}$.

Naast oxidatieve stress, wordt ER stress ook geassocieerd met obesitas en insuline resistentie. Er wordt gesuggereerd dat de metabole belasting van een 
cel bij obese personen is toegenomen, hetgeen resulteert in een verhoging van reactieve zuurstof radicalen en intermediare metabolieten. De ophoping van deze stoffen leidt tot de "unfolded protein response". Hierdoor is het niet verwonderlijk dat obesitas gepaard gaat met ER stress, wat geassocieerd is met verhoogde serine phosphorylatie van de "insulin receptor substrate-1" hetgeen de cel minder gevoelig maakt voor insuline ${ }^{27}$.

Samengevat kan worden gesteld dat uit resultaten van dit proefschrift blijkt dat morbide obesitas een systeemziekte is die onder andere wordt gekenmerkt door activatie van de aangeboren afweer. De systeemziekte morbide obesitas met de bijkomende inflammatie en aandoeningen kan alleen effectief behandeld worden met behulp van bariatrische chirurgie. Gezien het effect van overvoeding bij patiënten die bariatrische chirurgie hadden ondergaan, wordt duidelijk dat de anatomische veranderingen die deze ingreep met zich mee brengen geen tijdelijke oplossing zijn, maar levenslang van kracht moeten blijven. 


\section{References}

1. Gezondheidsraad. Overgewicht en obesitas, publicatie nr 2003/07. 2003.

2. Takken J PJ, Meerding WJ. Kosten van ziekten in Nederland. Bilthoven: Rijksinstituut voor Volksgezondheid en Milieu (RIVM rapportnummer 270751004, www.kostenvanziekten.nl) 2002.

3. NIH conference. Gastrointestinal surgery for severe obesity. Consensus Development Conference Panel. Ann Intern Med 1991;115:956-61.

4. Clinical Guidelines on the Identification, Evaluation, and Treatment of Overweight and Obesity in Adults--The Evidence Report. National Institutes of Health. Obes Res 1998;6 Suppl 2:51S-209S.

5. Obesity: preventing and managing the global epidemic. Report of a WHO consultation. World Health Organ Tech Rep Ser 2000;894:i-xii, 1-253.

6. Buchwald H, Avidor $\mathrm{Y}$, Braunwald $\mathrm{E}$, Jensen MD, Pories $\mathrm{W}$, Fahrbach $\mathrm{K}$, Schoelles $\mathrm{K}$. Bariatric surgery: a systematic review and meta-analysis. Jama 2004;292:1724-37.

7. Vilsboll T, Holst JJ. Incretins, insulin secretion and Type 2 diabetes mellitus. Diabetologia 2004;47:357-66.

8. Guidone C, Manco M, Valera-Mora E, laconelli A, Gniuli D, Mari A, Nanni G, Castagneto M, Calvani M, Mingrone G. Mechanisms of recovery from type 2 diabetes after malabsorptive bariatric surgery. Diabetes 2006;55:2025-31.

9. Mohanty P, Hamouda W, Garg R, Aljada A, Ghanim H, Dandona P. Glucose challenge stimulates reactive oxygen species (ROS) generation by leucocytes. J Clin Endocrinol Metab 2000;85:2970-3.

10. Mohanty P, Ghanim H, Hamouda W, Aljada A, Garg R, Dandona P. Both lipid and protein intakes stimulate increased generation of reactive oxygen species by polymorphonuclear leukocytes and mononuclear cells. Am J Clin Nutr 2002;75:767-72.

11. Houstis N, Rosen ED, Lander ES. Reactive oxygen species have a causal role in multiple forms of insulin resistance. Nature 2006;440:944-8.

12. Weisberg SP, McCann D, Desai M, Rosenbaum M, Leibel RL, Ferrante AW, Jr. Obesity is associated with macrophage accumulation in adipose tissue. J Clin Invest 2003;112: 1796-808.

13. Schaffer JE. Lipotoxicity: when tissues overeat. Curr Opin Lipidol 2003;14:281-7.

14. Cummings DE, Weigle DS, Frayo RS, Breen PA, Ma MK, Dellinger EP, Purnell JQ. Plasma ghrelin levels after diet-induced weight loss or gastric bypass surgery. N Engl J Med 2002; 346:1623-30.

15. van Dielen FM, Buurman WA, Hadfoune M, Nijhuis J, Greve JW. Macrophage inhibitory factor, plasminogen activator inhibitor-1, other acute phase proteins, and inflammatory mediators normalize as a result of weight loss in morbidly obese subjects treated with gastric restrictive surgery. J Clin Endocrinol Metab 2004;89:4062-8.

16. Hanusch-Enserer U, Cauza E, Spak M, Dunky A, Rosen HR, Wolf H, Prager R, Eibl MM. Acute-phase response and immunological markers in morbid obese patients and patients following adjustable gastric banding. Int J Obes Relat Metab Disord 2003;27:355-61.

17. Allende LM, Corell A, Manzanares J, Madruga D, Marcos A, Madrono A, Lopez-Goyanes A, Garcia-Perez MA, Moreno JM, Rodrigo M, Sanz F, Arnaiz-Villena A. Immunodeficiency associated with anorexia nervosa is secondary and improves after refeeding. Immunology 1998;94:543-51.

18. Skubitz KM, Kuroki M, Jantscheff P, Skubitz AP, Grunert F. CD66b. J Biol Regul Homeost Agents 1999;13:242-3.

19. Shoelson SE, Lee J, Goldfine AB. Inflammation and insulin resistance. J Clin Invest 2006; 116:1793-801.

20. Hotamisligil GS, Murray DL, Choy LN, Spiegelman BM. Tumor necrosis factor alpha inhibits signaling from the insulin receptor. Proc Natl Acad Sci U S A 1994;91:4854-8. 
21. Hundal RS, Petersen KF, Mayerson AB, Randhawa PS, Inzucchi S, Shoelson SE, Shulman GI. Mechanism by which high-dose aspirin improves glucose metabolism in type 2 diabetes. $J$ Clin Invest 2002;109:1321-6.

22. Yuan M, Konstantopoulos N, Lee J, Hansen L, Li ZW, Karin M, Shoelson SE. Reversal of obesity- and diet-induced insulin resistance with salicylates or targeted disruption of Ikkbeta. Science 2001;293:1673-7.

23. Wang J, Obici S, Morgan K, Barzilai N, Feng Z, Rossetti L. Overfeeding rapidly induces leptin and insulin resistance. Diabetes 2001;50:2786-91.

24. Ohannesian JP, Marco CC, Najm PS, Goldstein BJ, Caro JF, Kolaczynski JW. Small weight gain is not associated with development of insulin resistance in healthy, physically active individuals. Horm Metab Res 1999;31:323-5.

25. Peters JH, Ritter RC, Simasko SM. Leptin and CCK selectively activate vagal afferent neurons innervating the stomach and duodenum. Am J Physiol Regul Integr Comp Physiol 2006;290:R1544-9.

26. Luyer MD, Greve JW, Hadfoune M, Jacobs JA, Dejong $\mathrm{CH}$, Buurman WA. Nutritional stimulation of cholecystokinin receptors inhibits inflammation via the vagus nerve. J Exp Med 2005;202:1023-9.

27. Ozcan U, Cao Q, Yilmaz E, Lee AH, Iwakoshi NN, Ozdelen E, Tuncman G, Gorgun C, Glimcher LH, Hotamisligil GS. Endoplasmic reticulum stress links obesity, insulin action, and type 2 diabetes. Science 2004;306:457-61. 
Dankwoord 


\section{Dankwoord}

Een proefschrift komt nooit alleen door de schrijver tot stand, daarom is een bedankje het minst wat ik kan doen. Hieronder vindt $u$ dan ook een opsomming van mensen die, ieder op hun eigen manier, een bijdrage hebben geleverd tijdens het promotietraject.

Allereerst zijn dat de proefpersonen. Zonder hun medewerking was dit alles niet tot stand gekomen.

Vervolgens mijn beide promotoren Prof. dr. J.W.M. Greve en Prof. dr. W.A. Buurman. Voor beiden geldt dat ze, ondanks mijn eigenwijsheid, mij altijd zijn blijven stimuleren. Zonder hun standvastigheid was dit boekje niet tot stand gekomen. Daarnaast hebben ze mij de kans gegeven om het onderzoek te presenteren op verschillende binnen- en buitenlandse congressen.

Beste Jan Willem, bedankt dat je mij, nu zes jaar geleden, de kans hebt gegeven om te promoveren. Je hebt het de afgelopen jaren, mede door je professoraat, steeds drukker gekregen. Desondanks heb je altijd tijd voor mij vrijgemaakt, bedankt hiervoor. We zullen elkaar in de toekomst zeker nog tegenkomen en ik hoop op een vruchtbare samenwerking.

Beste Wim, de eerste ervaring die ik met je had was het sollicitatiegesprek. Natuurlijk was ik nog onervaren, maar ik dacht dat het na een half uurtje wel klaar zou zijn. Dat het bijna twee uur zou duren kon ik toen niet weten. Wat ik na die twee uur wist was dat ik een promotor zou krijgen met een zeer grote algemene ontwikkeling en onderbouwde mening over bijna alles. In totaal is het volgens mij 15 minuten over het onderzoek gegaan en de rest over politiek en andere interessante zaken. Ik ben het in ieder geval nog steeds met je eens dat een academicus verplicht (dagelijks) de krant moet lezen. Dat je altijd ter beschikking staat van je promovendi heb ik ervaren tijdens het schrijven van dit proefschrift. Elk tijdstip van de dag kon ik bij je terecht om dingen te bespreken, bedankt hiervoor.

Dr. S.S.M. Rensen. Beste Sander, toen jij het obesitas onderzoek kwam versterken was ik langzaam de draad aan het kwijtraken. Projectje hier, proefje daar.. jij hebt daar weer lijn in gebracht. Ik heb de samenwerking altijd als zeer prettig ervaren en ik ben blij dat je mijn co-promotor wilt zijn. Je hebt vooral in het laatste deel van het voltooien van dit proefschrift veel werk verricht in de vorm van corrigeren, het submitten van manuscripten en het geven van praktische adviezen. Daarnaast moest je je vrouw (wen er maar aan) helpen met haar proefschrift en was je bezig met de voorbereidingen op je huwelijk. Voor mij is de samenwerking nog zeker niet beëindigd en ik hoop dat ik vanuit 
de interne geneeskunde nog een goede bijdrage kan leveren aan het onderzoek. Veel succes de komende jaren.

I would like to thank all members of the reviewing committee: Prof. dr. E.E. Blaak, Prof. dr. M.H. Hofker, Prof. dr. C.D.A. Stehouwer, Prof. dr. P.B. Soeters and dr. C.W. le Roux, for their evaluation of the manuscript.

Zonder de studenten die mij hebben geholpen in de laatste jaren bij het verzamelen van de samples en het uitvoeren van kleuringen/ELISA's was het zeker niet gelukt, bedankt voor jullie inzet.

Mijn voorganger dr. F.M.H. van Dielen. Beste Francois, veel van de resultaten van dit proefschrift zijn afkomstig uit samples die jij hebt verzameld. Bedankt dat ik hiervan gebruik mocht maken.

Yanti, ik ben blij dat je doorgaat met het werk dat nu is opgestart. Nu Sander jij en Gaukje zijn begonnen is er echt sprake van een obesitas team. Ik hoop na mijn promotie meer tijd te hebben om jullie vanuit de kliniek te ondersteunen.

Rob, zonder jou is er geen bariatrische chirurgie meer denkbaar Jij bent de spin in het web en ik hoop dat we in de toekomst meer kunnen gaan samenwerken met het opzetten van een zorglijn. De chirurgen Sven van Helden en Nicole Bouvy wil ik ook bedanken voor hun hulp bij het verzamelen van de samples. Ruben, jij maakt het obesitas team compleet. Ik heb de samenwerking, ook al is die van korte duur geweest, altijd als zeer prettig ervaren.

Mijn keuze om internist te worden is in gang gezet door gesprekken met Prof. dr. N.C. Schaper. Na de soms lange brainstormsessies over de SSPG metingen, kwam steevast de mededeling dat ik internist moest worden. Nicolaas, mijn keuze om me te blijven bezighouden met obesitas, zorgt er in ieder geval voor dat we nog veel met elkaar zullen samenwerken, ik verheug me hierop.

Al mijn collega's op het lab heelkunde, eerst op de $2^{\mathrm{e}}$ later op de $5^{\mathrm{e}}$ verdieping, wil ik bedanken voor de gezelligheid. Zo nu en dan een geintje op de afdeling zorgde voor de nodige ontspanning. Ik zie me nog door het ziekenhuis dwalen op zoek naar een pakketje dat zogenaamd voor mij afgeleverd was. Mo, Tim, Annemarie en Trudi, zonder jullie kennis en kunde op het gebied van ELISA's, PCR, celkweken e.d. was mijn tijd een bij jullie een stuk moeilijker geweest. Mijn collega promovendi Marcel, Misha, Robert, Joep, Tim, Jacco, Geertje, Maarten, Martien, Maaike, Bart (2x), Bas en Yvonne; bedankt voor de leuke tijd 
en kritische vragen. Ik wens een ieder van jullie veel succes in jullie verdere carrière.

Kim en Evelien, bedankt voor de secretariële ondersteuning.

Natuurlijk moet ik de wekelijkse voetbalavond niet vergeten. Allemaal competitief ingesteld, maar niet op het vervelende af, waardoor er bijna elke week een leuke pot gespeeld kon worden. Jammer dat het niet gecontinueerd kon worden, maar bedankt voor de leuke tijd. (van die beloofde borrel is niet veel meer terechtgekomen, maar ik hoop een deel van jullie wel op mijn feest te zien).

Ik ben nu langzamerhand bij mijn huidige collega's aanbeland. Maar voordat ik daar ben eerst een speciaal woord van dank voor twee personen die ik of hevig discussierend of in totale wanhoop achter een scherm zag zitten met net niet significante top-data. Steven en Martijn, het was altijd weer gezellig buurten bij jullie, hulde!

Mijn collega's op de interne geneeskunde, zowel stafleden, AIOS, verpleging en ondersteunend personeel ben ik dankbaar voor de prettige sfeer waarin de opleiding plaatsvindt. Ik hoop de volgende jaren nog met plezier met jullie samen te werken.

Tiny, zonder jou expertise op het gebied van layout en planning was dit boekje er niet geweest. Dat je goed werkt levert blijkt wel uit de grote hoeveelheid boekjes die je al hebt afgeleverd. Bedankt!

Zonder vrienden ben je nergens. Alleen als je tijdens je promotietraject kinderen krijgt en ook nog gaat verhuizen dan blijft er niet veel tijd meer voor jullie over. Pom, Edo (en Timo) en Annemiek, ondanks de moeite met plannen van de kookclubjes komen we toch regelmatig bij elkaar om de meest onmogelijke recepten uit te proberen. Ik hoop dit nog jaren te blijven doen.

Jasper en Dorcas (en Éowyn), Mark en Esther (en Ben, Mirthe en Lieke), Mark en Marieke, Carine. De afgelopen jaren hebben we gewoon te weinig contact. Misschien en ik hoop het van harte gaat dit na de promotie verbeteren.

De paranimfen Annemiek en Jasper, bedankt dat jullie tijd konden vrijmaken om naast mij bij te staan tijdens de verdediging. Ik wens jullie beiden veel succes met het voltooien van jullie onderzoek.

De leden van opera comique Maastricht ook bedankt voor de leuke tijd en nodige ontspanning. Door de verbouwing en promotie heb ik de laatste tijd de 
repetities iets laten versloffen, maar ik kom terug en in november zullen we een mooie productie neerzetten, daar ben ik van overtuigd.

(vul hier je eigen naam in als ik je ben vergeten), heel erg bedankt voor de gezelligheid/hulp/mentale ondersteuning/samenwerking/vriendschap*.

( ${ }^{*}$ omcirkel wat van toepassing is)

Beste Margreet, als moeder van Kirsten kan ik het mij voorstellen dat het vaak moeilijk is om te zien dat ik je dochter niet alle aandacht kan geven die ze verdiend. Daarnaast is het door de tijdsdruk vaak niet mogelijk om naar Zwolle af te reizen. Ik ben je dan ook heel erg dankbaar dat je, ondanks de drukte van jouw baan de tijd vindt om zo nu en dan naar het zuiden af te zakken om toch nog wat tijd met ons door te brengen.

Thomas (en sinds kort Rachel), ik vindt het leuk voor je dat je, na al die jaren op een studeerkamer, een huisje hebt gevonden. Ik hoop dat je snel je draai vindt in Vlaardingen en daar een leuke baan vindt. Veel succes en plezier samen en tot ziens in jullie nieuwe huisje.

Bas en Suzanne, ook voor jullie geldt dat jullie net samen een flatje hebben betrokken. Het is altijd leuk om te zien hoe je kleine broertje zich settelt en bezig is zijn eigen leven op te bouwen. Bas, ik ben trots op je dat je het voor elkaar hebt gekregen om een HBO studie af te ronden. Suzanne, we zullen elkaar als ik meer tijd heb wel beter leren kennen.

Ronald en Yvonne (en Liam), de afgelopen tijd was ik er zeker te weinig voor jullie. Tijdens de onzekere tijd die jullie achter de rug hebben en die nog voor jullie ligt, zou ik er graag vaker voor jullie zijn. Nu de promotie achter de rug is hoop ik dat te kunnen doen. Los van alle perikelen van de afgelopen tijd is het de afgelopen jaren heel gezellig geweest, met als toppunt het totaal verregende weekje in Sorède.

Pa en ma, zonder jullie was ik niet geweest wie ik nu ben. Bedankt dat jullie me in al mijn keuzes hebben gesteund. Ook jullie hebben moeilijke tijden gekend en alhoewel we veel contact hebben, had ik er in bepaalde situaties meer willen zijn. Een speciaal woord van dank voor jou pa, zonder jouw hulp was het kopen van ons nieuwe huis niet mogelijk geweest, zeker niet met de promotie en de geboorte van Aimée daarbij. Ma, dank je dat we pa zo nu en dan mogen lenen.

Julian en Aimée, zonder jullie is het toch heel anders thuiskomen. Pappa is er de afgelopen tijd veel te weinig, het is zelfs zo erg dat zelfs zondag iemand anders het vlees snijdt. De komende tijd zal dat wel veranderen, maar pappa 
heeft een vak gekozen waarbij hij niet altijd thuis kan zijn als jullie dat willen. Maar ondanks alles moeten jullie je bedenken dat pappa heel veel van jullie houdt.

Kirsten, het is al meer dan vijftien jaar geleden dat wij wat met elkaar kregen. In die tijd waren we nog lang niet bezig met werktijden en dergelijke, maar als je toen geweten had wat je te wachten stond... Jij hebt gekozen voor een man die altijd bezig moet zijn. Het gevolg is dat ik het vrijwel altijd te druk heb. Alhoewel het tijdens mijn promotie beter is gegaan, realiseer je je maar al te goed dat er na de promotie weer andere uitdagingen wachten. Tot overmaat van ramp besloten we terwijl Aimée op het punt stond geboren te worden ons eerste huis te kopen. En niet zomaar een huis, nee eentje waar nog wat aan opgeknapt moest worden. Een relatie die een promotie doorstaat heeft zich al bewezen, maar eentje die én een verhuizing/verbouwing én een geboorte én een promotie doorstaat kan niet meer kapot. Ik beloof je, en nu staat het zwart op wit, dat ik de komende tijd meer aandacht ga besteden aan onze relatie. Dus collega's, vrienden en familie als jullie er weer bij inschieten, ik heb een heel goede reden.

Ik hef het glas op jullie gezondheid,

Jeroen 
144 
Curriculum Vitae 


\section{Curriculum Vitae}

De schrijver van dit proefschrift is op 29 mei 1976 geboren in Enschede. In Veenendaal ging hij naar de middelbare school om vervolgens in Maastricht te beginnen met de studie milieugezondheidskunde. $\mathrm{Na}$ in 1996 het staatsexamen scheikunde te hebben behaald is hij begonnen met de studie geneeskunde aan de Universiteit Maastricht. Tijdens deze studie heeft hij verscheidene functies als student-assistent gehad en fungeerde hij als penningmeester van het $3^{e}$ Maastricht Medical Students Research Conference (MMSRC). Daarnaast is hij actief geweest in het onderwijs door onderdeel uit te maken van blokplanningsgroepen en het studenten overleg skillslab. Zijn artsenbul haalde hij in 2002, in datzelfde jaar startte hij met het promotieonderzoek dat geresulteerd heeft in dit proefschrift. Vanaf 1 oktober 2006 is hij in opleiding tot internist (opleider: Prof. dr. C.D.A. Stehouwer).

Jeroen is getrouwd met Kirsten en heeft twee kinderen: Julian (2004) en Aimée (2007). 
Scientific output 


\section{Scientific output}

\section{Original contributions}

J. Nijhuis, F.M.H. van Dielen, J.W.M. Greve, W.A. Buurman. Leptin in morbid obese patients, no role for treatment of morbid obesity but important in the post operative immune response, Obesity Surgery, 2004;14:476-483.

J. Nijhuis, F.M.H. van Dielen, J.W.M. Greve, W.A. Buurman. Ghrelin, leptin and insulin levels after restrictive surgery, a 2 year follow-up study. Obesity Surgery, 2004;14:783-787.

J. Nijhuis, F.M.H. van Dielen, S.M.G. Fouraschen, M.A.J. van den Broek, S.S.M. Rensen, W.A. Buurman, J.W.M. Greve. Endothelial activation markers and their key regulators after restrictive bariatric surgery, a 2 year follow-up study. Obesity (silver spring), 2007;15:1395-1399 .

J. Nijhuis, W.A. Buurman, J.W.M. Greve. The surgical treatment of diabetic obesity. CMC-IEMA, 2007;7:19-29.

J. Nijhuis, F.M.H. van Dielen, N.C. Schaper, J. Wiebolt, A. Koks, F. Pracken, S.S.M. Rensen, W.A. Buurman, J.W.M. Greve. Short term overfeeding induces insulin resistance in weight stable patients after bariatric surgery. Obesity Surgery, 2008;18:300-305.

J. Nijhuis, S.S.M. Rensen, Y. Slaats, F.M.H. van Dielen, W.A. Buurman, J.W.M. Greve. Neutrophil activation in morbid obesity, chronic activation of acute inflammation. Submitted.

F.M.H. van Dielen, J. Nijhuis, N.C. Schaper, J. Wiebolt, A. Koks, F. Pracken, S.S.M. Rensen, W.A. Buurman, J.W.M. Greve. Insulin sensitivity during the first months after restrictive bariatric surgery, inconsistency between HOMA-IR and steady state plasma glucose (SSPG) levels. Submitted.

F.M.H. van Dielen, W.A. Buurman, M. Hadfoune, J. Nijhuis, J. W. Greve. Macrophage Inhibitory Factor, Plasminogen Activator Inhibitor-1, Other Acute Phase Proteins, and Inflammatory Mediators Normalize as a Result of Weight Loss in Morbidly Obese Subjects Treated with Gastric Restrictive Surgery. J Clin Endocrinol Metab, 2004;89:4062-4068. 
R.R.J. van Kimmenade, F.M.H. van Dielen, J.A. Bakker, J. Nijhuis, H.J.G.M. Crijns, W.A. Buurman, M.P. van Dieijen-Visser, J.W.M. Greve, Y.M. Pinto. Is Brain Natriuretic Peptide Production Decreased in Obese Subjects? JACC, 2006;47:886-887.

A.H. Bakker, J. Nijhuis, W.A. Buurman, F.M.H. van Dielen, J.W.M. Greve. Low number of omental preadipocytes with high leptin and low adiponectin secretion is associated with high fasting plasma glucose levels in obese subjects. Diabetes Obes Metab., 2006;8:585-588.

\section{Oral presentations}

Inflammatory and atherogenic markers after bariatric surgery.

Nederlandse Associatie voor de Studie van Obesitas, voorjaarsvergadering 2003 (Veldhoven)

Dissociatie van leptine en BMI na bariatrische chirurgie. Verantwoordelijk voor een fulminanter verloop van septische complicaties bij deze patiënten.

Symposium Experimenteel Onderzoek Heelkundige Specialismen 2003 (Amsterdam)

Ghrelin, Leptin and Insulin levels after bariatric surgery.

International Federation for the Surgery of Obesity, conference 2004 (Tokyo)

Ghrelin, Leptin and Insulin levels after bariatric surgery.

Chirurgendagen 2004 (Veldhoven)

Ghrelin, Leptin and Insulin levels after bariatric surgery.

Nederlandse Vereniging voor Gastro-Enterologie, voorjaarsvergadering 2004 (Veldhoven)

Ghrelin, Leptin and Insulin levels after bariatric surgery.

Nederlandse Associatie voor de Studie van Obesitas, voorjaarsvergadering 2004 (Utrecht)

sICAM-1 is a more sensitive marker for endothelial damage than sE-selectin and SVCAM-1.

International Federation for the Surgery of Obesity, conference 2005 (Maastricht) 
sICAM-1 is a more sensitive marker for endothelial damage than sE-selectin and SVCAM-1.

American Society of Bariatric Surgery, annual meeting 2005 (Orlando)

Downregulation of Macrophage Migration Inhibitory Factor (MIF) by insulin during the Steady State Plasma Glucose test, new insights in MIF regulation. International Federation for the Surgery of Obesity, conference European chapter 2006 (Lyon)

Downregulation of Macrophage Migration Inhibitory Factor (MIF) by insulin during the Steady State Plasma Glucose test, new insights in MIF regulation. American Society of Bariatric Surgery, annual meeting 2006 (San Francisco)

The effect of bariatric surgery on neutrophil activation in morbid obesity. International Federation for the Surgery of Obesity, conference 2006 (Sydney)

\section{Poster presentations}

Ghrelin and leptin levels after bariatric surgery, a 2 year follow-up study. American Society of Bariatric Surgery, annual meeting 2004 (San Diego)

Dissociation of leptin and BMI after bariatric surgery, a mechanism responsible for a more serious course of postoperative septic complications. American Society of Bariatric Surgery, annual meeting 2004 (San Diego) 